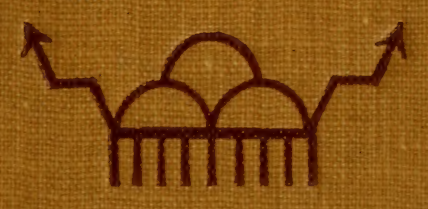




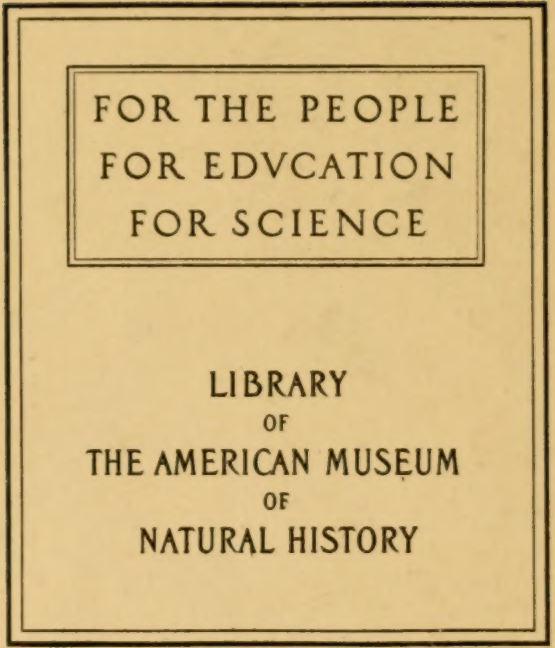


$-$ 


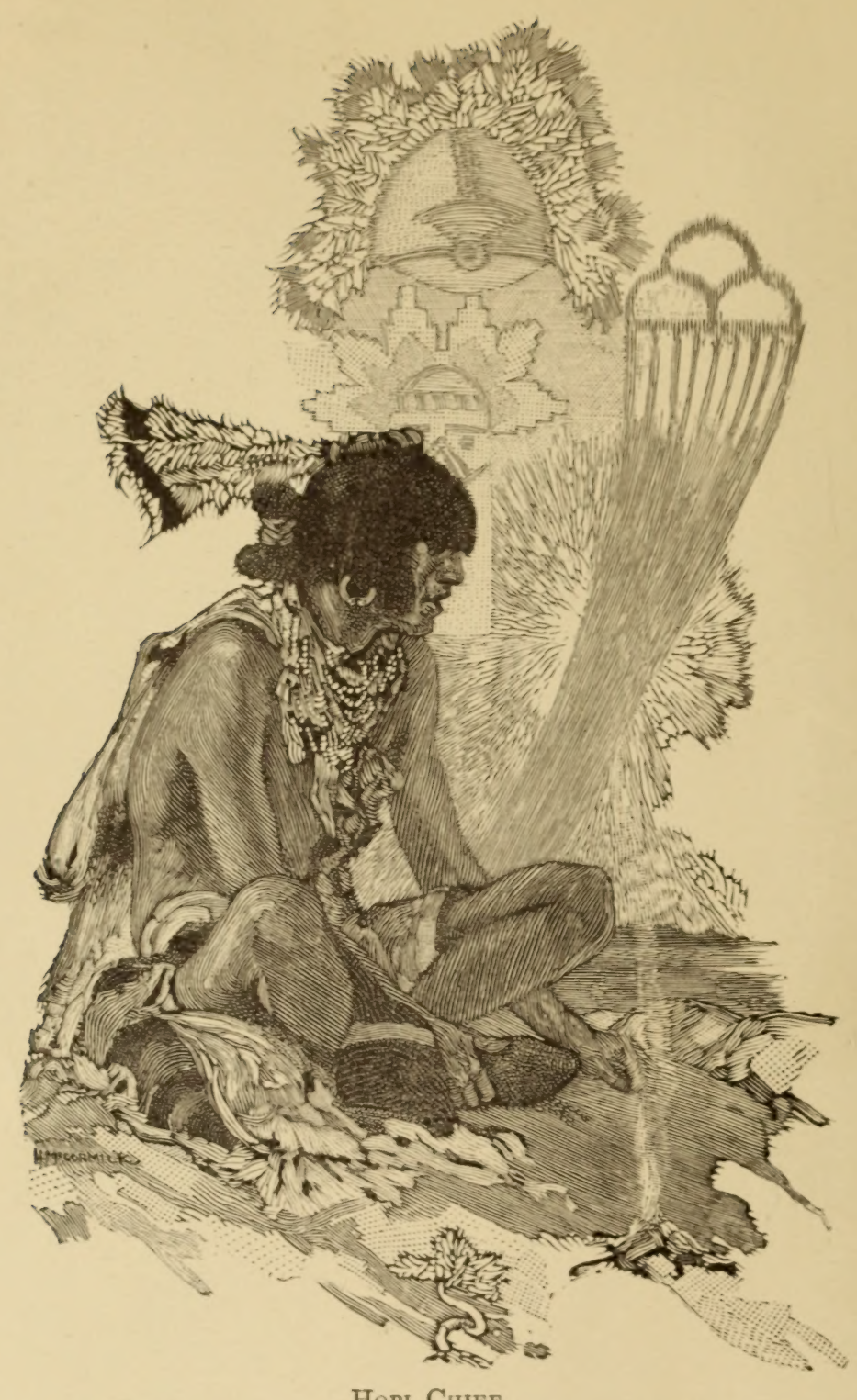

Hopi Chief.

(Drawn by Howard McCormick.) 


\section{INDIANS OF THE SOUTHWEST}

\section{$57.172,8$}

BY PLINY EARLE GODDARD

ASSOCIATE CURATOR OF ANTHROPOLOGY

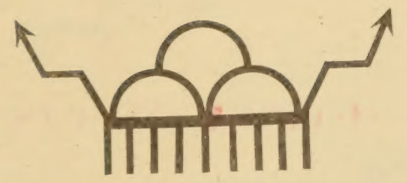

H A N D B O K SERIES, NO.?

NEW TORK

Americax Museum of Natural History

1913 
19.79361. May 26. 


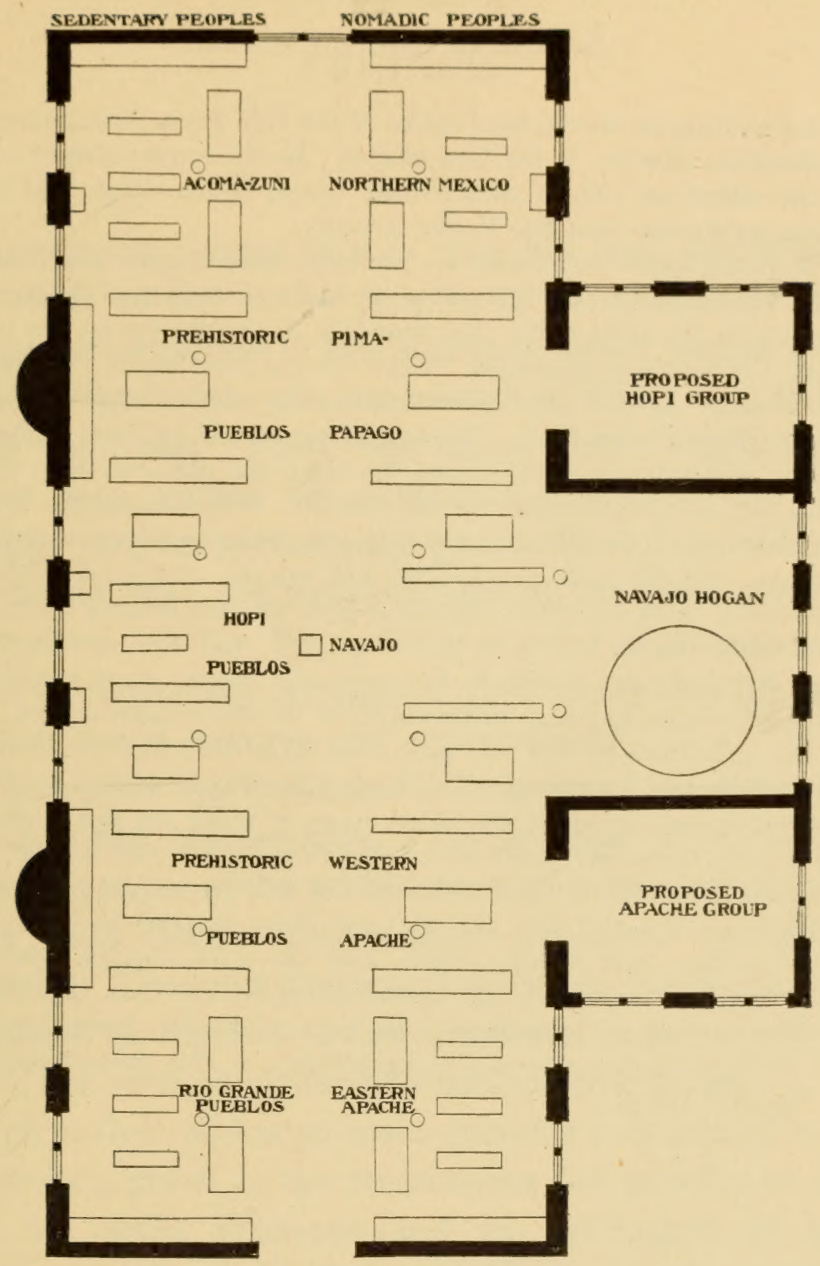

Plan of the Southwest Indian Hall.

This hall contains both the archaeological and the ethnological collections from the Southwest.

The former are on the left hand side of the hall in two alcoves marked Prehistoric Pueblos. The localities at present most fully represented are Chaco Canyon, New Mexico, explored by the Hyde Expedition, 
Tularosa Canyon on the headwaters of the Gila River, Casas Grandes, Chihuahua, Mexico, in the first alcove. In the second alcove will be found collections rich in textiles from Grand Gulch, Utah, and interesting specimens from Rio Verde, Arizona.

The ethnological collections are primarily divided into those from the sedentary peoples on the left side of the hall and those from the nomadic peoples on the right side. The sequence of the alcoves as one passes down the hall is geographical. First are the Rio Grande Pueblos and the Eastern Apache which show relationship to the tribes in the adjoining Plains Indian Hall. Toward the center will be found collections chiefly of ceremonial objects from the Hopi and opposite them a large collection of blankets made by the Navajo. Next beyond the Navajo are represented the Pima and Papago, the basket makers of southern Arizona. At the further end of the hall are the Acoma and Zuñi and collections from Northern Mexico which for the present have been given space there.

A Navajo hogan stands in the large side room. It is hoped that life-sized groups may soon be provided for the two smaller rooms.

The collections in this hall have been obtained chiefly by Museum expeditions and donations. The Hyde Expedition resulted in a great number of archaeological specimens, many of which are still in storage. Since 1909 there have been obtained by funds provided by the Committee on the Primitive Peoples of the Southwest the ethnological collections from the Rio Grande and Hopi pueblos and from the Apache, Pima, and Papago tribes, and the archaeological specimens from the Galisteo historic and prehistoric ruins and from Old Cochiti. A large number of the baskets were donated by Dr. James Douglas; the Navajo blankets represent the generosity of Mrs. Russell Sage and J. Pierpont Morgan. 


\section{PREFACE.}

Although a great deal of time has been devoted to the study of the native peoples of the Southwest and the prehistoric ruins in that region by many ethnologists and archaeologists our knowledge of them is still far from complete. There are many ruins which have never been visited by a trained observer; the Rio Grande peoples persistently oppose the study of their ceremonial life; and notwithstanding the great number of treatises on the Hopi, there is none of them which gives a satisfactory account of their every day life and of their social customs and organization.

The author has first hand knowledge of the Athapascan speaking peoples only. The accounts given in the following pages of the prehistoric and sedentary peoples have been drawn from papers published by many authors. The most important works on the Southwest are listed at the end of this book and in them will be found the sources of the information here given.

The author wishes to make grateful recognition here of the help given in the preparation and revision of the text by Bella Weitzner and his colleagues in the Museum. Mr. F. W. Hodge of Washington has kindly read the proofs. The various illustrations have been credited to the persons who have permitted their use. Their generosity has added materially to whatever interest and value this short account of Southwestern peoples may have. 



\section{CONTENTS.}

Preface . . . . . . . . 5

INTRODUCTION . . . . . . . . . . . . . . 11

Region Defined. Environment. Influence of Environment.

Social Tendencies.

\section{CHAPTER I.}

The Ancient Peoples .
Distribution; San Juan, Rio Grande, Pecos, Gila, Little Colorado. Buildings; Sites, Materials, Ceilings, Doors, Kivas. Types of Ruins; Cliff Palace, Spruce Tree House, Balcony House, Dulce Ruin, Pueblo Bonito, Cavate Lodges, Natural Caves. Means of Sustenance; Irrigation, Hunting. Manufactured Objects; Pottery, Baskets, Sandals, Cordage, Bags and Cloth, Metates, Turquoise. Disposal of the Dead. Religion.

\section{CHAPTER II.}

Modern Pueblos ${ }_{\text {Exploration; Cabeza de Vaca, Marcos de Niza, Coronado. }}$ The Conquest. The Rebellion. Distribution in 1540; Tusayan, Acoma, Tiguex, Salinas, Quirix, Tanos, Cicuya, Jemez, Tewa. Present Distribution; Rio Grande, Hopi, Zuñi. Habitations; Arrangement of Buildings, Building Material, Shelters. Kivas. Food; Agriculture, Preparation of Food, Hunting. Dress. Industrial Arts; Pottery, Basketry, Weaving. Decorative Art. Social Organization. Social Customs. Political Organization. Religious Practices; Festivals, Sia Rain Ceremony, Snake Dance. Religious Beliefs.

\section{CHAPTER III.}

The Nomadic Peoples . . . . . . . . . . . .

Distribution; Athapascan, Piman, Yuman, Shoshonean. Shelter. Food Supply. Clothing. Industrial Arts; Pottery, Basketry, Weaving, Silverwork, Beadwork. Social Organization. Social Customs. Political Organization. Games. Religion; Ceremonies.

\section{CHAPTER IV.}

Conclusion . 
MAPS AND ILLUSTRATIONS.

Hopi Chief . . . . . . . . . . . . . Frontispiece

Plan of the Southwest Indian Hall . . . . . . . . . 3

Culture Areas in North America . . . . . . . . . . 13

Villages and Tribes of the Southwest . . . . . . . . . 14

Topographical Map of the Southwest . . . . . . . . . 16

Distribution of Forests and Rainfall . . . . . . . . . 17

Square Watch Tower. San Juan River . . . . . . . . 25

Diagram of Typical Small Ruin . . . . . . . . . 26

Portion of Masonry Wall. Chaco Canyon . . . . . . . 27

Ceiling, Spruce Tree Ruin . . . . . . . . . . . . 28

Kiva at Spruce Tree Ruin . . . . . . . . . . . . 29

Cliff Palace . . . . . . . . . . . . . . 32

Dulce Ruin . . . . . . . . . . . . . . . . 35

Pueblo Bonito Ruin . . . . . . . . . . . . . . 37

Groundplan and Elevation, Cavate Lodge. Rio Verde Valley . 38

Prehistoric Coiled Ware . . . . . . . . . . . . . 42

Tularosa Pottery . . . . . . . . . . : . . . . . 43

Pueblo Bonito Pottery . . . . . . . . . . . . . . 44

Prehistoric Pottery. Lower Gila River . . . . . . . . 44

Types of Prehistoric Sandals . . . . . . . . . . . 46

Yucea Fiber Bag. Grand Guleh . . . . . . . . . . 47

Prehistoric Cotton Kilt. Grand Guleh, Utah . . . . . . 48

Prehistoric Implements used in Weaving . . . . . . . . 50

Objects of Wood and Bone . . . . . . . . . . 51

Flaked Stones . . . . . . . . . . . . 52

Prehistoric Stone Metate and Bowl . . . . . . . . 53

Stone Axes and Hammers . . . . . . . . . . . 55

Polished Stone Chisels . . . . . . . . . . . 55

Prehistoric Rattle and Flageolet . . . . . . . . . 56

Pueblo of Walpi . . . . . . . . . . . 69

Pueblo of Zuñi . . . . . . . . . . . . . . 69

Floor Plan of Hopi Living Room . . . . . . . . 70

Kiva and Oven. San Ildefonso . . . . . . . . . 75

Floor Plan of Hopi Kiva . . . . . . . . . . . . 77

Roof of Hopi Kiva . . . . . . . . . . . . 77

Hoes and Throwing Stick . . . . . . . . . . 80

Hopi Robe . . . . . . . . . . . . . . 86

Woman's Dress. Acoma . . . . . . . . . 88 
Embroidered shirt. Acoma . . . . . . . . . . . . 89

Santa Clara Woman firing Pottery . . . . . . . . . . 91

San Ildefonso Pottery . . . . . . . . . . . . . . 92

Hopi Pottery . . . . . . . . . . . . . . . . 94

Hopi Baskets . . . . . . . . . . . . . . . . . . . 95

Hopi Prayer Offerings . . . . . . . . . . . . . . 109

Clowns climbing Pole. Taos . . . . . . . . . . . . 112

Deer Dance. Nambe . . . . . . . . . . . . . . 114

Hopi Kachina Dolls . . . . . . . . . . . . . . . 115

Snake and Antelope Priests . . . . . . . . . . . . 120

Snake Priests dancing with Snake . . . . . . . . . . 122

San Carlos Apache Women building a House . . . . . . . 133

White Mountain Apache House . . . . . . . . . . . 134

Navajo House . . . . . . . . . . . . . . . . . 135

Jicarilla Woman gathering Mescal . . . . . . . . . . 137

Mescal Knife. San Carlos Apache . . . . . . . . . 138

Mescalero Girl in Native Costume . . . . . . . . . . 141

Navajo Man . . . . . . . . . . . . . . . . 142

San Carlos Apache Tray . . . . . . . . . . . . 144

Jicarilla Tray . . . . . . . . . . . . . . . . 144

Mescalero Unfinished Basket . . . . . . . . . . 146

Jicarilla and San Carlos Apache Baskets . . . . . . . . 147

Pima Trays . . . . . . . . . . . . . . . . . 148

Pima Storage Basket . . . . . . . . . . . 150

Papago Plaited Basket . . . . . . . . . . . . 151

Navajo Woman Spinning . . . . . . . . . . . . . 152

Navajo Woman Weaving . . . . . . . . . . . . 153

Navajo Belt Loom . . . . . . . . . . . . . . . 155

Navajo Chief Blanket . . . . . . . . . . . . . 155

Navajo Blanket . . . . . . . . . . . . . . 158

Hoop and Pole Game. Apache . . . . . . . . . . . 164

Jicarilla Relay Race . . . . . . . . . . . . . . . 169

Petroglyphs. San Juan Valley . . . . . . . . . . . 179 



\section{INTRODUCTION.}

THE Southwest claims the attention of those interested in ethnology in three important particulars. Such physical conditions as the rather scanty rainfall, the great evaporation, the high elevation of the tablelands, and the peculiar vegetation which exists under these conditions, set it off rather distinctly from the Eastern and Central United States. Under these not too favorable physical surroundings, there have been maintained for a long time two strikingly different cultures, both meeting in their own way these conditions with success. Finally, we have here an unusual perspective resulting from the splendidly preserved prehistoric ruins and from historical records and descriptive literature covering nearly four centuries of contact with Europeans.

\section{Region Defined.}

This region is separated from the culture area of the Plains by the staked plains where there exists neither fuel nor drinkable water. They were crossed in both directions: by the people of the Southwest who went eastward to hunt the buffalo and by the Comanche and Kiowa who raided the Mexican and Indian settle- 
ments of New Mexico. Between the Southwest and the great Aztec civilization in the Valley of Mexico were rough mountains and deserts inhabited by savage tribes. Articles passed northward in pre-Spanish times we know, but just how much influence these two advanced cultures had on each other is yet to be definitely determined. On the west a mighty river, the Colorado, backed by a real and pitiless desert furnished a barrier between the cultures of the Southwest and that of the California coast which is best illustrated by the remains found on Santa Barbara Islands. To the north, are rugged and snow-covered mountains around and through which, however, the Ute came, bringing with them the prevailing language and the customs of the Great Basin. Only on the northeast was a physical barrier lacking. The people of the Southwest and those of the Plains frequented the same hunting grounds for buffalo and were constantly either aroiding each other or having unsought and hostile meetings. When once partial isolation of a people has resulted in peculiar dress, habits, customs, and language, these differences are apt to become added barriers preventing free social intercourse and intermarriage. The existing barriers, both physical and social, were sufficient to allow the origin and maintenance in the Southwest of typical and distinct cultures with gradual transitions toward the Plains on the part of the nomadic peoples of the northeast and toward Mexico by the Pima speaking peoples in the southwest. 


\section{ENTHoNateNT.}

This region varies in altitude from the mountains east of the Rio Grande which have an elevation of nearly 14,000 feet, to sea level at Yuma, where the

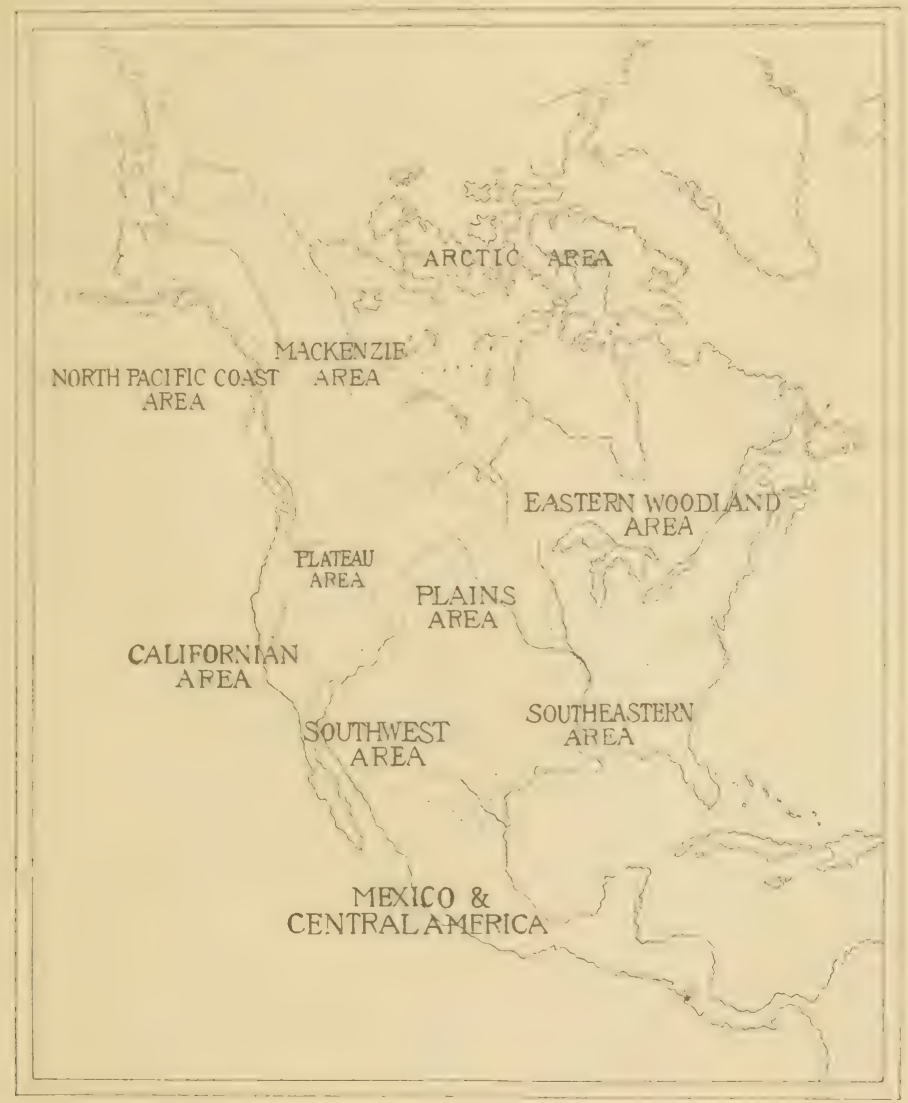

Culture Areas in North America. 
Gila flows into the Colorado. The average elevation is high, due to the great plateau between the Rio Grande, the Mogollon Mountains north of the Gila, and the Colorado River. This vast tableland, from 4000 to 8000 feet high, has on it isolated mountains such as San Mateo (11,389 feet) and San Francisco peaks $(12,794$ feet $)$, and innumerable flat-topped, sheer-walled mesas. South of the Mogollon Mountains the country tilts down and merges with the low dry semi-desert of southwestern Arizona. The rainfall varies with the elevation from 24 inches at Flagstaff to 3 inches along the lower portion of the Gila and averages from 10 to 15 inches over the greater portion of the region. The evaporation is so great that the streams decrease in volume as they proceed from the mountains until many of them disappear entirely. Even the Rio Grande may at times be crossed dry shod at El Paso.

The higher mountains and much of the high plateaus are covered with heavy growths of pine. Lower down are diminutive forests of piñon, cedar, and juniper. Below these flourish mesquite and sagebrush and on the lowest portions of the region are the giant cactus and the smaller ones adapted to arid conditions. The plants of greatest importance are the plums, cherries, agave (century plant), the yucca, the cacti, the piñon, and the mesquite.

With the exception of the buffalo which are commonly believed not to have crossed the Pecos in any large numbers, all the larger animals of the southern United States were formerly common. From the standpoint 
of food, the most important were the elk, deer, antelope, rabbits, prairie-dogs, and wild turkeys.

\section{Influence of Environment.}

The topography, the climate, and the vegetable and animal life of a region largely determine for the men living in it the character of their dress and houses and their manner of securing food.

Certain physical surroundings also in a large measure influence art, religion, and man's conception of the universe as a whole. In the Southwest is an atmosphere wonderfully clear through which one sees with great distinctness the sculptured mountain peaks and ridges and the variously colored, flat-topped, terraced mesas. The violent storms with terrifying thunder and frequent rainbows which mark the seasonal rains; the mirage, the shimmer, and the whirlwinds of the dry season have produced results which we find reflected in songs, formulated prayers, and pictorial art. Only in the Southwest do the gods travel with rainbows and lightning and wrap themselves in clouds tied with sunbeams. So pronounced are these features that one feels from whatever unknown source came the people themselves with their language and original customs that many features of their arts, their mythology, and their religion could only have arisen and could only continue to exist in the Southwest. 


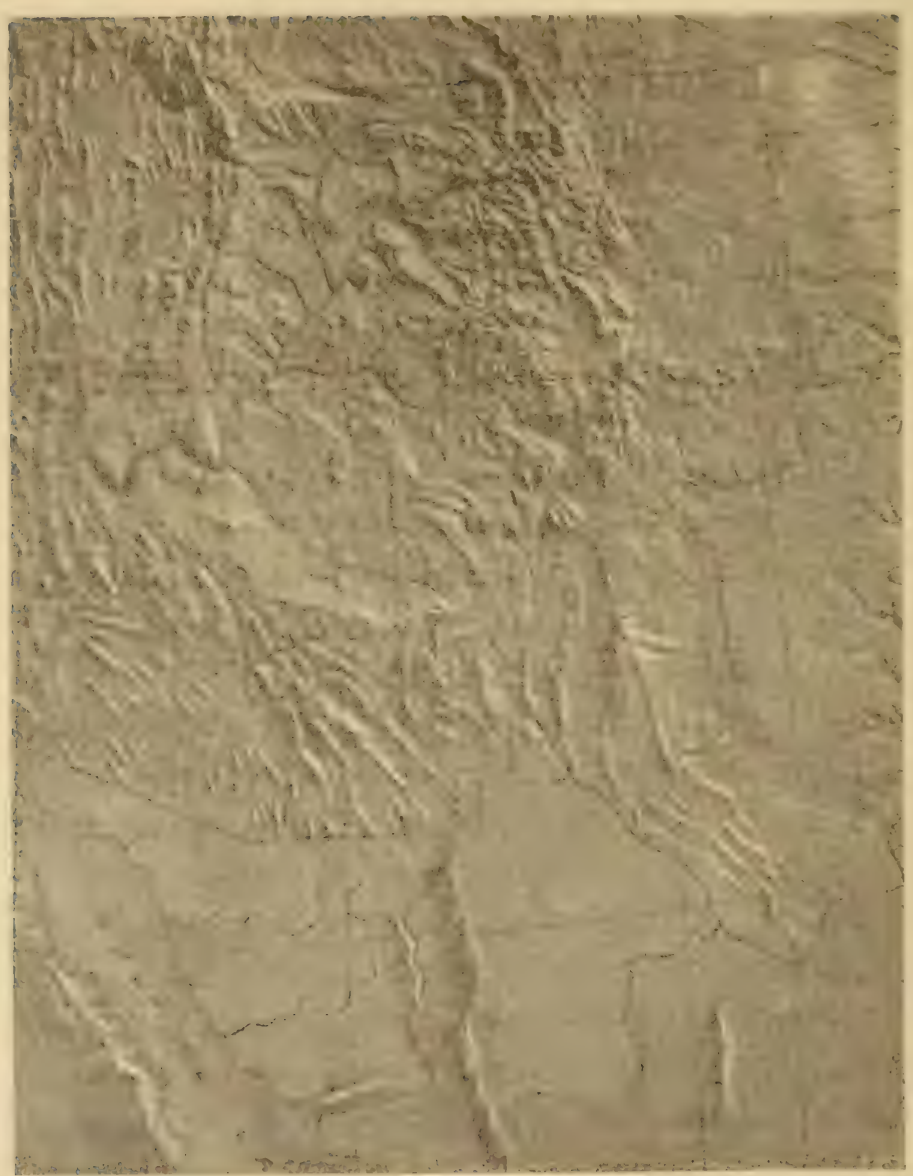

Topographical Map of the Southwest, showing the Mountain Ranges and an Elevated Plateau in the Middle. 


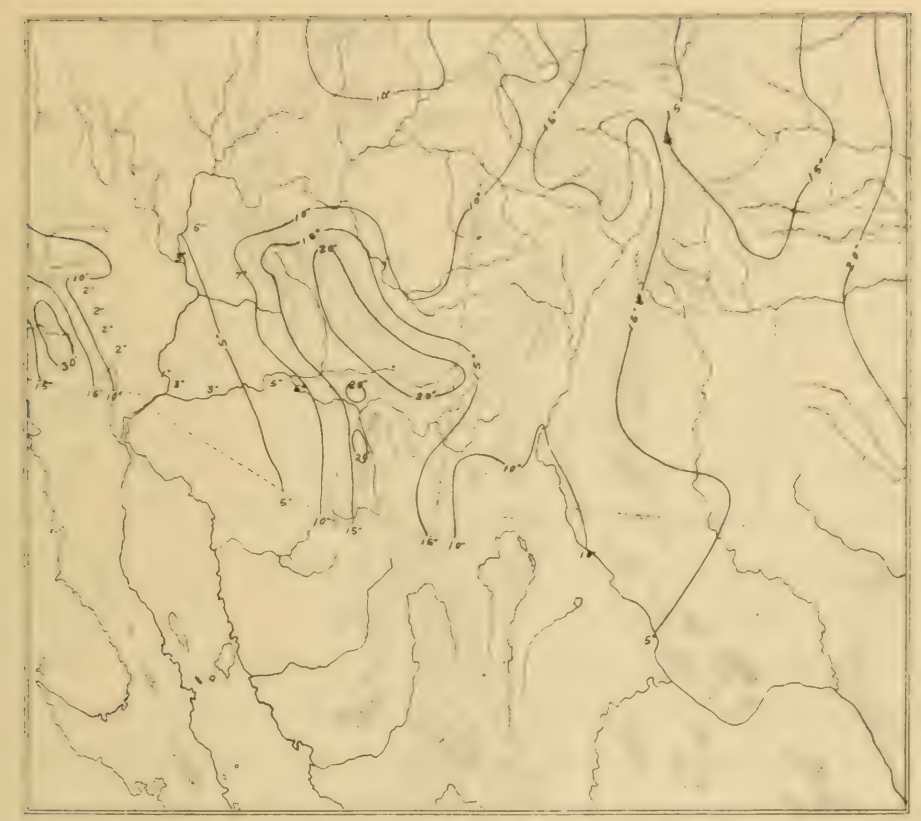

Distribution of Forests and Rainfall. Shaded Portion indicates Timber and the Black Lines Rainfall Areas.

\section{Social Tendencies.}

That physical environment has not been the only force which has molded the life and thought of the Indians of the Southwest is apparent from the fact that two rather distinct cultures exist there. One group of tribes, the Navajo, the Apache, and the Ute meet the physical conditions with certain habits of life and social tendencies. In former years they lived principally by hunting and were obliged to go to the 
more favorable places to secure game. These places were not the same at all seasons of the year and in all years and they therefore needed portable houses such as the tipis of the Plains, or structures easily and quickly built like the dome-shaped houses of the Apache. They had great fear of houses in which death had occurred and they deserted or burned them together with most of their contents. When several deaths had occurred in a locality, the place was avoided. Such customs prevented the building of permanent houses or the long occupation of the same site. The people lived scattered over considerable areas in large family groups under a minor chief. Only at long intervals and on special occasions did they all come together for the celebration of tribal ceremonies.

On the other hand the present day and prehistoric sedentary peoples of the Southwest practised agriculture the fruits of which mature seasonally and must be made to last from season to season. A provident people makes provision against crop failure and feels the need of at least a year's supply to ward off famine. Therefore, large places for storage must be built and these must furnish protection against moisture, animals, and less provident mankind. In many places these people made use of irrigation permitting them to live together in considerable numbers. Some peculiar necessity or social instinct resulted in considerable numbers of people living together in great community houses. It may have been the need of coöperation in defensive warfare, or it may have been the great 
economy of coöperative labor in building houses of such a sort that one roof and one set of outer walls served to shelter many families. Either as a cause or a result, we find a complicated religious system, with orders of priests, councils, and governors to control the people in their joint industries and in warfare, and a system of social grouping consisting of large divisions known as clans.

Under such a physical environment, shaped by such social tendencies, there developed in the Southwest a civilization comparable to that of Mexico and Peru, into which in 1540 the Spaniards came, with a knowledge of metals and firearms, bringing with them horses, cattle, and sheep. Later came the Franciscan missionaries who were intent on breaking down the religious beliefs and practices of native growth entwined into the daily life and social organization of the people and substituting Christianity. The fortunes of war transferred this territory to the United States in 1847. Notwithstanding this long period of contact with European peoples, customs, and religion, we still have in the Southwest many thousands of pure blood natives living in the same localities, in the same sort of houses, by the same means, thinking the same thoughts, and following the same religion they did when found by the Spaniards, and perhaps for many centuries before that time. 


\section{Chapter I.}

\section{THE ANCIENT PEOPLES.}

BECAUSE there are various kinds of ruins in the Southwest, it has been believed by some that they were the homes of two separate peoples: Those who built the houses under the cliffs and in cares have been called the Cliff-dwellers, while those who built in the valleys have sometimes been called Aztecs under the belief that the founders of ancient Mexico migrated from the Southwest at an early date. There is, however, little evidence for supposing that the inhabitants of the cliff ruins and the people who lived in the ruined pueblos of the valleys were of different races or that they lived at different periods of time. They seem merely to have adapted their dwellings to the character of the locality and the building materials at hand.

It is at present impossible to say how long ago the Southwest was peopled. There is no undisputed evidence of man's presence in America in very remote times. In Europe, men were capable of making serviceable tools half a million years ago. While no such age is claimed for man in America there is no reason for thinking he has recently arrived. 


\section{Distribution.}

As might be expected in a semi-arid region the agricultural population in prehistoric times was concentrated at the higher elevations where the rainfall was the greatest and in the river valleys where irrigation could be easily practised.

San Juan. One of the most important regions anciently occupied was that watered by the northern tributaries of the San Juan River. These streams are fed by the snows of the mountains of southern Colorado and Utah. At some distance from their sources they are confined in sheer-walled canyons which unite with each other as they approach the San Juan which enter's the Colorado above the Grand Canyon. Some of the ruins are on the tablelands between the streams, other's are at the head of the canyons, and many are in the canyons themselves either on their floors or under their overhanging walls. The Cliff Palace and the spruce Tree House, two of the largest and best known cliffruins, are in this region.

In Chaco Canyon, a branch of Chaco Valley, there is a cluster of eleven large ruins which evidently represent an important political group of prehistoric villages. One of these, Pueblo Bonito, is hardly surpassed in size and interest anywhere. Canyon de Chelly which joins Chinlee Valley has many ruins both on the floor of the valley and under the walls.

Rio Grande. On the western side of the Rio Grande 
Valley are many large ruins. Some of them are in the valley of the Rio Chama; many of them are on the mesas of the Pajarito tableland south of it; and others are in the Canyon Rito de los Frijoles. In the Valley of the Rio Grande itself and along its eastern tributaries, are ruins older than the Spanish era, others which were deserted during the rebellion, 1680-1692, and a number of villages which have persisted until the present day.

Pecos. The Pueblo of Pecos on the river of that name was occupied until 1838. In prehistoric times there were many pueblos for 40 miles along the valley. Between the Rio Pecos and the Rio Grande there are many ruins and evidences of former occupation by a sedentary, pottery-making people. Some of these ruins, notably those known as Abo, Quara, Tabira or Gran Quivira were still occupied under Spanish rule.

Gila. Along the upper tributaries of the Gila and Salt Rivers there are evidences of a dense population which occupied cliff-dwellings and community houses standing in the valleys. Further down these rivers, the houses were mostly built with mud walls; only mounds of earth and boulders marking the outlines of the walls remain. Not far from Florence, Arizona, near the Gila River is a large and noted ruin called Casa Grande. A number of houses were surrounded by a wall. These are of peculiar construction and resemble ruins in Chihuahua, Mexico, known as Casas Grandes. The Rio Verde which flows into the Salt from the north has a great number and a great variety of ruins 
in its valley which seem to mark the western limit of this prehistoric culture.

Little Colorado. There remains another large tributary of the Colorado which flows through the heart of the Southwest, the Little Colorado. On it are many prehistoric ruins, villages with old Spanish churches deserted in historic times, and the still inhabited villages of the Hopi and Zuñi.

While there is no valid reason for making a distinction between the ancient villages that were deserted and those which remained occupied until the coming of the Spanish, it is convenient to treat them separately since in the one case all our information is derived from the ruins themselves and their contents, and in the other we have descriptions left by the Spanish and observations made in our own time.

\section{Buildings.}

Sites. The building sites chosen by the prehistoric people seem to have depended in part upon the topography of the particular locality and in part upon the needs of defence in a given area. Few available caves seem to have been overlooked. The overhanging cliffs protected the building from rains and most such situations were easily defended. The size of the buildings was of course limited by the extent of the care. Many of the pueblos were built on the valley floors or in open plains, little thought being given to the ease with which 
the enemy might approach. But becanse of their peculiar arrangement and construction such buildings were often easily defended. They were built either in the form of a rectangle or a semicircle around a court from which they were terraced back toward the outer wall which had no openings low enough to be reacherl by the enemy. Some of these like Pueblo Bonito in Chaco Canyon had hundreds of rooms. A great number of villages were placed on the tops of mesas the walls of which were steep enough to furnish a considerable degree of protection. Puré, one of the largest ruins on the Pajarito Plateau, is so situated. In many cases a location was chosen at the head of a canyon, on each side and at the end of which the houses were built making it impossible for the enemy to completely surround the settlement. There are ruins in many places which both from their character and their location seem to have been built solely for defense. These are round or square towers of considerable height which have a few small openings adapted by their size and location for the ohservation of the enemy and for the discharge of arrows. They are usually placed so as to command a wide riew of the surrounding country of ten being perched on the top of a boulder or block of stone. Widely scattered are small ruins consisting of a few rooms on three sides of a small plaza in which is a circular room known as a kiva, or estufa. Near by is usually a rubbish pile in which human remains are almost always found, showing that they were generally used as burial places also. 
Materials. The material employed in building apparently depended upon the ease with which stone could be quarried. In the San Juan region, the sandstone was not difficult to work and on the Pajarito Plateau the tufa was cut with ease. As a result, in

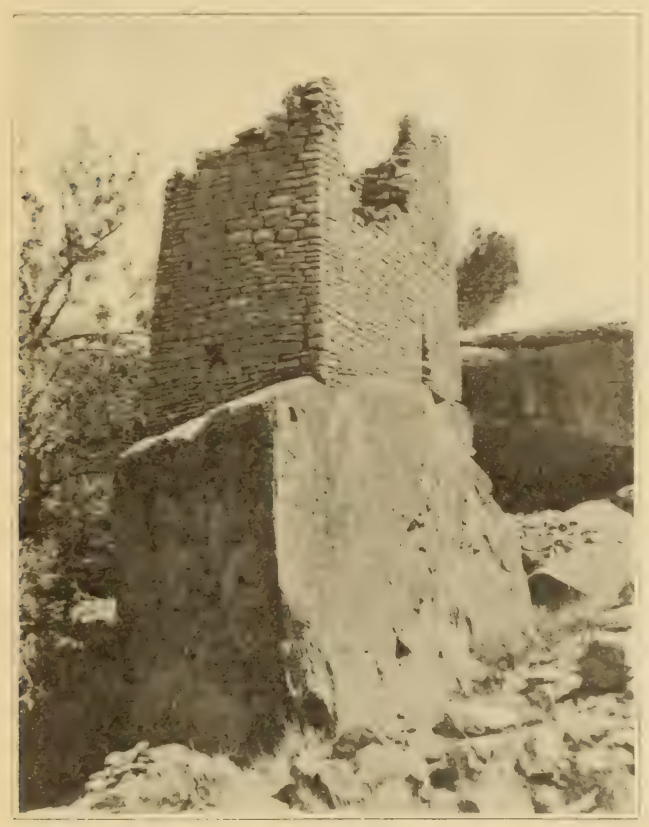

Square Watch Tower, San Juan River. (Courtesy of Dr. Prudden.)

both places the walls are mostly built of well-dressed blocks of stone. In other localities the stone is in thin strata and was broken off and dressed only enough to make the surface of the walls even. The spaces 
between the larger undressed stones were filled with small fragments. Some of the walls show regular courses of large stones alternating with courses of smaller ones producing a banded effect evidently sought for as a decoration.

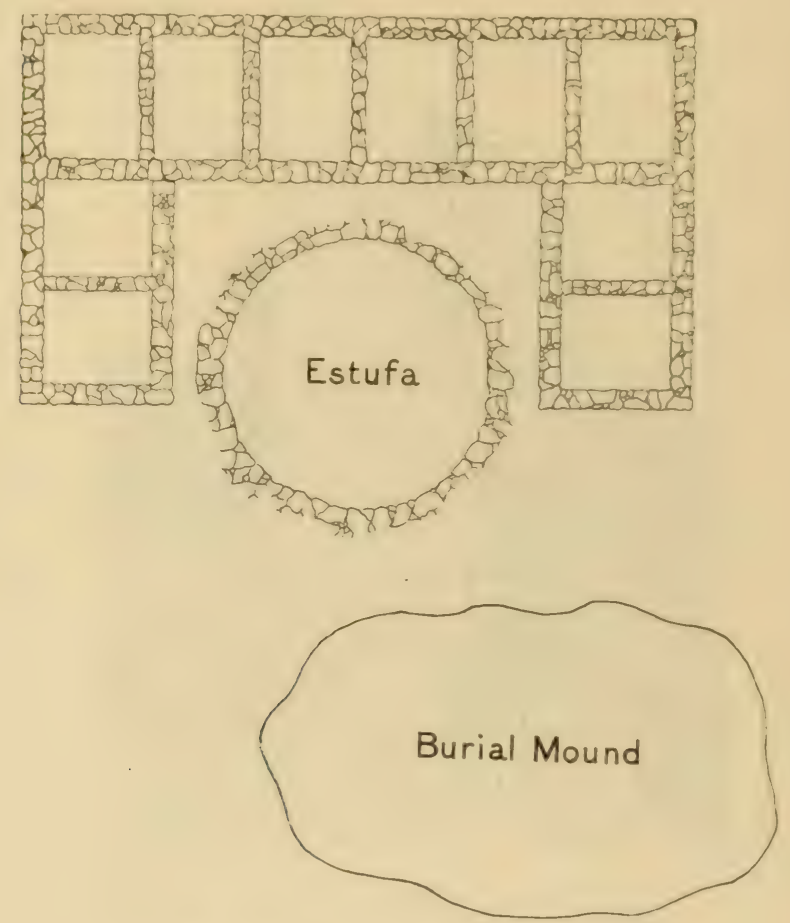

Diagram of Typical Small Ruin.

(Courtesy of Dr. Prudden.)

Along the lower Gila and Salt Rivers bed-rock as a source of building material was not arailable and round river boulders were used, the greater part of the 
walls being composed of adobe, the peculiar clay so abundant in the Southwest. The walls of Casa Grande seem to have been made by pouring moist clay and

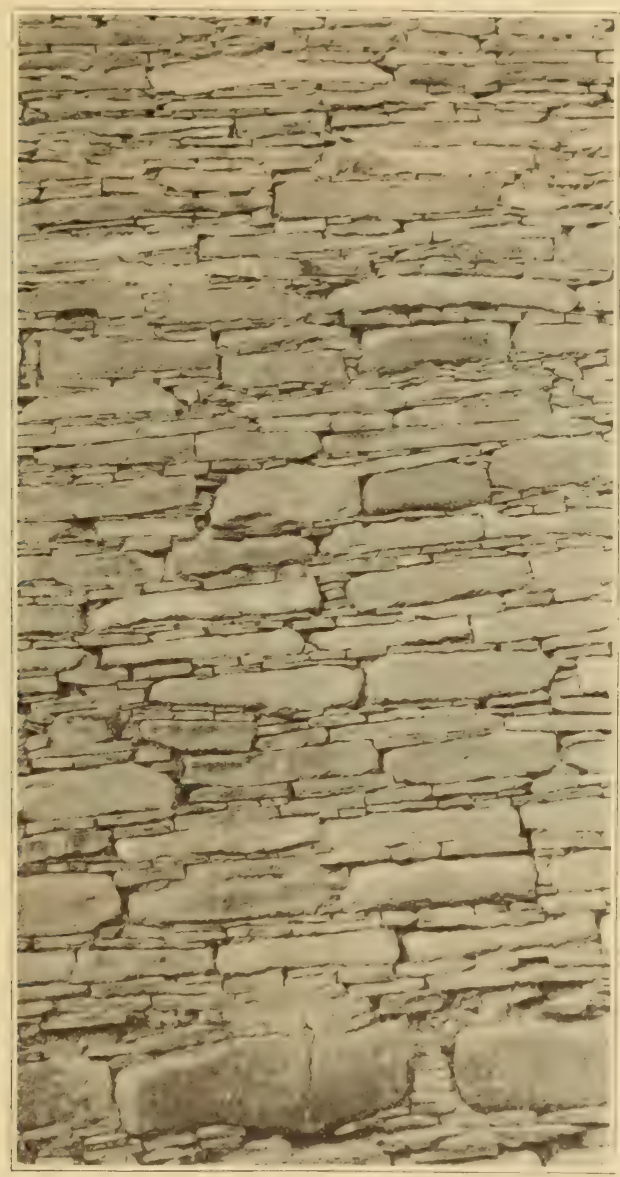

Portion of Masonry Wall, Chaco Canyon.

(Courtesy of Dr. Prudden.) 
gravel into forms as concrete walls are now made. When a section of the wall had hardened, the forms were moved and another section made. Many of the walls of the prehistoric pueblos of the Galisteo Basin were built of large blocks of adobe laid in adobe mortar.

The inner walls were almost always plastered and

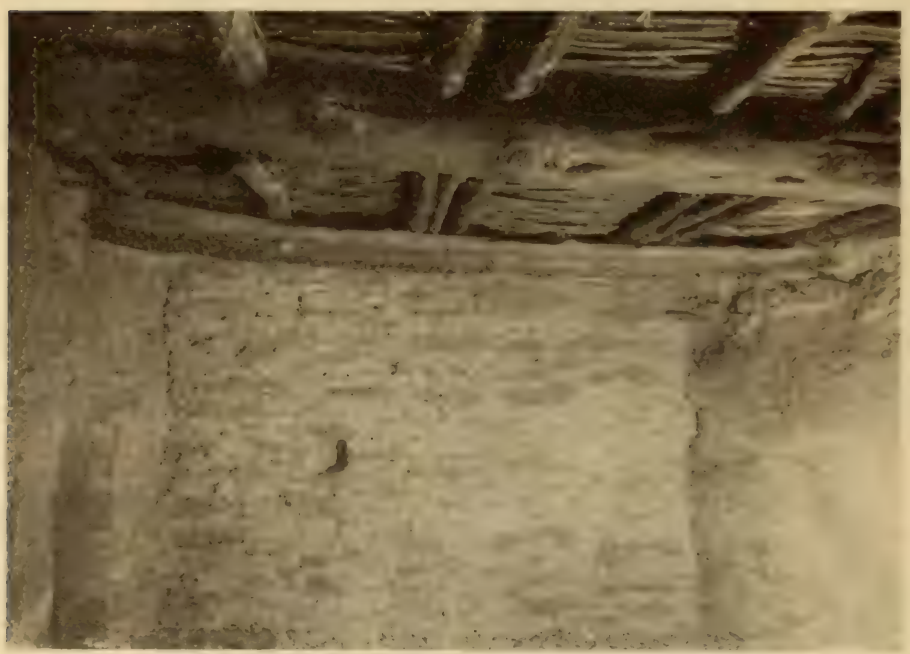

Ceiling, Spruce Tree Ruin.

(Photo. by Yussbaum )

sometimes ornamented by painting. The impresions: of the hands of the plasterers found here and there indicate that the women did that part of the work at least.

Ceilings. The ceilings and roofs of the rooms were made hy placing round logs crosivise with their ends 
resting on or built into the walls. Above these were placed small poles much closer together and ruming in the other direction and on them a layer of brush and small sticks. A thick coating of clay was then applied and well packed down probably by tramping it with the feet. This formed the roof or the floor of the story abore, as the case might be.

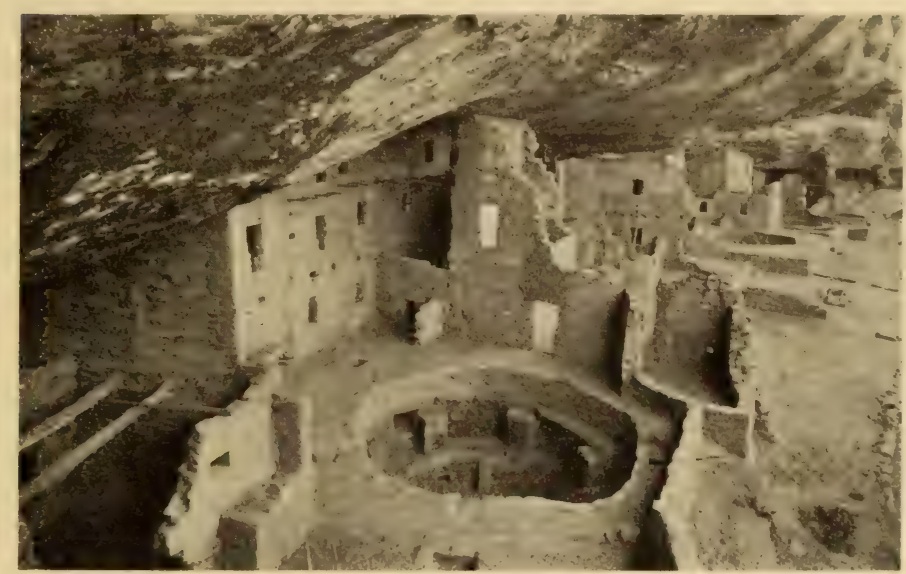

Kiva at Spruce Tree Ruin.

(Photo. by Nussbaum.)

Doors. The walls of the lower stories were usually without openings except small ones to admit light and air and through which one might look out. The larger openings in the upper portions of the walls were either rectangular or T-shaped, and were raised a foot or two above the room floor and served for both doors and windows. They were evidently reached by ladders 
and in some cases had balconies below them on which a landing from the ladders was made. These balconies were supported by the large ceiling timbers which were allowed to project beyond the walls for this purpose. The lower stories were reached by hatchways and ladders, either from the rooms above or from the roofs when the building was terraced.

Kivas. The kivas, peculiar rooms found in all large ruins, are for the most part circular and below ground and are ordinarily located in the courtyard. They vary greatly in size from ten or twelve feet to thirty or more feet in diameter. A firepit is usually found near the center and in most cases there is an airshaft of some size opening at the level of the floor and a masonry wall or stone slab in front of the opening to prevent a direct draft. It is not unusual to find masonry walls extending into the circular kivas for some feet, but the purpose of such construction does not appear. They were evidently entered by hatchways through the roofs which were in all probability of construction similar to those of the ordinary rooms.

\section{Types of Ruins.}

Cliff Palace. The largest and perhaps best known cliff-dwelling is situated in the Mesa Verde region a few miles southwest of Mancos, Colorado. It has been named Cliff Palace and has been described by many writers since it was first mentioned in public print about 
1890. The cave which shelters it is 425 feet long, 80 feet wide in the middle, and reaches an extreme height of 80 feet. It occupies the eastern end of Cliff Palace Canyon which is here about 200 feet deep. The cave opening, therefore, faces the west, with its axis roughly north and south. It resulted from the wearing away by the elements of a stratum of soft sandstone which was protected above by a harder layer that has remained to form the roof. Parts of the rock have broken from this roof and have fallen to the floor below where they have either remained or rolled out to form a sloping talus along its base. The floor of the cave as a result is very uneven so that the structure stands upon four terraces of varying height with some of the rooms resting upon large blocks of rock.

It appears that it was not planned and built as a whole but that the first buildings were added to from time to time, both on the sides and above. The walls of this structure which enclose 117 rooms, not counting those of the upper stories, were built of red sandstone well dressed and laid with adobe mortar in regular courses. The irregularities are chinked with stone fragments. The corners of the walls are not bonded nor are the joints of the stones regularly broken in the courses. It seems that these devices and that of the arch and its keystone were unknown to the ancient peoples. These walls which are from one to two feet in thickness were generally plastered on the inside and sometimes on the outside with a yellow plaster laid on and smoothed with the hands, the prints of which 
are often plainly visible. In a few cases, the walls are ornamented with paintings.

Both rectangular and T-shaped doorways are found and several of them are provided with grooves in which slabs of stone were placed to close them.

Many of the ninety-four rooms which were evidently

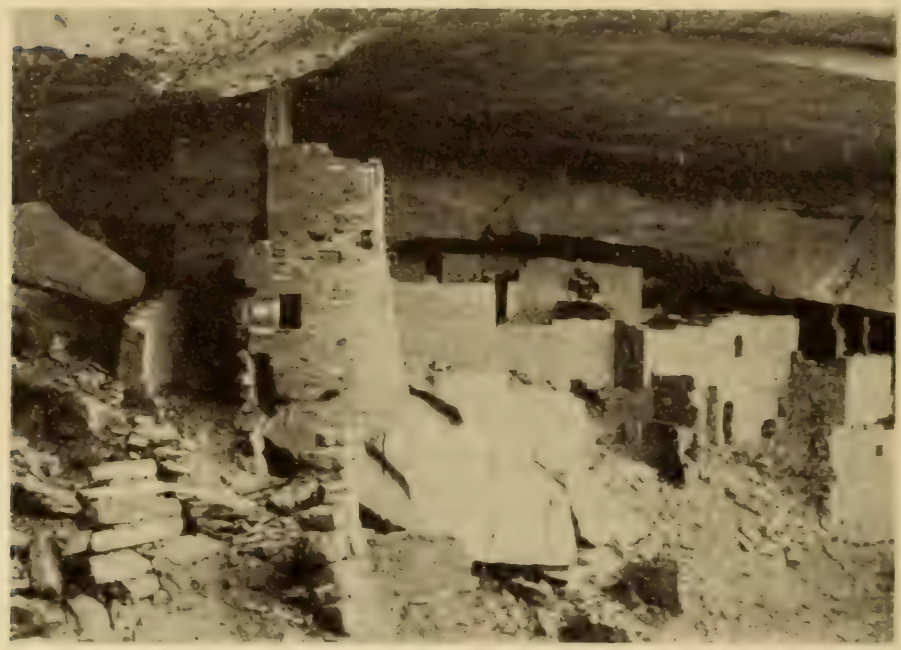

Cliff

used for household purposes have fireplaces either in one corner or in the center. The walls are blackened with smoke for which no other exit was provided than the doors and windows. In a few of the rooms there is a raised bank along one side which may have furnished sleeping places. Certain rooms, especially those with other rooms above them, show no signs of fire or smoke and since they were entirely dark were without 
doubt used as storerooms for the food supply. A number of rooms deroted to the grinding of corn have boxes made of slabs of stone in which the grinding was done on metates as at present in the Southwest. One room has four such boxes side by side with the metates still in place. There are many fireplaces in an open

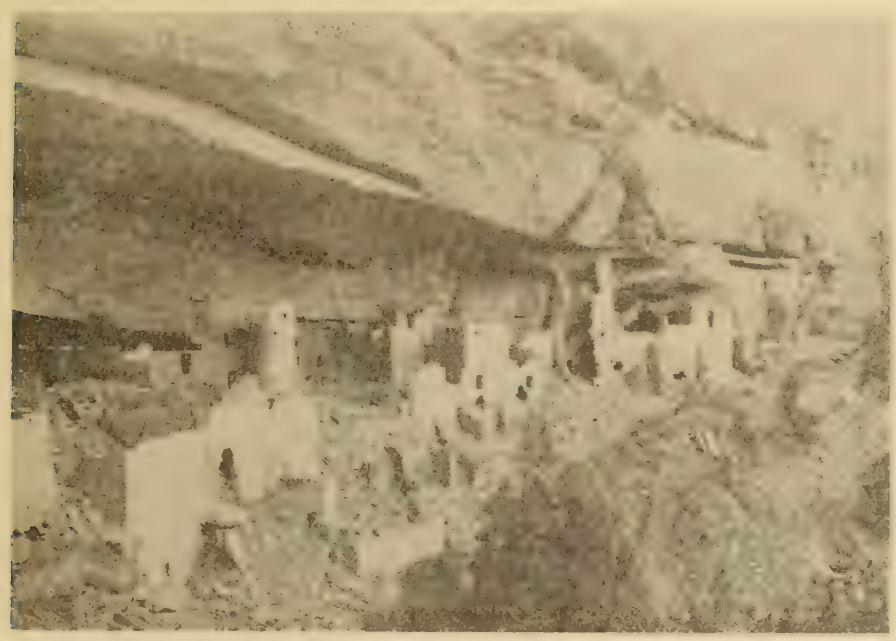

Palace.

(Copyrighted by F. K. Vreeland.)

plaza in the middle of the village where much of the cooking was probably done.

There are twenty-three kivas, situated in a court, most of them having their roofs level with the floors of the ordinary rooms of the first story. To give some of them the required depth the solid rock was excavated for several feet. 
A round tower rising from the summit of a block of rock reaches the ronf of the cave. It has been supposed that this served as a watch-tower. It may have been that the whole structure was intended as a place in which the reserve food supply might be stored and defended, since in the neighborhood are ruins of other community structures in less easily defended situations.

Spruce Tree House. About two miles northeast in an adjoining canyon is another cave with a dwelling nearly as large and much better preserved. It is named Spruce Tree House from a tree found growing in the ruins which when cut in 1891 showed an age of 169 years. In this dwelling are several ceilings in a good state of preservation. This building and Cliff Palace have been restored under the direction of Dr. J. W. Fewkes and it is expected that they will remain in this condition as permanent examples of such structures.

Balcony House. Not far from Cliff Palace and in the same canyon is Balcony House, named so because one of the balconies below the doors of an upper story was found intact by Nordenskiöld who describes it as follows:

"The second story is furnished, along the wall just mentioned, with a balcony; the joists between the two stories project a couple of feet, long poles lie across them parallel to the walls, the poles are covered with a layer of cedar bast and, finally, with dried clay. This balcony was used as a means of communication between the rooms in the upper story."

Dulce Ruin. I good example of a small cliff-dwelling is situated in the extreme eastern border of the San Juan watershed about twelve miles southwest of Dulce, 
New Mexico. It the head of a small canyon draining into the San Juan through the Navajo River is a cliff about sixty feet high. Forty feet from the base is a small cave facing the southwest in which are two rows of rooms. The largest room is against the cliff at the northern end having the rock of the cliff for its back wall. This was the living room of the group as is shown by its blackened walls and a fireplace in the

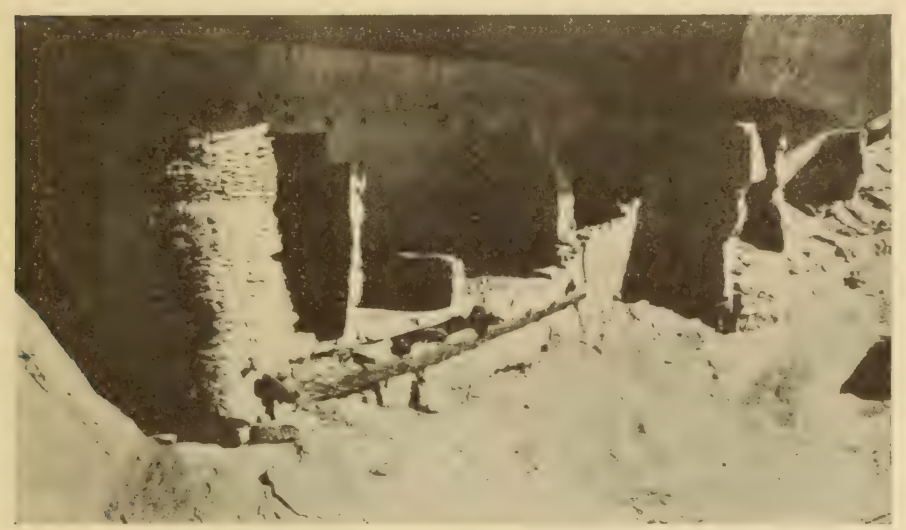

Dulce Ruin.

(Photo. by Mrs. Wyckoff )

northern wall of the room, a foot or two above the floor. The smoke from this fireplace escaped through a shaft in the wall itself. This room which is 12 feet long and 8 feet wide is the only one large enough for a person to lie extended. South of this room is a jug-shaped one twenty-three inches by twenty-seven inches at the top but opening out considerably toward the bottom. 
This was probably used as a cistern since it is plastered inside and may originally have been water-tight. In front of these rooms are four smaller ones the outer walls of which rested upon small aspen poles and a cedar log so placed as to overeme the slope of the cave floor. These poles are still sound with their bark intact. The back wall of the front row of rooms shows where ceiling joists once rested providing a roof six feet high. There were two other rooms at the southern end not in line with the first four. These smaller rooms were evidently used for storage and they still contain many corn cobs. At the base of the cliff was formerly the ruin of a single room in which a burial had taken place. This structure furnished an excellent storage place difficult to find and easily defended.

Pueblo Bonito. In Chaco Canyon stands a typical unprotected ruin of a large community house known as Pucblo Bonito. It is close to the wall of the canyon, roughly semicircular in shape, with five rows of rooms on the ground, and was originally four or five stories high. Across the front was a double row of rooms one story high which enclosed a large court, in which were twenty or more kivas. The entire length of the structure was 667 feet and its width 315 feet and it contained more than 500 rooms. The masonry of the walls varies in character, that of the first story being composed of medium-sized hewn stones and the upper stories of small flat stones faced to form the outer surface. Many sticks of timber are included in the walls to strengthen them. This ruin was excarated by the Hyde Expedi- 


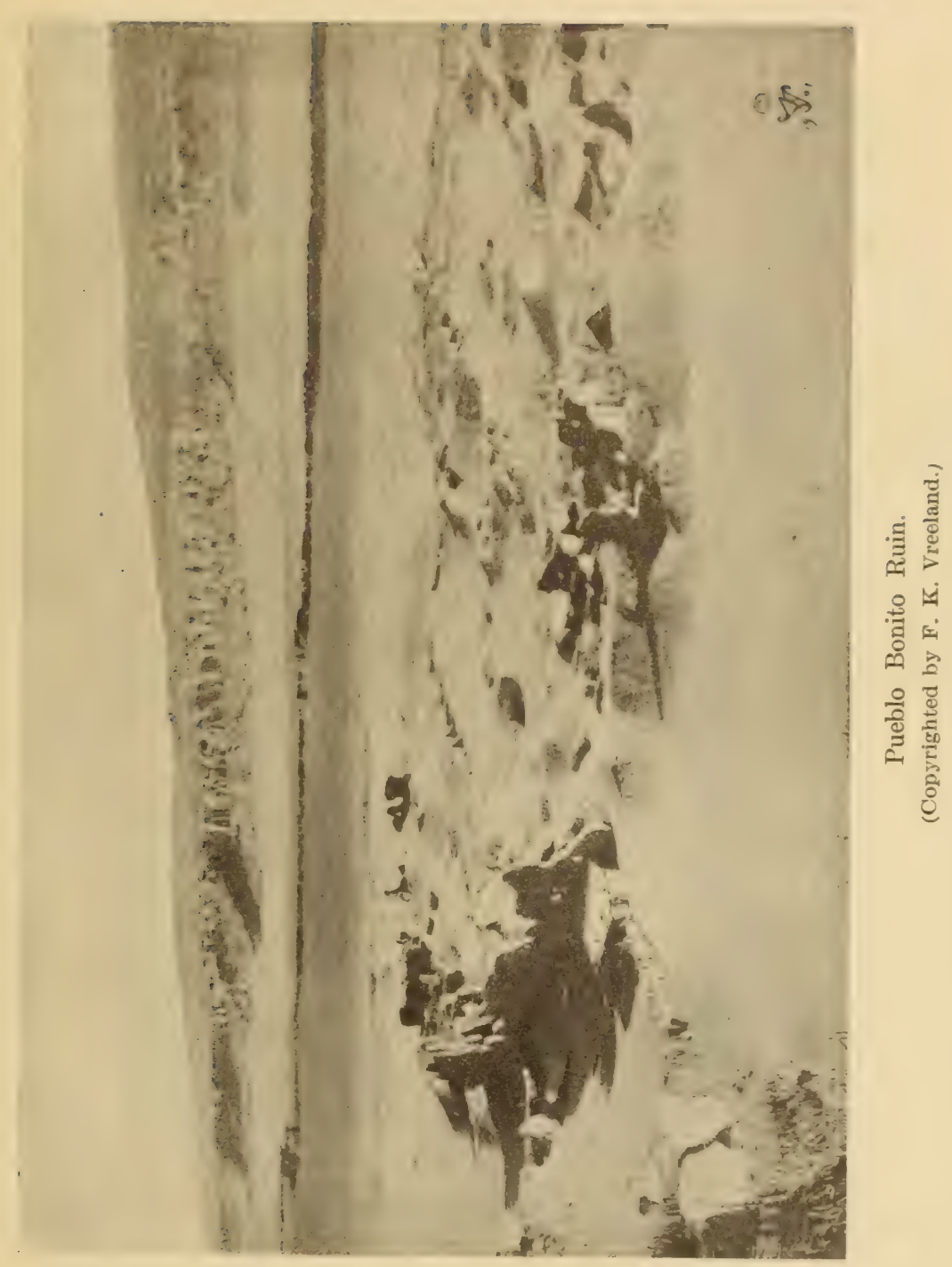


tion of the American Museum in 1895-1900 and many remarkable specimens were recovered.

Cavate Lodges. Along the Rio Grande and Rio Verde are the simplest possible dwellings, those excavated in the soft rock walls of the canyons. It is along the Rio
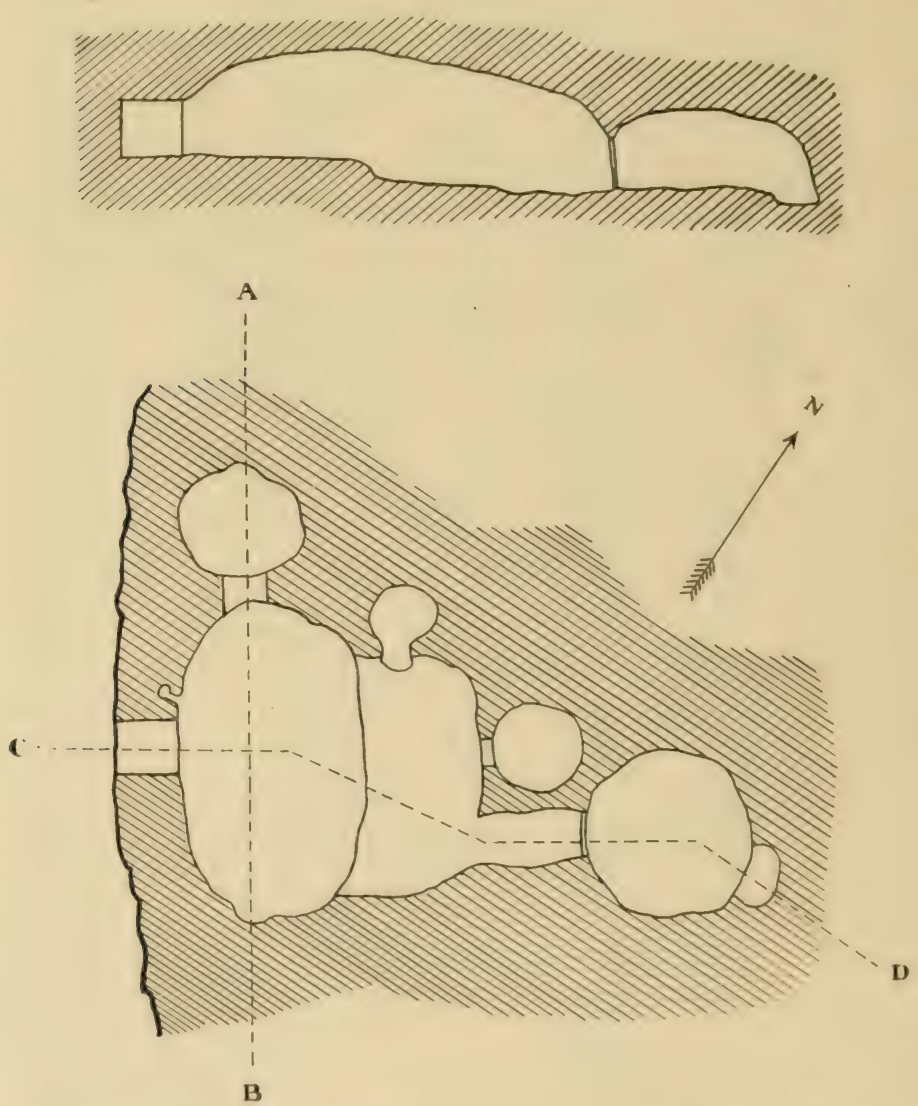

Groundplan and Elevation, Cavate Lodge, Rio Verde Valley. (After Cosmos Mindeleff.) 
Verde that the most elaborate of these excavations are found. A round opening was made in the face of the cliff for the door and sufficient rock excavated to make a good-sized living room twelve feet or more in its dimensions and high enough for one to stand. Behind this were storerooms usually of less size and height. There are hundreds of such rooms in the canyon walls.

Natural Caves. A curious series of natural caves near the headwaters of White River in eastern Arizona has some time been inhabited. These caves vary in size and open into each other by low and narrow passageways which are also often steep since there is considerable change in level. In some places the rock may have been excavated and there are a few masonry walls subdividing the larger rooms. The walls are black with smoke and the floors are covered with dirt which rises in dust since it is almost completely without moisture. Several of these natural rooms have small openings in the face of the cliff which admit air and light.

\section{Means of Sustenance.}

That the ancient people were agriculturists we know from the corn and beans found in the ruins. In the Museum collections are specimens of corn in the ear, a basket of shelled corn, and a bag of corn meal. Beans are also found and squash and gourds are known to have been raised.

We know little of their method of tilling the land. 
Their tools must have been rude, probably of wood. with which the ground was dug before and after the seed was planted. In much of the territory occupied near the sources of the streams, the valley lands were kept moist by the underflow and did not require irrigation. At the elevation at which these streams leave the mountains there is considerable rain in late summer, enough to mature corn even on the upland mesas. Reservoirs are found near many of these mesa pueblos which received the water from the mountain gulches and retained it for household purposes. In some cases the water thus impounded was used to irrigate the land. Near Solomonville on the upper portion of the Gila River the gardens were arranged in terraces on the sides and at the bases of mesas, and were watered from reservoirs which retained the water falling above.

Irrigation. It is along the middle and lower courses of the Salt and Gila Rivers that evidences are found of irrigation practised on a large scale. The Hemenway Archaeological Expedition, in 1887-1888, explored Lcs Muertos, a veritable city with thirty-six large communal structures, nine miles southeast of Tempe, Arizona. This city, nine miles from the Salt River, was supplied with water by a large canal $7 \mathrm{ft}$ deep, $4 \mathrm{ft}$. wide at the bottom, and $30 \mathrm{ft}$. wide at the top. The walls and the bottom of the canal were very hard as if they had been plastered with adobe clay after the soil had been thoroughly packed by tramping. It was suggested by the investigators that fires had been built in the canals and the clay baked by this means. Many 
side canals were provided for the distribution of the water over the fields. The posts of the gates for regulating the flow were found at the heads of these laterals. Mr. Hodge, who reported these excavations, estimates that similar canals provided for the irrigation of at least 200,000 acres, about half of the land in the valley available for such uses.

Hunting. The large number of bones of game animals found in the houses and refuse heaps indicates that hunting was not neglected. The weapons probably employed were the bow and arrows, spears, and possibly clubs. The numerous pieces of large rope clearly show they had the means at hand for snares as well.

\section{Manufactured Objects.}

Pottery. The prehistoric pottery of the Southwest is of excellent quality and unusually beautiful in its decoration. It bears evidence of being made by coiling. The succeeding rounds of clay are made to adhere to the preceding ones by pressure with the fingers and then are either left rough, or smoothed down and polished so as to completely obliterate the individual coils.

The larger cooking pots are often undecorated. In some of them the unsmoothed coils and the marks of the fingers in pressing the coils together produced decorative effects but that the result was intentional is not clear. On many of them, however, indentations are applied in a symmetrical way or so as to produce simple patterns. 
A red ware decorated with black painted designs is found in Galisteo Basin, along the Little Colorado River and southward to the Mexican line in considerable abundance. On the Little Colorado, and so far nowhere else, have been found pots with a white slip on which designs have been painted in both black and red. There are also specimens painted in dark green.

The prevailing type of decorated pottery has a white or grayish slip on which decorations are painted in
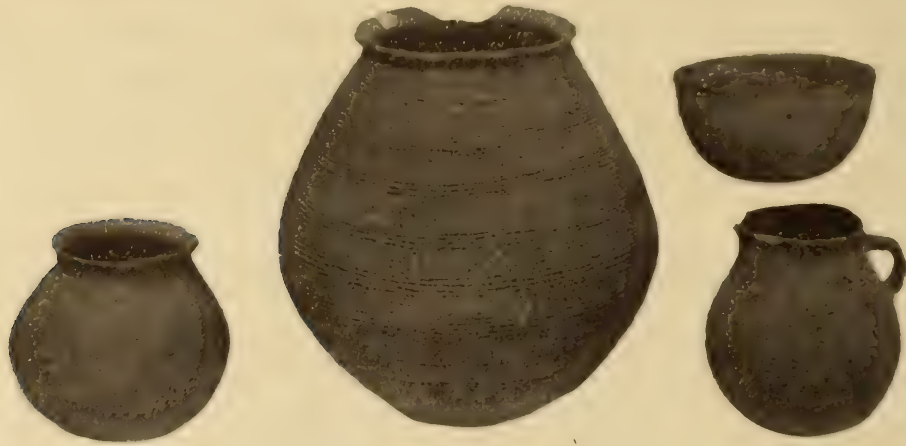

Prehistoric Coiled Ware.

black. Ware of this character abounds along the northern tributaries of the San Juan, in Chaco Canyon, in the Rio Verde Valley, and reached perhaps the best development on the San Francisco River and its tributaries at the head of the Gila. From the latter region a very remarkable series of pots was taken by Henry Hales in 1892 and 1893. The American Museum possesses a large number of these pieces secured by purchase or gift at various times. At Pueblo 
Bonito 173 pots were found in a single room, nearly all of them being cylindrical in shape.

The forms of the pots are of interest. Those of the black ware are usually bowl-shaped or cylindrical in
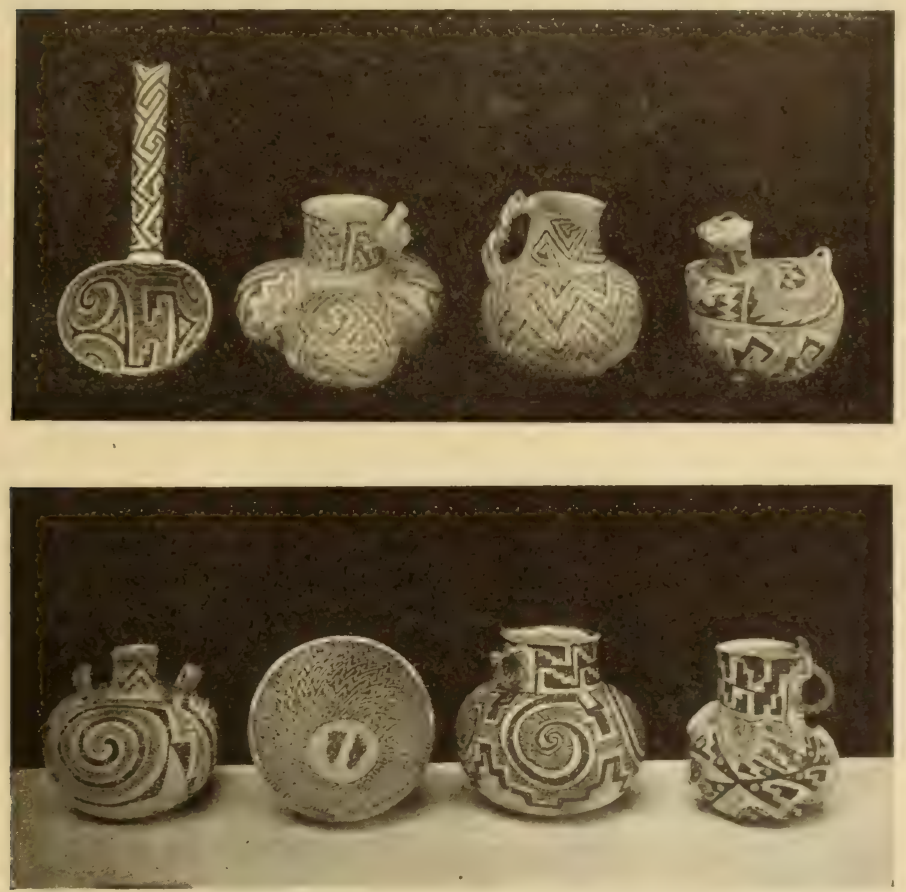

Tularosa Pottery.

form while the gray and black ware occurs in the shape of mugs with handles, in a variety of bowl shapes and molded in the forms of animals and birds. Some of these show a considerable knowledge of anatomy and a high degree of skill in modeling. 
The designs on the ancient pottery of the southwest are largely geometric and purcly decorative. Straight lines and acute angles often combined into intricate patterns predominate, hut graceful curves and spirals

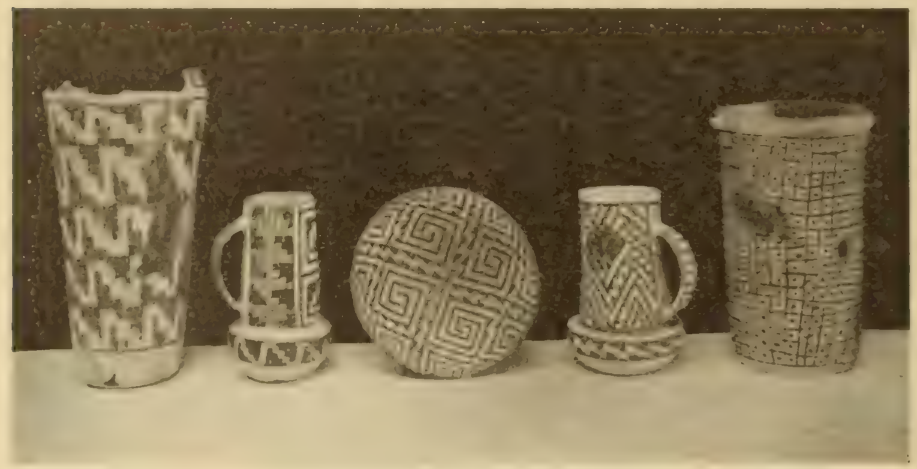

Pueblo Bonito Pottery.

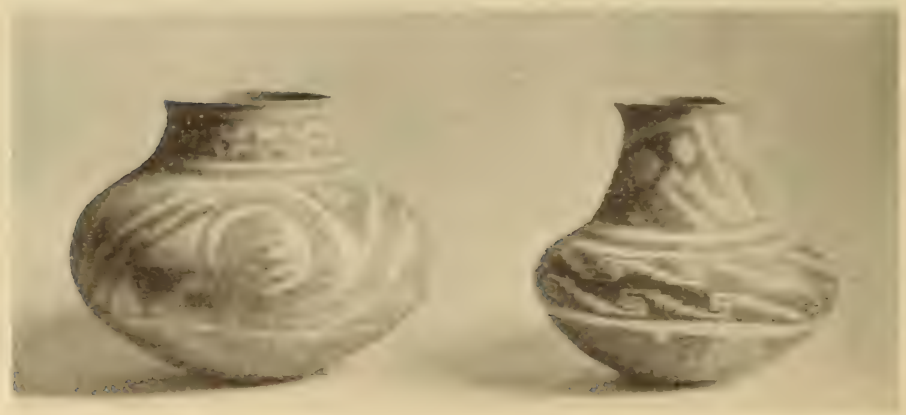

Prehistoric Pottery. Lower Gila River.

(Courtesy of Peabody Museum.)

are also common. Several of the cylindrical pots from Pueblo Bonito are evidently intended to represent ears of corn, the kernels being figured in rows of black 
squares. A small bowl from Tularosa has the feet of a child represented on the bottom. The red and black pottery of the Little colorado often has animal forms either slightly or highly conventionalized.

Pottery vessels and fragments have been found in ruins undoubtedly prehistoric that show clear evidence of having been treated before burning in a way to produce a vitreous glaze. This may have resulted from an application of the salt found along the streams where it had been deposited by evaporation.

It is expected that by a minute and careful study of the designs upon the pots and potsherds in the Southwest, definite cultural subdivisions of the area may some time be made and possibly earlier and later occupations of the same region may be determined.

Baskets. Fragments of baskets have been found in many of the ruins and it would appear that they were made over the entire area. The common type is of diagonal plaiting with a heary wooden rim for a border. The material used was chiefly wide strips of yucca leaves and there were no attempts at decoration. The northwest portion of the area, however, seems quite exceptional in the number, variety, and excellence of the specimens recovered. The collections in the Museum were taken from Grand Gulch and Cottonwood ('reek, Ltah. The majority of the specimens were found with burials either in cares devoted to that purpose or under the floors of dwellings built in caves.

These baskets are coiled with a single rod foundation, a peeled twig probably willow or sumach. The 
sewing material is apparently the outer portion of such twigs obtained by splitting them and removing the inner portion. In shape, the baskets are broad and shallow, only a few deep bowls haring been found.

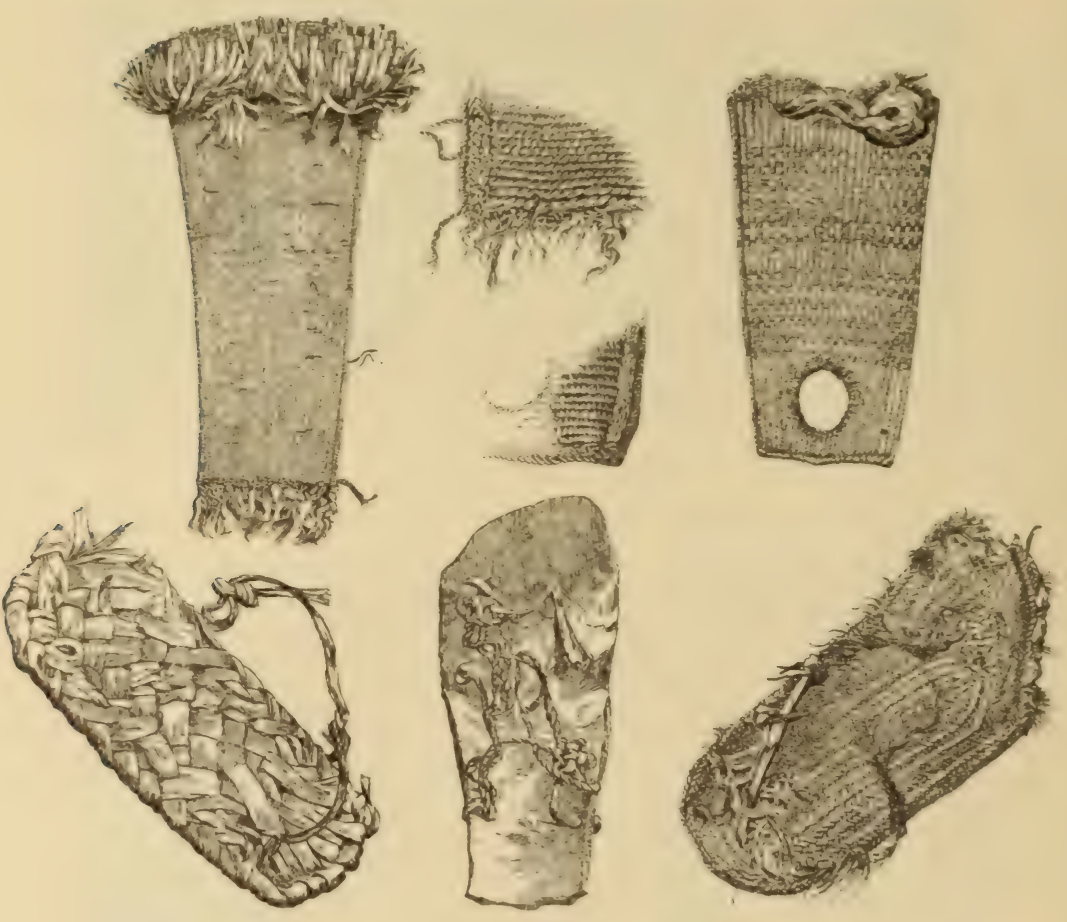

Types of Prehistoric Sandals.

Large baskets with flaring sides, sometimes conical, were found inverted over bodies.

They were decorated by the use of sewing material dyed black and red or brown. The former color is 
fast but the latter has faded somewhat. While the designs are usually geometric, a few of them are realistic. One openwork specimen is interesting; its foundation

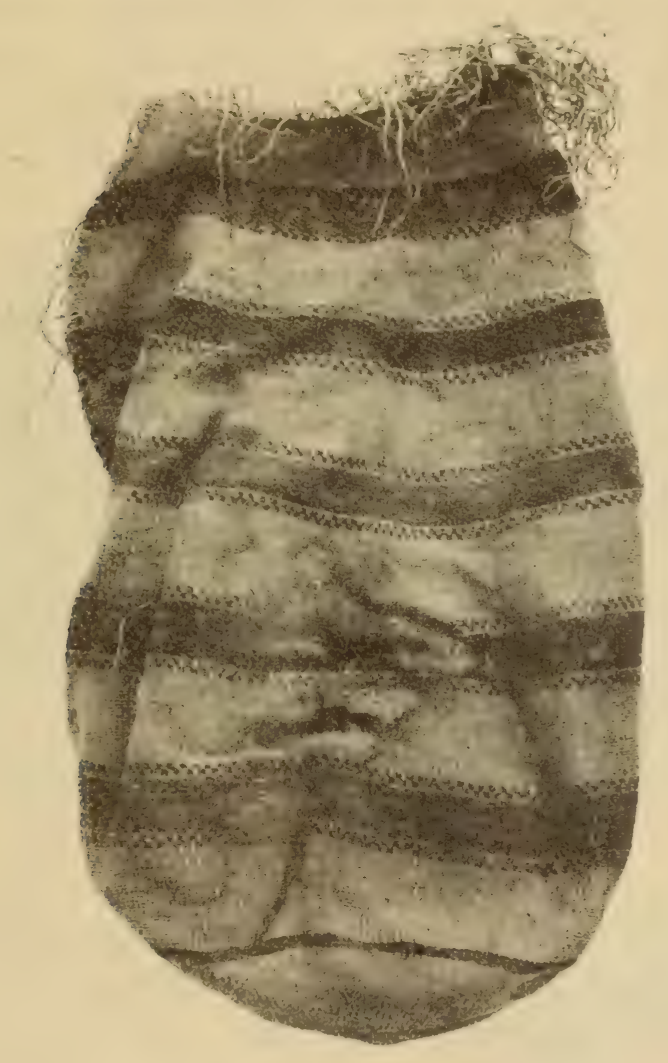

Yucca Fiber Bag. Grand Gulch. 
is eoiled but the woof is twined with two st rands crosiced between each coil of the foundation leaving considerable spaces between both the warp and the woof.

sundals. The sandals, of which there is a long series in the Museum collection, show great variety in the methods employed in making them and in their ornamentation. The simpler ones are diagonally plaited with broad strips of yucea leaves. Others are twined with two strands and usually have the lower side thick-

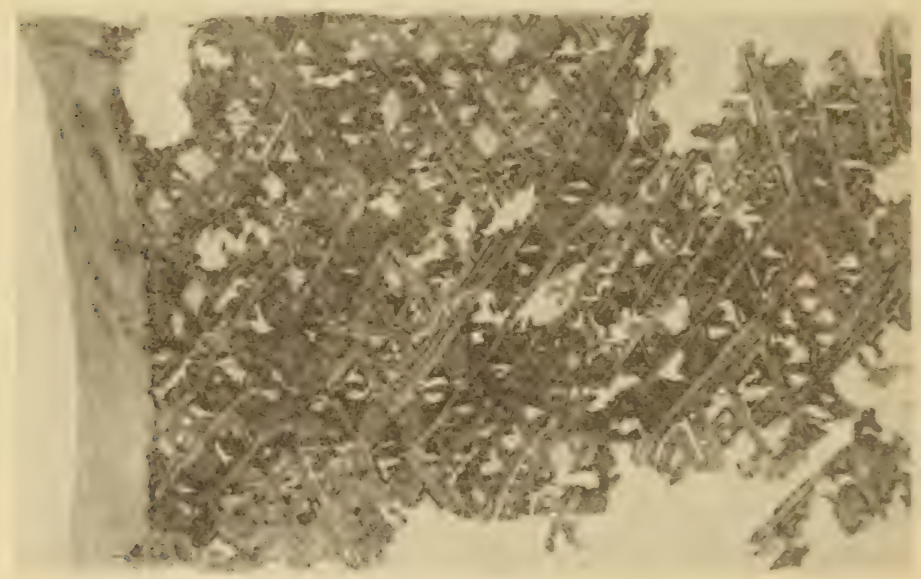

Prehistoric Cotton Kilt. Grand Gulch, Utah.

ened and cushioned by imbrication or the attachment of additional material in the form of numerous loops or rows of twine. The warp is usually of coarse stiff fibers, probably derived from yucea leaves, but the woof appears to be of cotton. The designs in red and black are usually arranged in horizontal stripes and hands. 
Cordage. There are many examples of rope and twine usually composed of two twisted strands. Aprons consist of bunches of such twine gathered at the waist where they were attached by a string or girdle and left loose and flowing at the lower end. Such twine was also made into openwork nets, into the twists of which the quills of feathers were caught making a feather blanket, probably of the kind which were still being worn in the Southwest in Coronado's time. There are many specimens of twine made of human hair.

Bags and Cloth. There are a number of bags in the collection, several of them being in nearly perfect condition. They are made without seams by twining with two strands of yucca fiber thread. The warp is of the same material resulting in a pliable and originally a very durable bag. The decorations are in the form of horizontal bands; one of the bags has a red stripe between two black ones, repeated four times with wide undecorated spaces between. Another has alternating red and gray bands each of which is composed of alternate stitches of colored and uncolored material to which a border composed of small rectangles is added. Both the rectangles and the speckled appearance of the bands are produced by using one colored strand and one uncolored one so that they appear alternately on either side. One of the best preserved specimens was found full of corn meal. It has a long fringe around the top produced by allowing the ends of the warp strands to extend for a considerable distance. Such bags were probably made largely without the aid of mechanical 

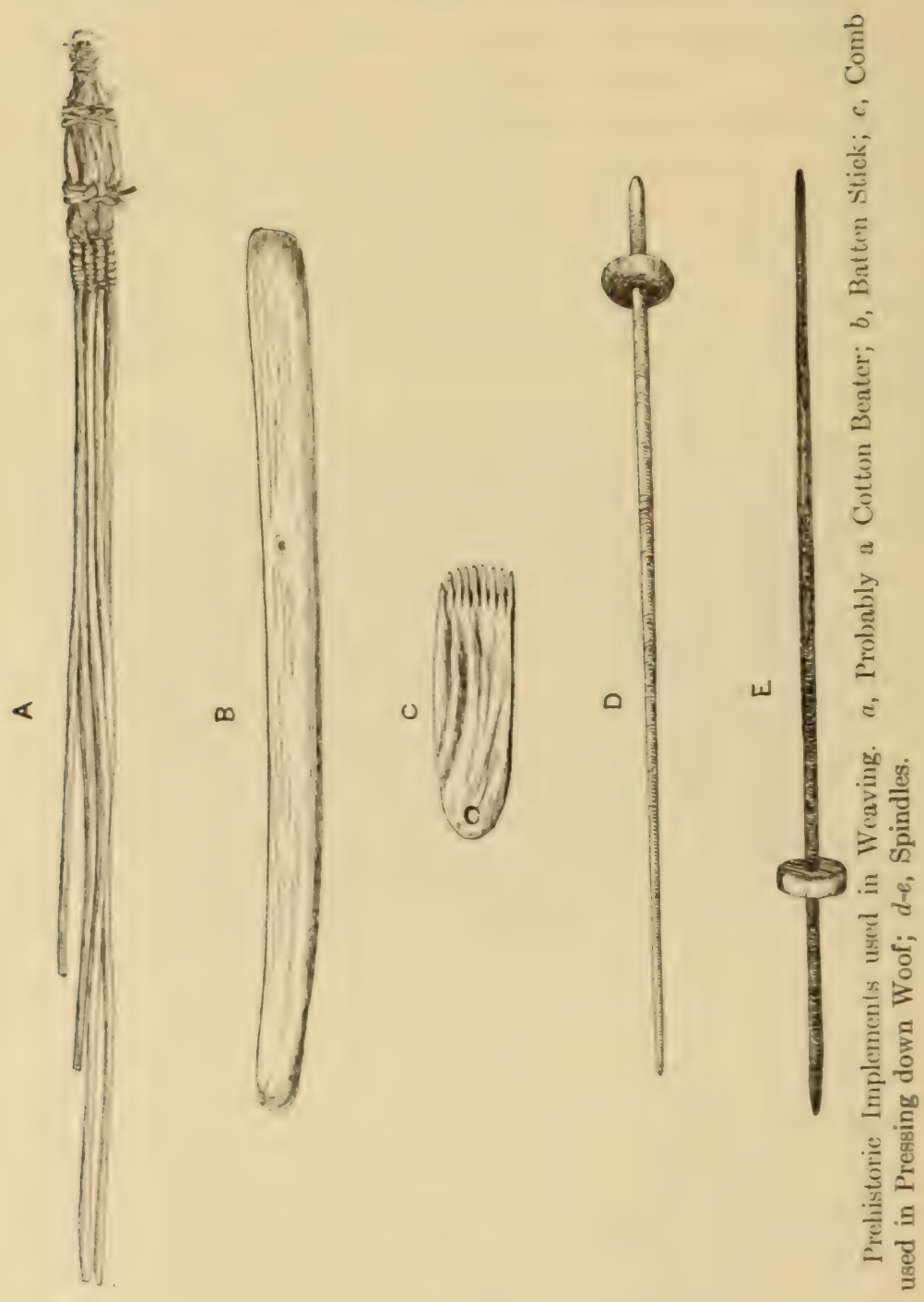
devices in the manner in which baskets are twined. A small bag has the ordinary looped and twisted crochet stitch.

There are many fragments of woven cotton cloth which were without doubt made on some sort of a loom. The most interesting piece is a small robe or kilt found wrapped around a body. The weaving is diagonal,

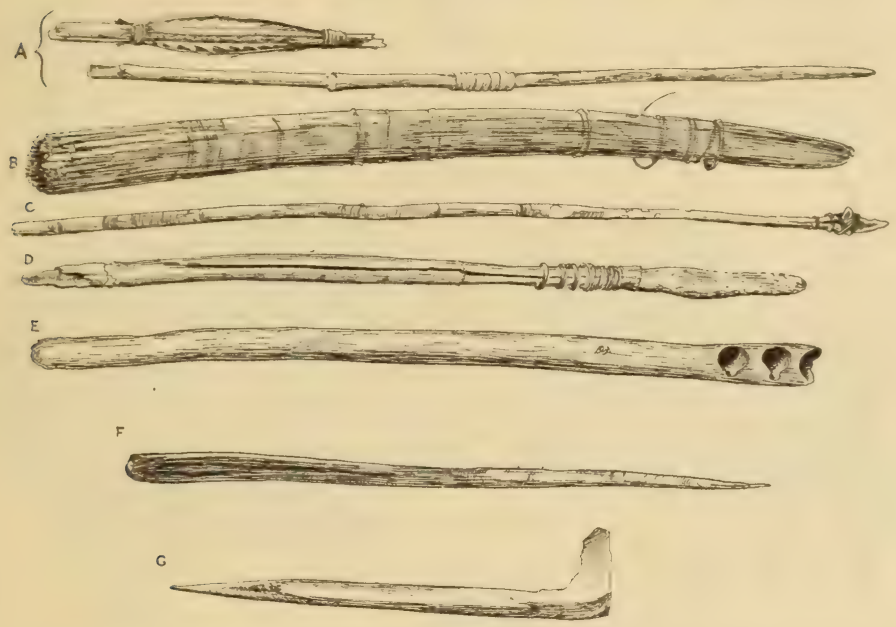

Objects of Wood and Bone. $a$, Arrow; $b$, Sinew-wrapped End of Bow; $c$, Flint-pointed Drill; $d$-e, Firedrill; $f$, Wooden Awl; $g$, Bone Awl.

producing raised patterns which are further accentuated by the use of black, red, and yellow dye. This is probably the finest piece of textile work known from the Southwest.

The implements used in the preparation of the cotton and in weaving it are well represented. There are 
several diverging small round sticks, joined in a handle which may have been used in beating the cotton. spindles with wooden rylinders and balls to give momentum have been found. There are also wooden forks and long batten sticks, similar to those used at the pres-
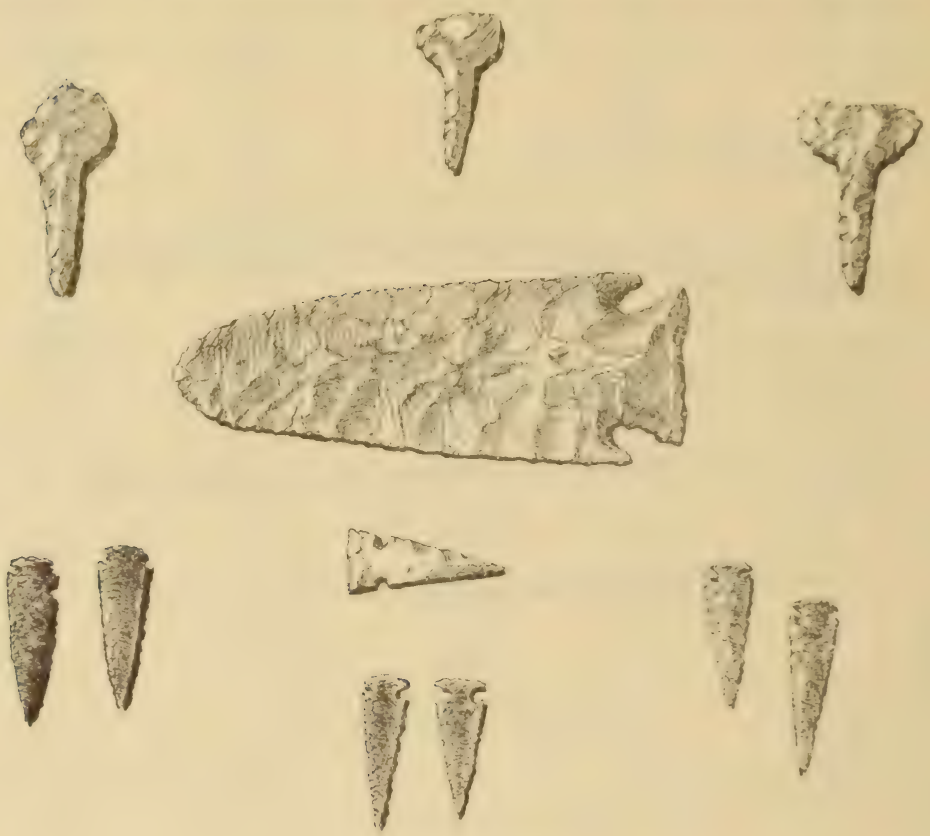

Flaked Stones.

ent time in the Southwest to press the woof strands firmly into place. The many wooden and bone awls were probably used in the manufacture of baskets and sandals.

While the specimens recovered from the northwestern portion of the area indicate a great variety and perfec- 
tion in textile art, there are many examples of cotton and yucea fiber textiles from all parts of the area.

Metates. The grinding stones employed wore metates of the same sort now used in the southwest and found in the southern portion of California, in Mexico, and Central America, and generally in south America. The bottom stone is a slab roughened by pecking and often ground down in the middle so that it has a raised border on either side. For use, it has the front end raised making an angle of about 30) degrees from the
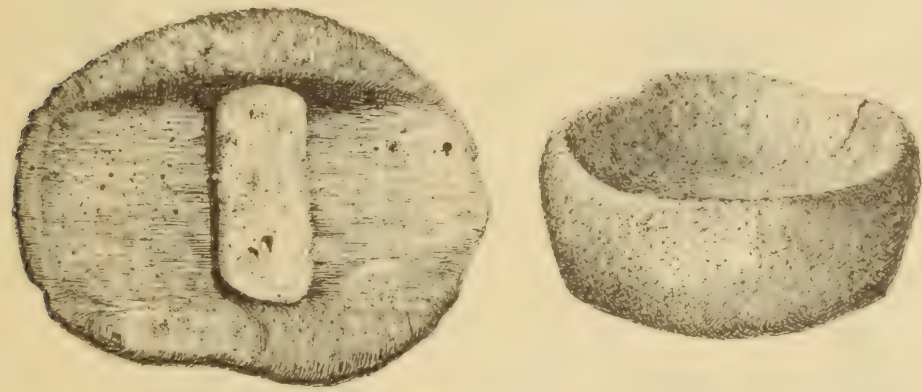

Prehistoric Stone Metate and Bowl.

floor. The upper stone is usually a rectangular prism which is grasped by both ends with the hands of a kneeling woman and rubbed up and down over the bottom stone.

The axes and pestles, made by pecking and grinding selected stones, are gracefully shaped and excellently made. The usual method of attaching a handle to the ax was to wrap stout withes around it in the one or more grooves provided. 
The flaked objects of jasper and flint show excellent workmanship and many of them are very pleasing in outline. There are many arrow-heads and drill points and a few large pieces which were evidently used on spears. Some of the arrows are of reeds with foreshafts while others have simple shafts. The drills are also simple and arrow-like. The fire-making appa-
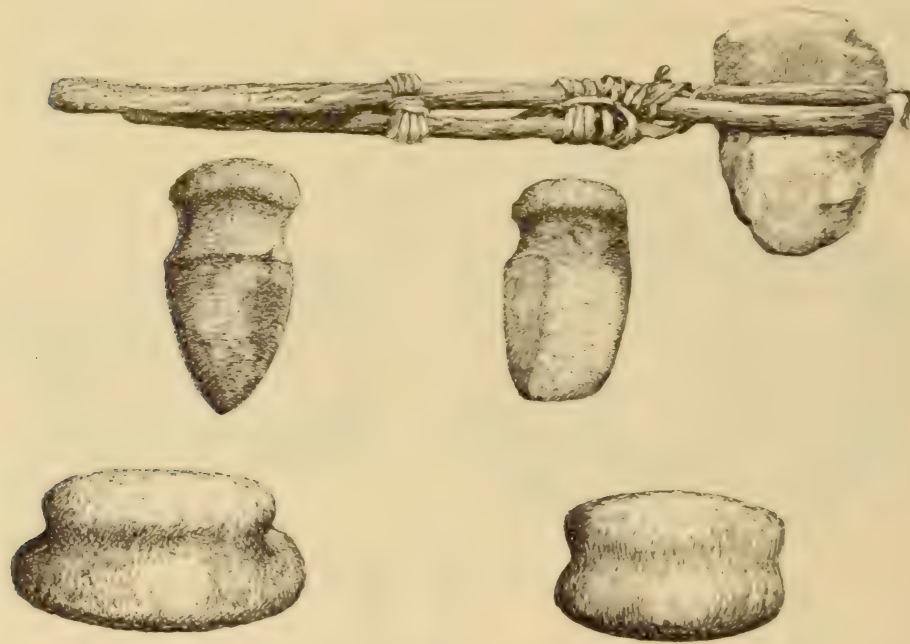

Stone Axes and Hammers.

ratus is represented by several large fragments of the hearth or bottom piece and drills some of which are compound like a fore-shafted arrow.

Turquoise. The wonderful deposits of turquoise obtained at Pueblo Bonito by the Hyde Expedition illustrate both the ability and the esthetic taste of these early inhabitants of the Southwest. There are 
thousands of dise-shaped perforated turquoise beads, rectangular pieces which seem to have been fastened to the clothing, splendidly carved birds and insects, and remarkable mosaics. As examples of the latter may be mentioned a cylinder the core of which had disintegrated greatly but with the mosaic covering still in position, a bone scraper with an inlaid band, and a frog of jet with an inlaid turquoise necklace and eyes.
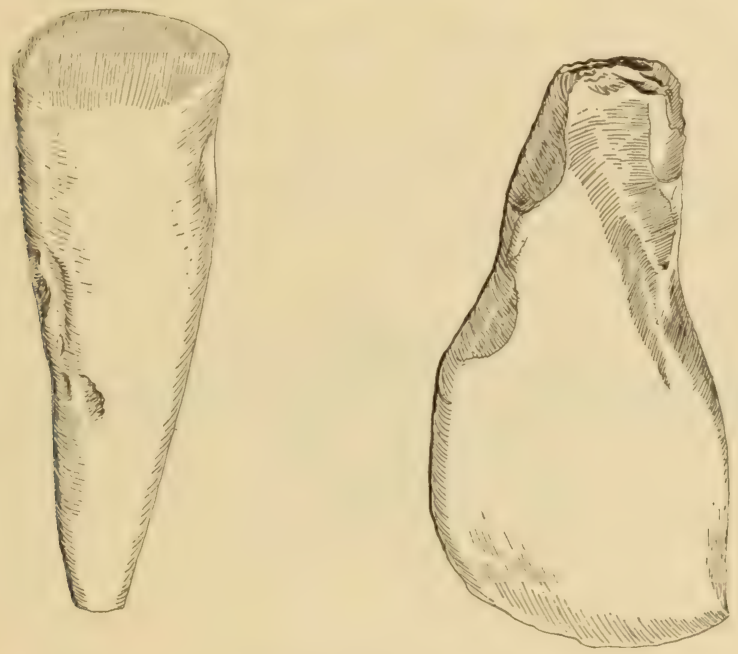

Polished Stone Chisels.

At Pueblo Bonito were also found several flageolets, some of them decorated with painted designs, and one or two with carved figures of birds. From Grand Gulch there is a rattle of small hoofs of deer or antelope and dice together with a cup from which they may have been thrown.

There is no reasnn to suppose that the prehistoric peoples of the Southrest knew how to secure and make 
use of the copper which is abundant in that region. 1 few pieces of eopper in the form of bells and ornaments were found at Pueblo Bonito but it is more than likely they were brought from Mexico in trade. Some remarkable pieces of pottery with a textile backing and examples of cloisomé work are believed to have reached Pueblo Bonito in the same manner.

\section{Disposal of Dead.}

The dead were variously disposed of. In the northwest along Grand Gulch and Cottonwood Creek they were buried in caves and under the floors of houses.
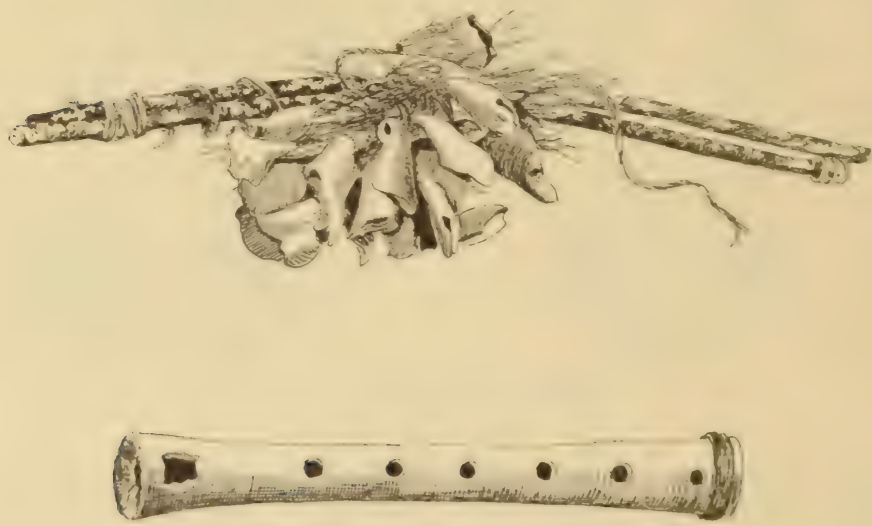

Prehistoric Rattle and Flageolet.

In the Mesa Verde region eremation seems to have been generally practised. In the Pajarito Plateau, the bodies of children were sometimes placed in a house 
wall and enclosed with masonry but adults were buried in emeteries. Burial under the floors was practised in (ialisteo Basin and on the upper Gila but lower on that stream cremation and urn burial of the ashes as well as house burial was the custom followed.

\section{RELIGION.}

We know little of the religious practices in prehistoric times. There are many objects which may with reason be supposed to have been ceremonial in their use. In the Rio Grande region are found large stone images that have long been supposed to be idols. Mr. N. C. Nelson, while excavating Pueblo Largo ruin in Galisteo Valley, found a stone image before which on a raised adobe platform were several pottery vessels and queer-shaped stones. These objects and their arrangement certainly present an early type of the altar still in use among the Pueblo Indians. 
Chapter II.

\section{MODERN PUEBLOS.}

\section{Exploration.}

In the first half of the sixteenth century the successors of Cortes were extending the rule of Spain beyond the Valley of Mexico. Antonio de Mendoza was the viceroy of Mexico, and Nuño de Guzman had explored the Gulf of California and organized its eastern shore into the province of New Galicia. Narraez with a considerable company had sailed from Cuba with the purpose of taking possession of the region about the mouth of the Rio Grande. The party was landed much too far east but painfully made their way westward, finally building small ressels in which they attempted in vain to sail to their destination.

Cabeza de Vaca. Eight years later, in 1536, Cabeza de Vaca, the treasurer of this ill-fated expedition, accompanied by two spaniards and a Yegro named Estevan, arrived in New Galicia on foot having crossed Texas and Northern Mexico. They had heard of great "cows" on which the natives of the vast plains lived and also of seven wonderful cities of great wealth. 
Now, the ancient Mexicans had a myth which told of their origin in the north where there were seven eares or canyons from which they believed they had migrated. Furthermore, it was an adventurous age and men were looking for new lands where there was gold ready mined, and men to kill or to convert, as occasion demanded.

Marcos de Niza. To investigate this report of seven cities to the north, Marcos de Niza was sent with a small escort and the negro, Estevan, as a guide. As they went toward the north they continually heard of the great and rich cities; but great and rich and cities meant one thing to Europeans acquainted with Mexico and Peru and another thing to the ignorant natives.

When they reached Vacapa, in central Sonora, Estevan was told to go in advance and discover the best route. He was ordered to send back word of what he might find and not to proceed more than fifty or sixty leagues. Estevan sent back messengers but hurried on himself and after some days of delay the friar followed. A month later when he had reached the mountainous country near the headwaters of the Salt River one of the men who had been with the gro met him and told him that they had reached the sought seven cities but that the natives had killed Estevan. Friar Marcos went on until he could see buildings in the distance and was then forced to return by his unwilling followers.

Coronado. The report which he brought back was sufficiently glowing to bring about an expedition the next year by Francisco Vazquez Coronado who had 
been the governor of New Galicia. Hernando de Mrarado was his chief lieutenant. The advance guard arrived at Cibola, supposed with good reasons to be the former villages of the Zuni, on July 7, 1540. Ifter some fighting during which Coronado was wounded the Indians took refuge on Thunder Mountain, leaving their villages to the spaniards. Hearing a report of seven other cities to the northwest, Don Pedro de Tovar was sent to investigate. He risited the Hopi villages known to the Spaniards as Tusayan and returned, hringing an account of the villages and a report of a great river with an uncrossable canyon to the west.

Alvarado, the second in command, was sent with a few men to explore toward the east. He passed the village of Icoma, perched on its high mesa, and arrived at the Rio (irande probably near Bernalillo where there were villages similar to those of Cibola. Coronado joined him here with the main army and passed the winter in one of the villages. The natives, at first friendly, were offended by the constant demands for food and clothing and by the ill-treatment of their women and drove off the horses and mules of the Spaniark. The village involved was attacked and some of the men surrendered. The officer in charge prepared two hundred stakes for these prisoners but when the Indians saw they were to be roasted alive they seized the stakes and renewed the fight with the result that they all died more agreeable deaths. During the winter, the Rio Grande was explored to the north and south and the various pueblos described A captive 
from the Plains Indians, called by the Spaniards the Turk, told of a still more wonderful country, Quivira. In the spring a division of the army started to visit this country with Turk as a guide. They soon came to open country where there were rast herds of buffalo and Indians following them with skin tents and dogs that transported their property. After weeks of travel Turk was discredited and another Indian led them to some unimportant villages of agricultural Indians. The distances and directions would have brought them to the neighborhood of eastern Kansas. The Indians may have been Pawnee or Omaha.

After a stay of twenty-five days they returned to the Rio Grande where they spent the winter. Coronado fell from his horse and was seriously hurt. A council decided upon an immediate return to Mexico and all went gladly except two monks who chose to remain behind and preach but who perished at the hands of the natives. The expectations of those who had organized the expedition had been great. They had been looking for another Mexico or Peru with great cities and great wealth. Nothing seemed to have resulted from the expedition worth the labor and expense involved.

\section{The Conquest.}

It was forty years later, in 1580, that Francisco Sanchez Chamuscado accompanied three Franciscan missionaries up the Rio Grande to New Mexico and left 
them to begin the christianizing of the Indians, but during the following winter all three were killed. When their fate was known in Mexico, Antonio de Lspejo, with fourteen Spaniards visited the principal pueblos. The interest created by his report resulted in allowing Juan de Oñate to colonize the country. He came in 1598 with 130 white men and many Indians, visited the important pueblos, received their submission, and established a capital and built the church San Gabriel at Chamita, where the Chama flows into the Rio Grande. Oñate continued as governor until 1608. By 1630 most of the pueblos were provided with churches and missionaries.

\section{The Rebellion.}

The natives who were made vassals of the King of Spain, were probably forced to work the mines which had been discovered. The priests were eager to establish their religion and forced it upon the Indians, at the same time repressing the native beliefs and practices. These two causes produced a feeling of resentment which finally resulted in rebellion in 1680. The heads of the pueblos communicated with each other and appointed a day on which all the white people should be killed. One of the inhabitants of San Juan was kindly disposed toward the rulers and priests and gave them warning. But this only resulted in an immediate attack in which the priests in all the nearby villages 
were killed. Word was sent to the other villages of the miscarriage of the plot and the priests and Spaniards living in them were killed. Governor Otermin, after several days of unsuccessful fighting about Santa Fé, which had become the capital, fled with many of the Spanish inhabitants to El Paso. He returned the next year, succeeded in capturing Isleta, but failed to reestablish his rule.

Diego de Vargas, having been appointed governor, conducted a vigorous war from 1692 until 1696 during which he tried in vain to take the Black Mesa near Española upon which the inhabitants of San Ildefonso had established themselves, but succeeded in capturing Old Cochiti in a night attack. After the warriors, most of whom had escaped, by a counter attack had released half of the 340 women and children held as prisoners, Vargas burned the village and took the stored corn to Santa Fé. In the end peace was established but the Indians were not again forced to work the mines and the priests were more tolerant toward the native religious practices and less insistent upon anything but a nominal acceptance of Christianity.

\section{Distribution IN 1540.}

If we assume that all the inhabited pueblos, with one exception mentioned below, were seen by members of Coronado's party, it appears that there had already been a considerable shrinkage in the pueblo area. 
They did not hear of villages anywhere on the San Juan or Gila Rivers or their tributaries. With the Coronado expedition was a man interested in ethnology, Pedro de Castaneda, who has not only left a most readable narrative of the journey itself, but interesting observations concerning the number and location of villages and the manner of life of the natives. He listed the rillages and described them as located in the following provinces:-

Cibola. The first discovered, had seven villages, two of which have been identified; Hawikuh near Ojo Caliente, the first one seen, and Matsaki, the largest of the ruins at the northwest base of Thunder Mountain. One after another of these villages was deserted until in 1680 there were only three inhabited. When the rebellion was over in 1692 , the people all came together in the village of Halona which has since been the only pueblo and is known as Zuñi.

Tusayan. The province of Tusayan also had seren villages situated near the sites of the present Hopi pueblos. One of the most important of these, Awatobi. was attacked by the other Hopi people in 1700 because it received a missionary after the rebellion, and was abandoned. At about the same time Hano near Walpi, on the first mesa, was settled by Indians who came from pucblos on the Rio Grande. Castaneda estimated the population of the two provinces of Cibola and Tusayan at between three and four thousand. Acoma. The high mesa with Acoma on its top, reached by difficult trails, is ummistakably described. 
The cisterns on the mesa which hold the rain and melted snow are mentioned. The population is given as two hundred men.

Tiguex. The province of Tiguex, on the Rin Grande near Bernalillo, had twelve villages scattered along the valley on either side of the river. None of these villages is now inhabited. Below along the river was the province of Tutahaco with eight villages probably in the neighborhood of Isleta which may occupy the site of one of them. Still further down the Rio Grande were three villages which may have been situated as far south as San Marcial where there are ruins.

Salinas. East of the river were at least three villages not mentioned by any of Coronado's followers but included later in the district of Salinas, named from the salt lakes in the neighborhood. These villages of Abo, Quara, and Tabira, generally known as Gran Quivira, were hard pressed by the Apache and appear to have been deserted before 1680. In that year, when Governor Otermin passed down the Rio Grande the inhabitants of the villages on the lower Rio Grande, Socorro, Sevilleta, and Alamillo, collectively known as the Piro, now few in number from the raids of the Apache, joined him and were established near El Paso where a few of their descendants are still living at Isleta del Sur.

Quirix. Just north of Tiguex was the province of Quirix with seven villages probably those now represented by Santo Domingo, San Felipe, Santa Ana, Sia, and Cochiti, the location of many of which was changed during the rebellion. 
Tamos. To the east of these, was Ximena, with three villages in Cialisteo Valley, deserted at the time of the rebellion. San Cristobal and Galisteo, the largest of these, were excavated for the American Museum during the summer of 1912 by Mr. N. C. Nelson. In the "snowy mountains", by which probably the Sandia Mountains were meant, there were seven villages not referred to by name now completely in ruins and hard to identify.

Cicuye. On the Pecos River was the one large pueblo known to the men of Coronado by the name Cicuye. It was estimated at that time to contain 500 fighting men. The population of Pecos slowly decreased, room after room of the great pueblo being abandoned, until in 1838 the handful of survivors moved to Jemez.

Jemez. This was originally a province, given the name Hemes by Castañeda, which in his time consisted of seven villages with three additional ones at Aguas Calientes, Jemez Hot Springs. The population was concentrated during the seventeenth century until only two of these villages were occupied. After the rebellion during which Jemez suffered particularly, only one village was maintained.

Teua. Northward was Yuqueyunque by which probably San Juan was meant situated east of the Rio Grande at the mouth of the Chama and six villages in the mountains which probably included the pueblos north of Santa Fé. Finally, several leagues to the north were the two pueblos of Picuris and Taos, the latter called Braba, both located nearly as they stand to-day. 
Besides these inhabited villages, others are mentioned as having been recently destroyed by a Plains tribe, the Teya, possibly the Comanche.

('astañeda summarizes the Rio Grande region with a statement that these sixty-six villages were scattered over a distance of 130 leagues having the province of Tiguex near the middle with a combined population of 20,000 men.

It appears that the area which ruins show once to have been inhabited by sedentary peoples had been reduced nearly half at the time the Spanish first entered the country, and the number of inhabited villages today is much smaller than when Coronado visited them in 1540. The Pueblo of Pecos, those of the Galisteo Valley, and of the Salinas district, and all those on the Rio Grande.south of Isleta are in ruins.

Nor are more than one or two of the pueblos situated exactly as they were in 1540. Immediately after the rebellion, the pueblos in less easily defended situations were deserted and rebuilt in more secure locations. The inhabitants of San Ildefonso took refuge on the top of Black Mesa; those of Cochiti left their village on the slope of the mesa and rebuilt it on the top, where they were joined by refugees from other pueblos. Nearly all the Hopi villages were also moved at that time to mesa tops. The inhabitants of Zuñi went to the top of Thunder Mountain. Although some of the pueblos were captured by the Spanish and certain abandoned pueblos were burned during the re-conquest, most of the changes in location seem to have been made voluntarily in anticipation of Spanish vengeance. 


\section{Present Distribution.}

Rio Grande. The villages now occupied are usually separated into two groups, the Rio Grande and the Hopi Pueblos, with Zuni standing by itself. The Rio Cirande Pueblos are again divided into the Tanoan and lieresan, chiefly because the languages of the two are totally different, but in part because there are aloo minor differences in culture. The Tanoan group consists of Taos, Picuris, San Juan, Santa Clara, San Ildefonso, Tesuque, Pojoaque, Nambe, Jemez, Sandia. and Isleta. Those which use the Keresan language are san Felipe, Cochiti, santo Domingo, santa Ina, sia, Laguna, and Acoma.

Hopi. The Hopi villages are geographically separated into the first or eastern mesa on which stand Walpi, Sichumovi, and Hano; the second or middle mesa with shipaulovi, Mishongnovi, shumopori; and on the third mesa, Oraibi, the largest of all.

Quite recently the conservative party of Oraibi, who wish to live as they formerly did, has withdrawn and built a new village a few miles away on the same mesa. Forty miles westward is the summer village of Moenkapi situated where conditions are favorable to agriculture. The language of the Hopi proper is Shoshonean connected with Ute and Comanche. One of the villages, however, Hano, still has its Tewan dialect maintained since the migration from the Rio Grande early in the eighteenth century. 


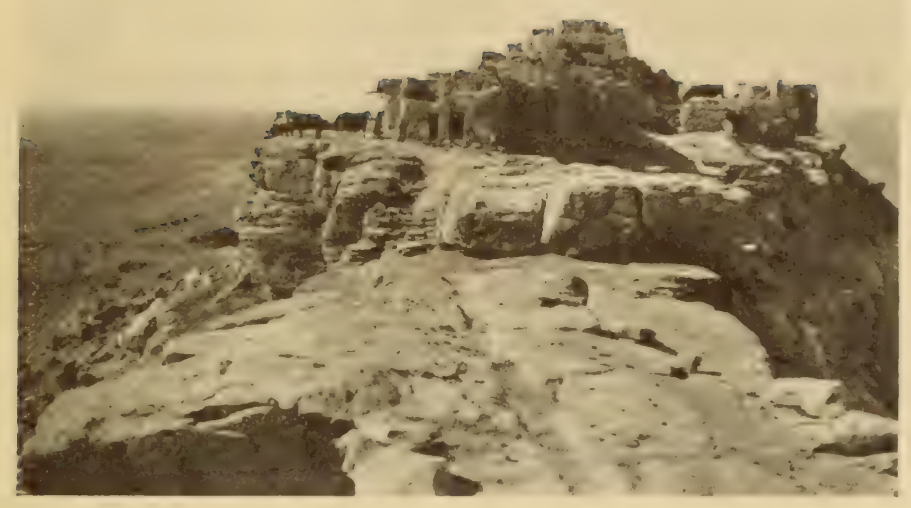

Pueblo of Walpi.

(Photo. by Howard McCormick.)

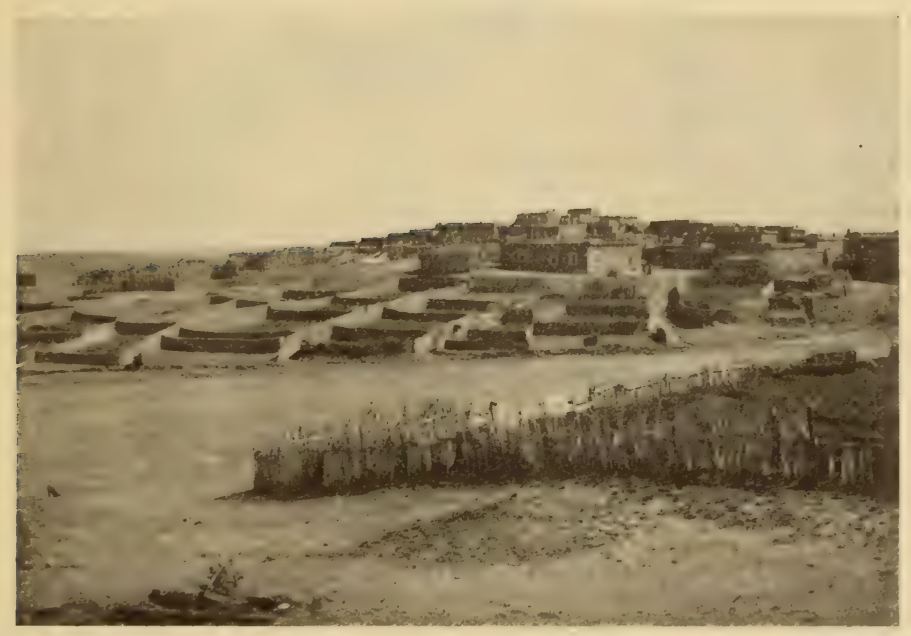

Pueblo of Zuñi.

(Copyrighted by Fred Harvey.) 
Zuni. The Pueblo of Zuñi, which by itself is the deseendant of the seven cities of Cibola, has three outlying farming villages, Pescado, Nutria, and Ojo Caliente which are fast becoming permanent settlements. The Zuñi language is believed to be entirely independent of all others.

\section{Habitations.}

The houses of the sedentary peoples of the Southwest retain the two chief characteristics of those of the ancient peoples which are really the most striking

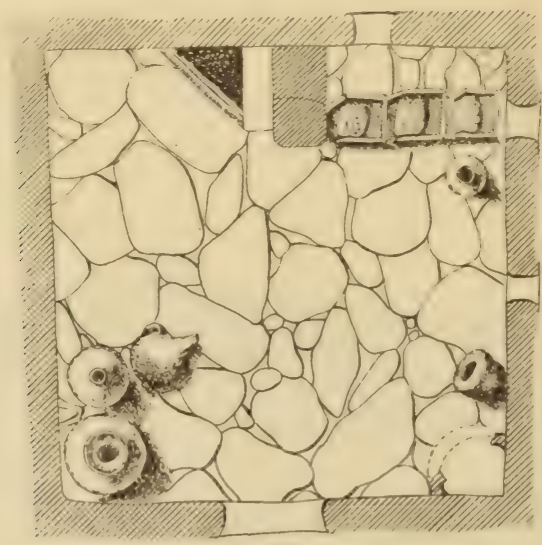

Floor Plan of Hopi Living Room. (After Cosmos Mindeleff.)

features of Southwestern culture: they are communal, honeycomb-like, and almost without exception terraced. 
Arrangement of Buildings. The modern villages present three types of arrangement. A large square or rectangular building, terraced back from all four sides results in a pyramid which is easily defended. The common prehistoric arrangement around an enclosed court from which the upper stories recede is still found. The third type has the houses in long parallel rows terraced back from the streets.

In the Rio Grande region Taos has two large houses of the pyramidal type on either side of a beautiful stream. One of these is five and the other four stories high. San Ildefonso, Jemez, Santa Clara, and San Felipe have one or more enclosed courts. Acoma is an excellent example of the third sort. It has three rows of three story houses, terraced back from the streets. Santo Domingo and San Juan have a similar arrangement.

Zuñi combines both the first and second types of arrangement. It is terraced back from the outside but also has several courts within, in one of which the old church is situated. It is intersected by a number of corered passageways or streets leading to the interior.

It is at Hopi that structures more like those of prehistoric and early Spanish times are found. One of the smaller pueblos, Shipaulovi, is built about a square court from which it is terraced back and upon which the lower terrace has its openings. Several of the other pueblos show signs of having been first built around a court and then added to as the village grew in numbers until there are now several courts. Mishongnovi has 
three completed ones and the beginning of another. Shumopovi has one well enclosed court and another partly enclosed but the houses are terraced so as to face the east. Walpi, which has grown until it has nearly covered all the available space, has the older portion of the building surrounding a court from which it was terraced back. Oraibi is arranged in long irregular rows.

Building Material. The pueblos of the Rio Grande region are largely built of adobe brick, the art of making which was pretty certainly learned from the natives of Mexico who came into the Southwest with Onate and later. Clay, first mixed with straw and water, is molded in rectangular forms and allowed to dry in the sun. These bricks are laid in regular courses with similar material for mortar. Such walls are durable only when they are protected from water by means of extended roofs, or by constant plastering.

Castañeda gives a description of the older method of preparing adobe. He says fires were made of small brush and sedge-grass upon which, when the sticks were falling to ashes, water and clay were thrown. The material was then molded into balls and laid like stone in courses with mortar of similar material. This masonry work he tells us was performed by the women but that the men did the carpenter work, preparing the timbers and putting them into place. The inner walls were plastered and sometimes painted but he does not tell us what material was used. At the present time burned gypsum is employed but this 
method has probably been adopted from the Mexicans who also make use of it.

Acoma is built of rubble and clay. A village in the same situation as the present one and probably the one described by several of Coronado's party, was partly burned in 1599 . The village was not destroyed during the rebellion a century later, and the walls now in use may be the same as those seen in 1540 , repaired and in part rebuilt from time to time.

While Zuñi is built mostly of adobe, the cornices frequently have several courses of flat stones.

The Hopi houses are built of stone poorly dressed and poorly laid as compared with the best prehistoric masonry. Mindeleff, who published a splendid account of Pueblo architecture, observed women building a detached house with the help of one man who lifted the timbers into place. While the men are said to build the walls sometimes, the women are always expected to do the plastering. The ceilings are made in the prehistoric fashion with ceiling beams, cross poles, brush, and clay spread over all and tramped down. The floors are sometimes paved with large flat stones. The walls inside are generally whitened with gypsum and sometimes ornamented by leaving unwhitened bands above and below. The fireplaces situated in one corner of the room are provided with hoods which receive the smoke and communicate with chimneys which are generally topped with a pot or two from which the bottom has been broken. In another corner of the room is generally found the three-sectioned milling 
box with three grinding stones. The rooms of the lower terrace are mostly used for storage.

There are a few T-shaped doorways like those found in prehistoric ruins still to be seen in the Hopi houses. During the Spanish period windows in the walls were more generally used. They were covered with thin sheets of selenite which was the substitute for glass in general use in the Southwest. Ordinary windows and hinged doors are now coming into common use.

\section{Shelters.}

For the shelter of the men who are tending the crops and as a camping place for the family when the fields are far from the village, temporary structures are built. The common type is made by setting four posts at the corners of a rectangle so that their forked tops are seren or eight feet above the ground. These posts support a platform of poles and brush which casts a shade and furnishes on its top a storage place away from dogs and stray animals. The Hopi often cut trees or brush and set them in curved or straight lines so as to break the wind and furnish the desired shade. The two forms are sometimes combined so that the space under the platform has a wall of brush on one side.

\section{KIVAS.}

The modern pueblos with a few exceptions are each provided with one or more kivas. In a general way, 
they resemble the prehistoric kivas, both in their structure and their location. Some of them are circular and nearly all, in part at least, are underground. They are as a rule, located in the plaza or some distance from the communal house.

Those of the Rio Grande region are freculently circu-

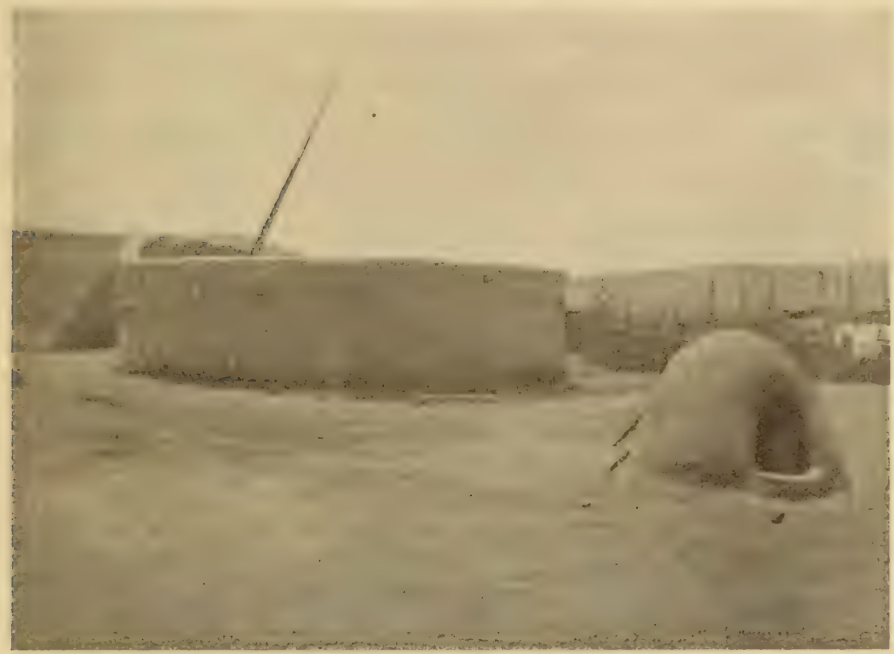

Kiva and Oven. San Ildefonso.

(Copyrighted by Fred Harvey.)

lar, the roofs of some of them being level with the ground while others are built up to a considerable height so that their forms are readily apparent from the outside. Details as to their structure are not arailable except that they are entered through hatchways by means of ladders which project to a considerable height. With the exception of the fireplace, the ladder, and the 
posts supporting the two main roof beams, they are said to be entirely without furnishings. The Keresan kivas of which there are always two to a village, known as the summer and winter kivas, are said in some instances to be permanently decorated with the pictures of the animals associated in mythology and ceremonies with the cardinal points. The kivas of San Juan and Santa Clara are rectangular and above ground and those of Jemez and Acoma are included in the regular house structure differing externally from ordinary rooms only in the projection of ladder tops.

The Hopi frequently place their kivas on the side of the mesa so that the wall of the kiva on one side is exposed to light and air while the roof is still kept level with the surface of the mesa. They are all rectangular, about twenty-five feet long and half as broad. The floor, which is generally pared with stone, is in two levels. The higher portion a foot above the other occupies about one third the entire floor space. This is reserved for spectators. In the lower part, there is a fireplace, a mere rectangular pit placed in the center directly under the hatchway; and at one end there is a small cavity covered by a plank in which is cut a hole furnished with a close fitting plug. These represent the lower world and the place of emergence through which the people and animals originally came to this world, and through it the deities are now supposed to come during the ceremonies. Along the sides of the room are placed slabs provided with holes to receive the posts of the looms which are usually set up and used 
in the kivas. A stone-capped bench is sometimes provided along one or more of the side walls for seats. It the further end of the lower level a similar bench about two feet high is used as a shelf on which images are

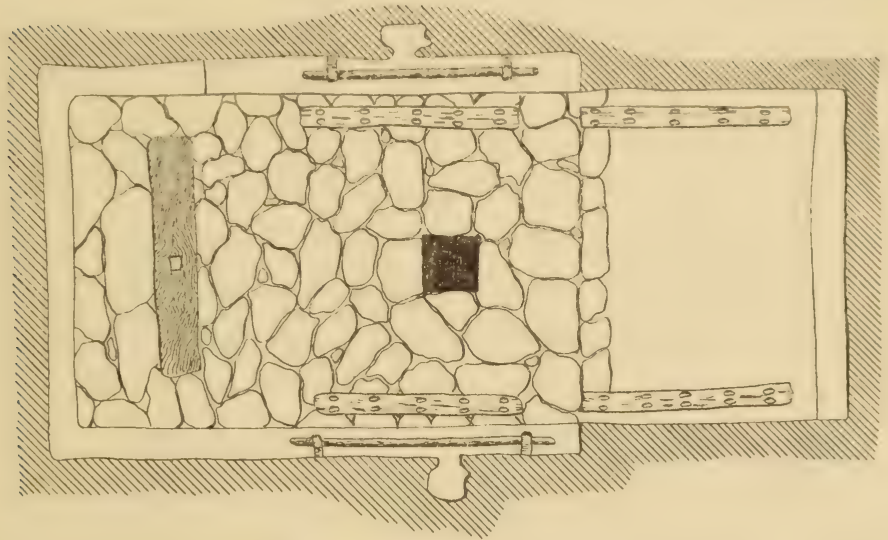

Floor Plan of Hopi Kiva.

(After Victor Mindeleff.)

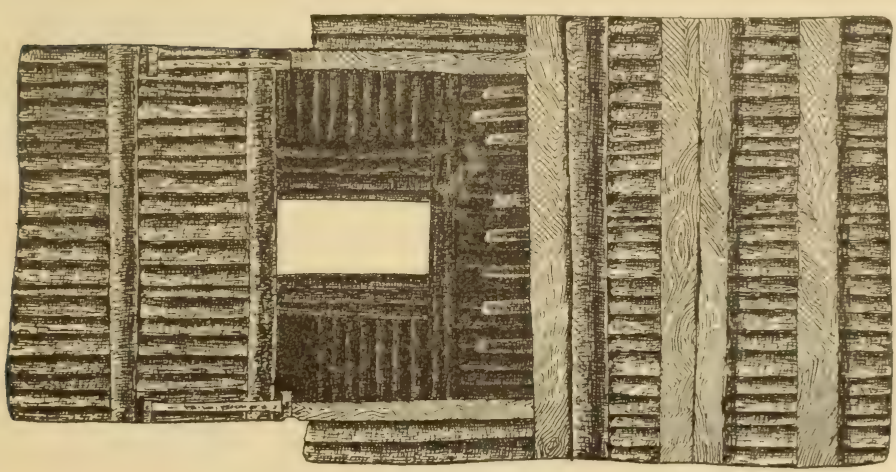

Roof of Hopi Kiva.

(After Victor Mindeleff.) 
placed and an opening in front holds cert ain masks when they are not in use.

The walls which are of stone are kept nicely plastered by the women. The roof is composed first of large logs placed crosswise resting on the top of the two side walls; next, by many smaller poles placed lengthwise which are in turn covered with brush and well packed clay. In the midalle a space five feet by seven is left for the hatchway. Masonry walls resting on the ceiling beams are carried up for a few feet on all four sides. Across the top of these walls are laid planks leaving an opening four and a half feet long and two feet wide. Through this hatchway a ladder projects ten or twelve feet.

The eeremonial rooms at Zuñi are all included within the large structure perhaps to conceal them from the spanish priests of past centuries. Their floors, however, are always somewhat below the level of the earth outside.

Castaneda and other early Spanish writers seem to have been amused by these kivas, estufas (stores) they called them. They are described as being situated in the yards of the buildings with their roofs level with the ground. There were in that day both square and round kivas. Those of Taos are mentioned in particular, one of which was said to have twelve pine posts of large size supporting the roof. The floors were paved with large smooth stones with a boxed-in fireplace in which small brush was burned for heat enabling the occupants to remain in them as in a bath.

The kivas to-day are used as clubrooms and loafing 
places as well as workshops, the weaving usually being done in them. They are generally spoken of as ceremonial chambers and it is quite true that ceremonies are held in them. The Hopi kivas, at least, are constructed with certain unmistakable adaptations to ceremonial uses. In this connection, certain remarks of Castañeda are of interest:-

"The young men live in the estufas... The houses belong to the women, the estufas to the men. If a man repudiates his woman he has to go to the estufa. It is forbidden for women to sleep in the estufas or to enter these for any purpose except to give their husbands or sons something to eat." (Winship, 520,521.)

These statements suggest a very likely explanation of the earlier uses of the kiva. It is very common in the Pacific Islands and elsewhere for the unmarried men to sleep in a large community dormitory. The Yurok and the Hupa men in northwestern California, whether married or single, slept in such a structure throughout the winter months.

FOOD.

The method of securing food is always the central fact in a people's existence around which social life, art, and religion are largely built. There are considerable regions in North America where agriculture was not practised. In the great plains the chief dependence was upon the buffalo, while on the North Pacific Coast the people lived largely on fish. The inhabitants of 
the Plateau area lived upon wild regetables, small game, and insects. The sedentary peoples of the Southwest placed their first reliance on the crops which their fields produced. These were in earlier times, corn, beans, and squash to which wheat and other small grains and regetables have been added. Hunting was by no means neglected for flesh was needed to

$A$
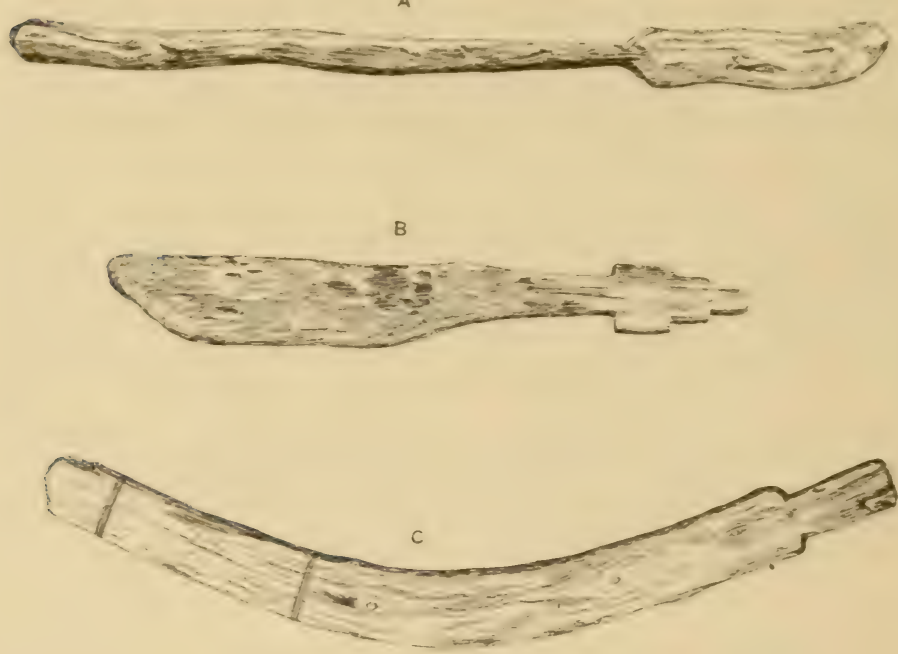

Hoes and Throwing Stick.

produce a balanced diet. The wild regetables in the neighborhood were gathered and preserved for future use.

Agriculture. The fields of the Rin Grande peoples are situated in the river bottoms and along the smaller streams near their villages. Irrigation is now practised and was being practised at many of the pueblos at 
least, when the Spanish first entered the area. There were however, no great difficulties involved and no large canals like the prehistoric ones of the lower Salt River were necessary. The fields of the Acoma are fourteen miles away at Acomita, apparently where they were when Espejo visited them in 1583. He mentions both the cornfields two leagues away, and the river from which he says they watered them.

The Hopi fields are situated near the mesas wherever there is sufficient moisture from some gulch or spring. Corn is planted ten or twelve inches deep with a planting stick which makes a suitable hole. The corn is not raised in rows, but in large clumps of eight or ten stalks, at considerable distances from each other. While the plants are young, they are protected from the wind and the drifting sand by windbreaks of brush or stone. Irrigation is not practised except that vegetables are sometimes watered by hand. Ditches, however, are provided to carry off the excessive waterfall during heary showers.

Because of the large population of Zuñi many of their fields are at a great distance; the people move in large numbers to the neighborhood of these fields where the farming villages of Nutria, Pescado, and Ojo Caliente are maintained. Mr. Frank H. Cushing has described the old Zuñi method of agriculture. A man without land chose a piece of ground where a gulch opened into a valley or on to the margin of the plain. Across this he made an earthen dam which retained the water and mud brought down during heavy rains. 
Since the gulch was ordinarily a dry one, the water did not stand for any length of time but enough of it sank into the ground to supply what moisture was needed for a crop of corn.

Quite contrary to the usual custom among the North American Indians, the men till the fields and do the greater part of the work connected with raising and harvesting the crops. This is probably because in the southwest agriculture is the chief means of securing food while in other regions it is of less importance than hunting and fishing to which the men principally devote themselves. The only primitive implements used in tilling the soil appear to have been the planting stick and a knife-like wooden paddle which served as a hoe or shovel. Castañeda tells us the ground was not broken before planting the seed. He, of course, greatly exaggerated the productiveness of the soil when he said that one crop was sufficient for seven years. He mentions large quantities of corn in Galisteo Valley stored in underground chambers. The Hopi Pueblos still maintain at least a full year's supply of corn to guard against crop failure.

After the corn is gathered it is thoroughly dried either by hanging it in long braids or by spreading it in the sun on the roofs of the buildings. It is stored in the back rooms of the lower stories where the braids are hung up and the loose ears piled in tiers. The pumpkins and squashes are cut in long strips which are twisted together and hung about the houses together with many strings of red peppers. 
The Hopi have many peach orchards but fruit was not cultivated when the Spanish first became acquainted with the Southwest. They did make use of pinon nuts which are frequently mentioned. That they used cherries, wild plums, the fruit of the yueca, and the pods and beans of the mesquite, is also probable although Castaneda says that pine nuts were the only fruits used by them.

Preparation of Food. The method of grinding corn has changed but little since it was first described by Castañeda.

"They keep the separate houses where they prepare the food for eating and where they grind the meal, very clean. This is a separate room or closet, where they have a trough with three stones fixed in stiff clay. Three women go in here, each one having a stone, with which one of them breaks the corn, the next grinds it, and the third grinds it again. They take off their shoes, do up their hair, shake their clothes, and cover their heads before they enter the door. A man sits at the door playing on a fife while they grind, moving the stones to the music and singing together. They grind a large quantity at one time, because they make all their bread of meal soaked in warm water, like wafers." (Winship, 522.)

The meal boxes are often in one corner of the living rooms of the modern pueblos and the women still sing at their work but without the accompanying flute. Before grinding, the corn is often parched or roasted. The wafers mentioned probably refer to piki, the paper-thin bread made of corn meal of various colors and rolled into bunches which keep indefinitely. This bread is cooked on thin slabs of stone or more recently on pieces of sheet iron. Tortillas, having the shape and thickness of pancakes, are also popular. The 
Hopi place pots of mu-h in holes in the ground which have been heated by a fire and cover them with ashes and hot coals until they are thoroughly cooked. At Zuñi and along the Rio Cirande, the Mexican domeshaped ovens are generally used.

Hunting. The eastern pueblos, those of Taos, Piruris, and Peros especially, used to make experditionsto the Plains, principally along the Canadian and Arkansas Rivers to hunt buffalo. Such trips could be made safely only by a large number of men and with the greatest precaution against surprise hy the Plaintribes. They were under the control of the war chief as were all communal hunts. The communal hunting of antelope, deer, and elk, because of their scarcity has not been practised in recent years, but such hunts for rabbits are still maintained. The men and boys surround a large tract of suitable land, drive the rabbits toward the center and then kill them with bows and arrows and with throwing sticks. These clubs resemble in form the Australian boomerang but do not have the particular character which make- that implement return to the thrower. Deer and antelope may have been hunted in a similar manner, but ('apt. Bourte in 1881 saw corrals of brush near Hopi into which antelope were driven. Still hunting by individuals was. of course, practised. Mr. Cushing tells in detail how fetishes were used in such hunts.

Fish for food were taken in the Rio Grande region where there seems to be no taboo against their use. One of the most interesting phases of South- 
western life was the relation existing between the sedentary and nomadic peoples. We are told by the Coronado writers and by Espejo that the nomadic peoples of the plains and of the mountains of the Southwest brought the meat and the hides of buffalo and deer to the pueblos and exchanged them for mantles of cotton and for corn. This exchange of products allowed one people to concentrate upon agriculture and the other upon hunting, yet each to have both corn and meat for food, and cotton cloth and dressed skins for clothing.

\section{Dress.}

The dress of the sedentary Indians of the Southwest changed but little from the time it was first described in the sixteenth century until the American occupation and railroads brought other styles and cheaper materials.

In the east, at Taos, Picuris, and Pecos, skins were almost, if not quite exclusively worn. The men were described as wearing small shirts with fringes, and robes of buffalo skin decorated with painted designs. The women's clothing of these particular pueblos is not mentioned at an carly date but at the present time the long buckskin dresses of the Plains type are occasionally seen at Taos. The dress of the men at that pueblo is hardly to be distinguished from that worn by the Indians of the Plains; long leggings of fringed buckskin, or of red or blue flannel are still generally worn. The 
breech cloth of similar flannel is wide and long, hanging nearly to the ground. Buckskin shirts, which are less common, are of the usual Plains type.

For all the other pueblos, the sixteenth century dress of the men was an apron or kilt. These were of cotton and are described as resembling napkins of that period

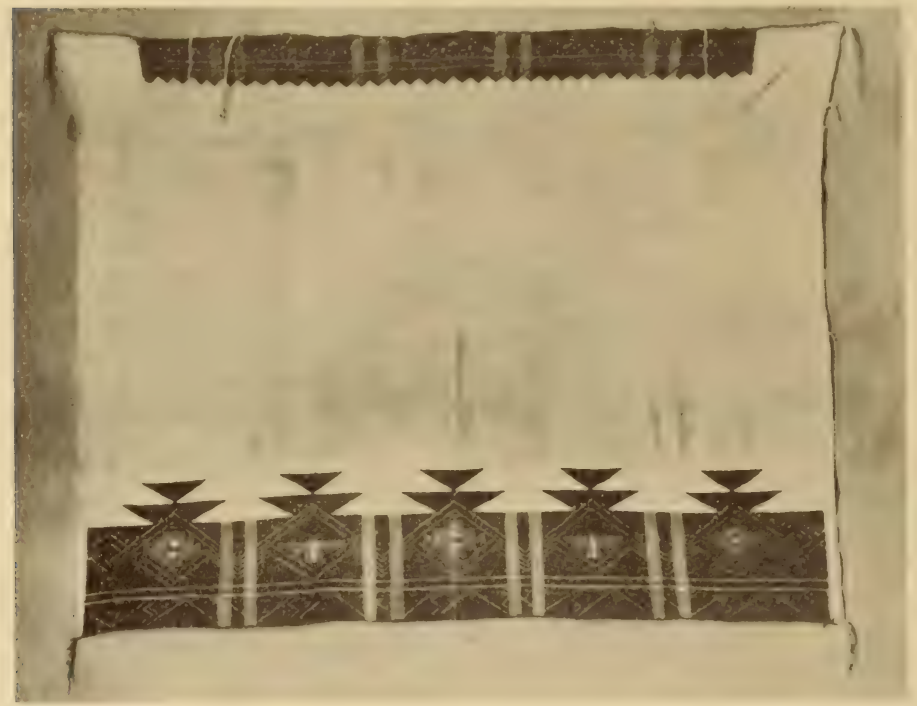

Hopi Robe.

but having tassels at each corner. Kilts which are probably similar to these are still worn as ceremonial garments. At the present time a short, narrow breech cloth of white cotton, falling only a few inches from the belt before and behind, is the only essential garment for men at hard work or engaged in ceremonies. 
A robe of some sort is a necessary adjunct at all ordinary times regardless of the season. In Coronado's time these robes were of cotton, woven rabbitskins, dressed skins, often buffalo, and turkey feathers fastened to a net. Large flocks of turkeys used to be kept to supply feathers for these garments and for ceremonies. Robes of feathers have not been in use for many years but the other materials have been displaced only recently, first by woolen blankets bought of the Navajo, and later by the gayly colored factory products introduced by the American traders.

White cotton trousers coming some inches below the knee, but split on the outer side, and a cotton shirt falling over the trousers, girded with a cotton belt, were additions adopted from the Spanish and still worn by the older men.

The woman's dress as first described, consisted of a single garment, of yucca fiber at Zuñi, but of cotton elsewhere, which reached from the shoulders to the knees. It was fastened over the right shoulder but open at the left where two tassels hung. A belt was worn at the waist. Later, the material changed to wool, dyed blue or black and woven diagonally, but the form remained the same until a few years ago. It is still worn on ceremonial occasions and generally by the older Hopi women. Specimens of the old cotton dresses embroidered in colors with woolen yarn are still in existence. The Museum has a few excellent specimens of these which came from Acoma. An under garment of white cotton was adopted by the 
women of the Rio Grande region and is worn so that the lace border shows below the outer skirt.

The hair of the Zuñi women was described by Castaneda as done up above the ears in large whorls. The pratetice is still maintained by the Hopi maidens who are thus distinguished from the matrons who wear

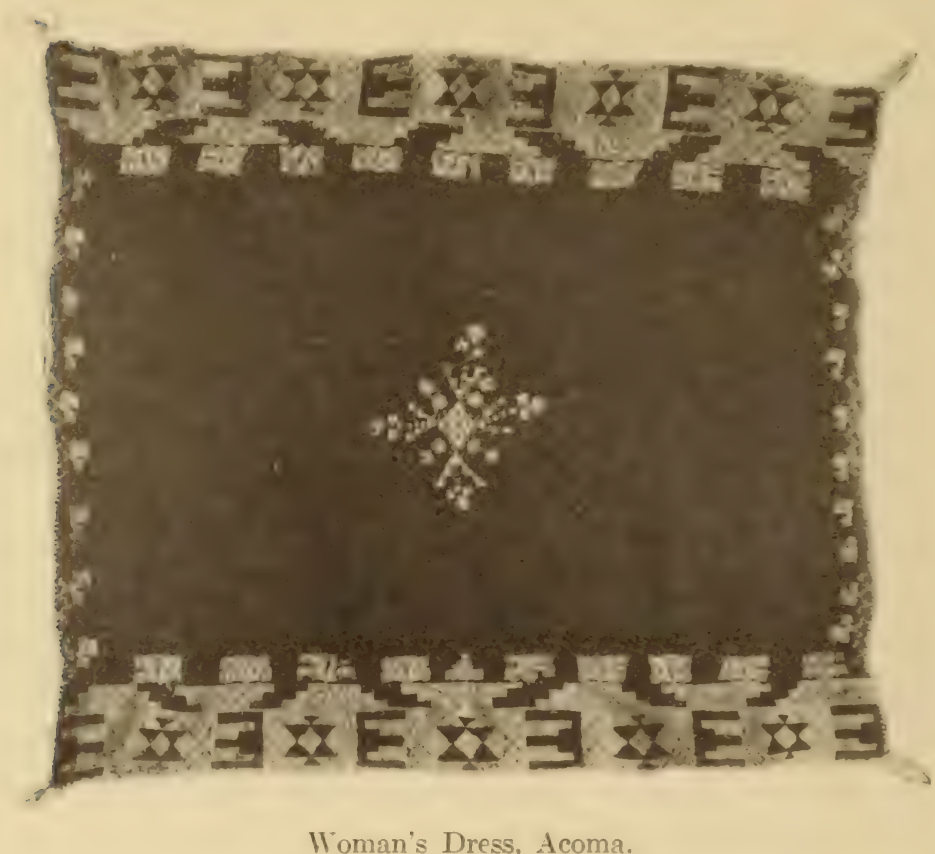

their hair in two braids. Both men and women. except at Taos and Picuris, wear the front hair banged above the eyes and the side locks cut square, even with the mouth. On the Rio Grande, the men frequently tie their hair with yarn, in two folded clubs. At Taos 
the braids are wrapped with fur or flannel as is the eustom of the Plains Indians. The hair of both men and women is frequently washed with yuea root suds.

The moceasins of both men and women have hard soles, a fact emphasized by Castañeda as new and important, who adds that buskins reaching the knee were worn in winter. The women's moccasins are now

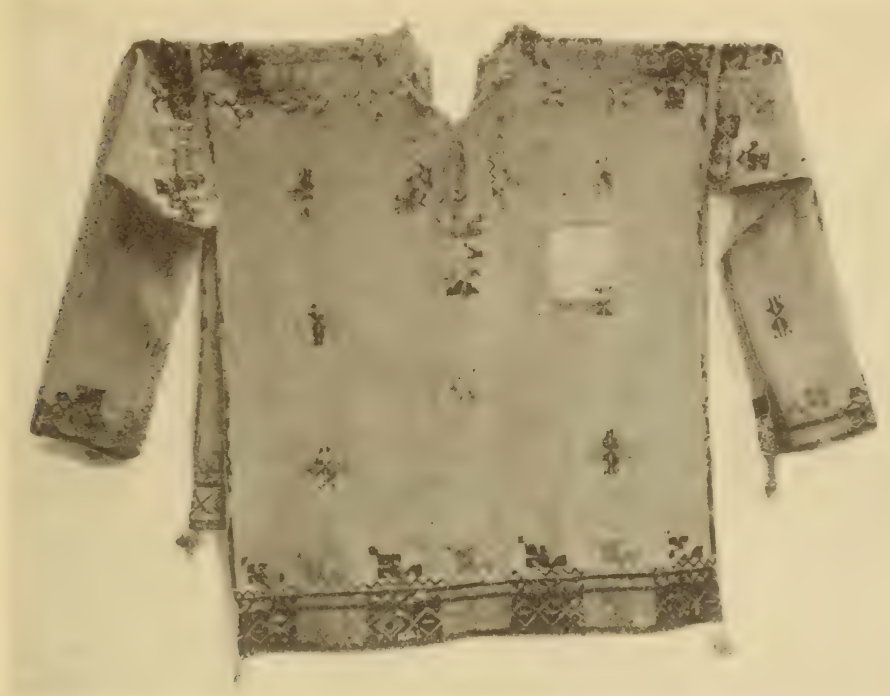

Embroidered Shirt. Acoma.

provided with a long strip of buckskin which is wrapped many times around the lower leg. They are whitened with white earth. Under these leggings are worn footless stockings knit of black woolen yarn.

The ornaments of turquoise and sea shells worn in 
the ears and about the neck in earlier times were later supplemented by silver beads of native manufacture. The earrings of inlaid turquoise mosaic mentioned by the early Spanish are still worn by Hopi women.

The native cotton originally employed in clothing was largely cultivated at Hopi and to some extent on the Rio Grande below Cochiti in Coronado's time. Very little cotton is now grown. Wool was introduced with sheep at an early date, for we know they had large flocks at the time of the rebellion.

Industrial Arts.

Pottery. The household vessels of the modern sedentary peoples are mostly of clay. These are used for transporting and storing water and for the storage, cooking, and serving of food. For making them the clay found commonly in the Southwest is tempered with pottery fragments finely ground. When sufficiently softened with water, a lump of this is hollowed to form the nucleus of the bottom of the vessel. To this round after round of clay, rolled inte a slender cylinder, is applied and made to adhere by pressure. The interior and exterior surfaces are molded with the hand and smoothed with a piece of gourd shell. Water must constantly be applied to keep the clay in workable condition. When the vessel has been built in this manner to the desired size and shape, it is allowed to dry thoroughly in the sun. It is prepared for orna- 
mentation by polishing it with a stone and giving it a thin slip of fine clay after which it is repolished. The designs are then painted on by means of a brush of yucca fiber or a sharpened stick.

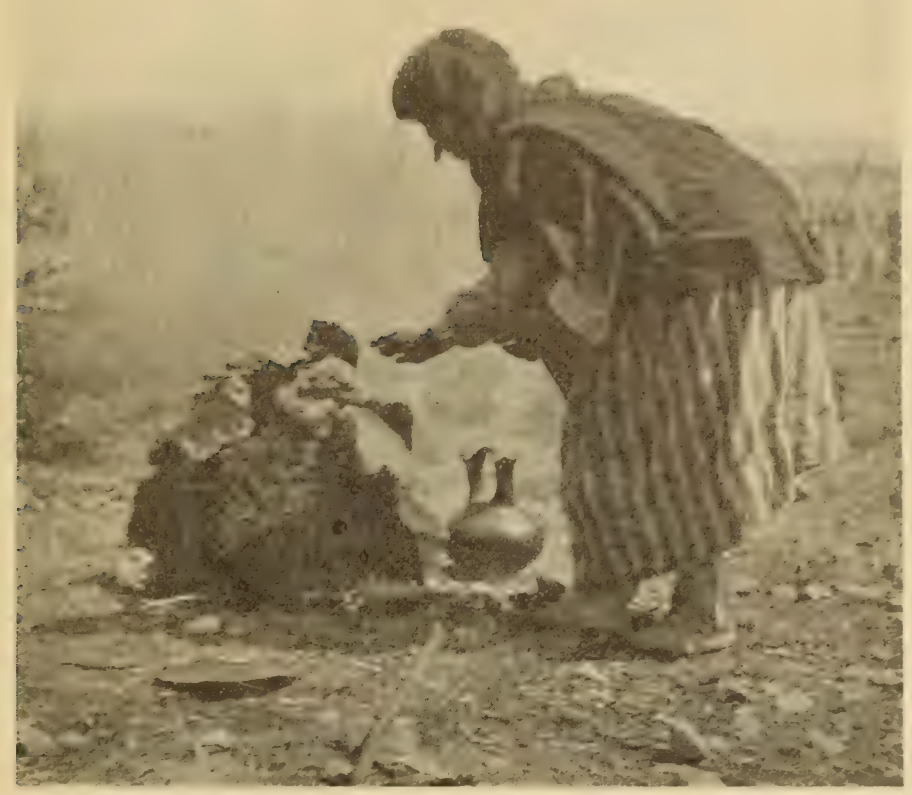

Santa Clara Woman firing Pottery

(Copyrighted by Fred Harvey.)

The vessels are fired by placing several of them bottom side up on small stones and covering them with dry sheep manure which is used for fuel. This maintains a uniform and continuous heat until they are 
properly burned. If the smoke is confined by adding a supply of fresh fine material at the right time, the carbon of the smoke unites with the paint and produces a black ware characteristic of Santa Clara.

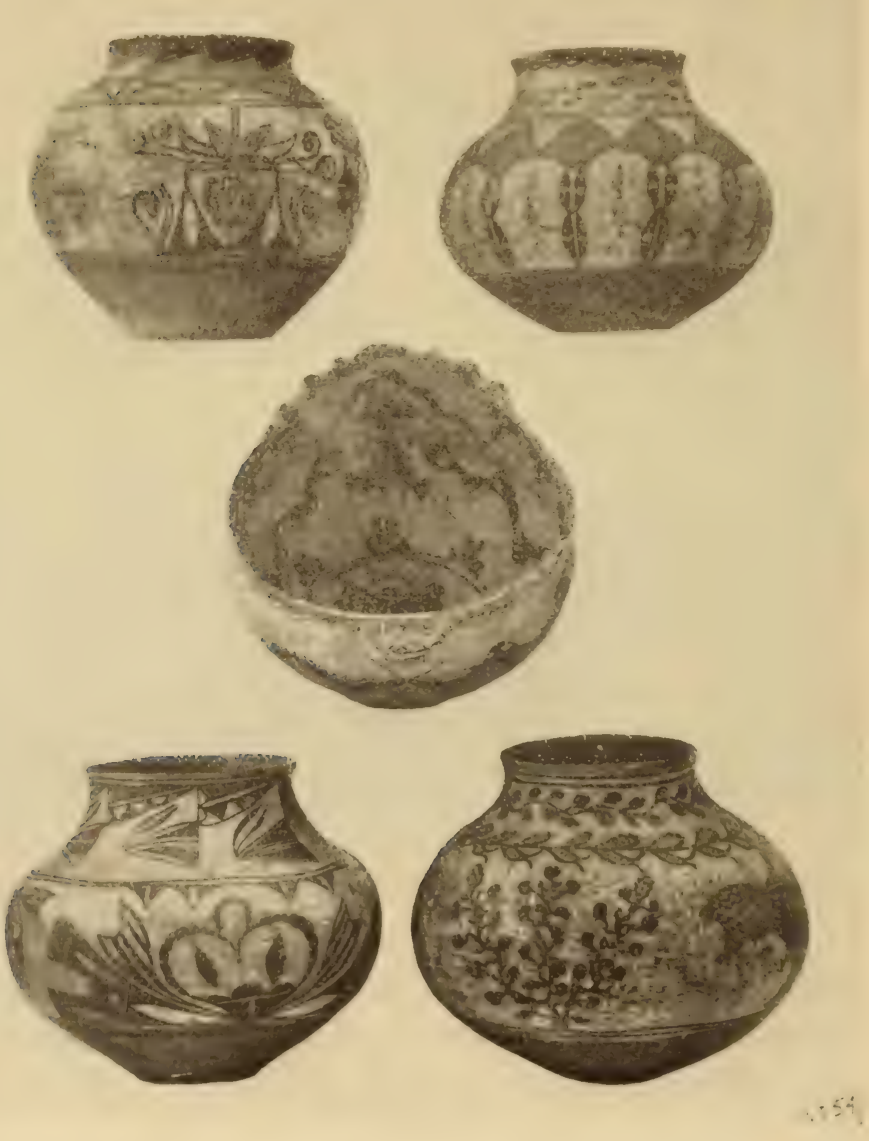

San Ildefonso Pottery. 
This uniformly black ware gains in graceful lines what it lacks in gay colors. At San Juan a peculiar form is a pot, red above, and undecorated below. This red applied as a slip is also sometimes used as a background on which designs in other colors are painted. The more common background, however, is the cream color of the uncolored clay to which rarely a little red is added, producing pink. The designs are painted on in black, obtained from the juice of the wako weed, and in red and yellow derived from iron ore.

These designs are partly geometrical and purely decorative; partly representations of mountains, clouds. and rainbows, so highly conventionalized as often to appear geometrical; and partly realistic representations: of flowers and animals. Among the latter are most frequently found those which are of economic value or of ceremonial importance, such as the sunflower, cotton plant, the parrot, and the turkey. The larger animals like the antelope, frequently seen on Zuñi pot:-, have the positions of the internal organs indicated.

The background of the Hopi pottery has a chararteristic yellow tone. The upper portion of the bowls is often drawn in sharply making the top nearly flat. The designs, which are of the same general sort found in Rio Grande pottery, are executed in a peculiar style. In recent years both the shapes and the decorations have been considerably modified to meet commercial demands. This is especially to be noted in the more frequent use of symbols which belong more properly to ceremonial objects. 
Basletry. At Zuñi and Hopi, baskets quite similar to those found in the prehistoric ruins are still plaited of yucea leaves attached to a heary wooden rim. Rude (arrying baskets and cradles with a basketry band for the protection of the head are in general use. At Hopi, decorated, nearly flat trays are also made, but those of Oraibi are strikingly different from those of the middle mesa where the eoiling method is employed and very thick foundation coils are used. The Oraibi make use of twining with the foundation material

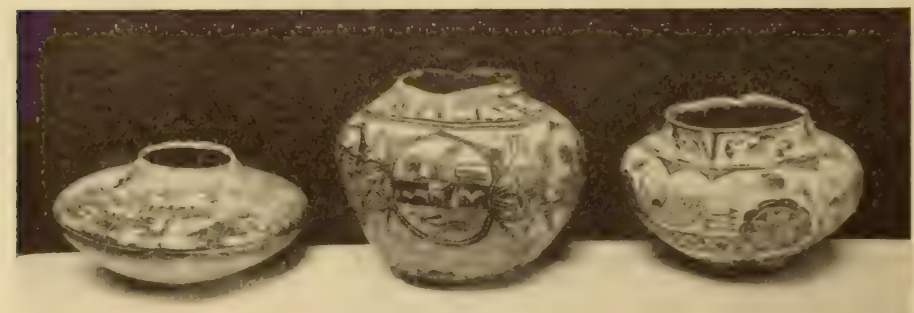

Hopi Pottery.

radiating from the center. These flat baskets are used in ceremonies, certain features of which the decorations often symbolize.

Weaving. Recently weaving which flourished in earlier centuries has declined; at first because of the large output of the neighboring Navajo and later from the introduction of European goods. The garments needed in the ceremonies are still made at Hopi and every bridegroom must weave or have woven a trous- 
seau for his bride. The Hopi, and probably others of the Pueblos, beside the diagonally woven women's dresses with raised diamond patterns, made large robes. Those characteristic of the Hopi were decorated by narrow horizontal stripes, chiefly of blue. The imple-

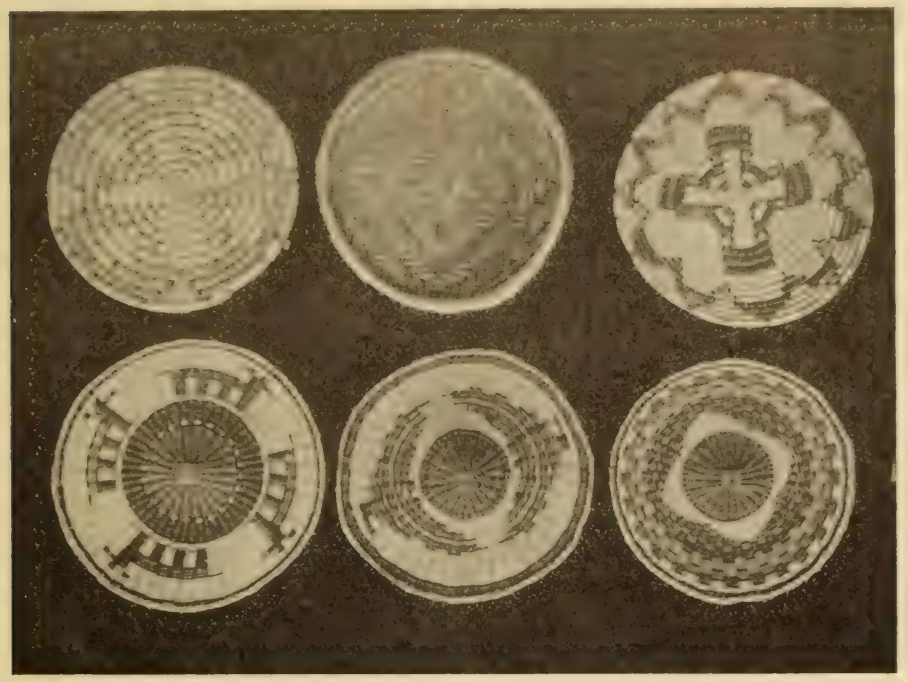

Hopi Baskets.

ments and processes are those still employed by the Navajo and will be described in another section. The spinning and weaving is looked upon as the work of the men and is generally done by them in the kivas. 


\section{Decorative ArT.}

Decorative art is chiefly displayed in freehand painting on the surface of pottery vessels. The geometrical patterns are well devised and well executed. Both flowers and animals are reproduced viewed as flat with no attempt at perspective, but real talent or genius in drawing is never displayed. Apparently the older art gave way under European influences to new forms which for some reason have not reached the perfection of the old seen in the black and white ware from the Tularosa ruins and the excellently colored resiels from the Little Colorado. Since we know certain of the villages in the latter region were deserted at an early date, we are justified in concluding that this art reached its flower near the beginning of the historic period.

Symbolic art, while found upon pottery, is particularly developed in ceremonial painting and carving. Not only are such cloud symbols as that seen on the cover of this book common, in which semicircles stand for clouds, zigzag arrows for lightning, and vertical lines for rain, but many other conventions are employed. The prayer bowls and the wooden headdresses worn in dances often have their tops fashioned in terraces which represent both mesas and mountain peaks and stand in general for the earth. In the dry or sand paintings, described in another section, excellent flat representations of animals are produced.

It is difficult in a sentence or a paragraph to gire the 
reader an adequate conception of the extent to which color and number enter into the myths, songs, prayers, and ceremonial observations. All important things are repeated for each of the cardinal points with changing color and symbolism. These conceptions of color and number, while put to a ceremonial use, are almost certainly esthetic in their origin.

\section{Social Organization.}

One form of social grouping, that by clans, is represented in several parts of North America as well as in Australia and elsewhere in the world. The political body is composed of a definite number of groups each consisting of individuals of all ages and sexes who consider themselves related through their mothers. The essential point in this system is that this maternal relationship should be considered sointimate that marriage cannot take place within the group. There is also often an element of religion associated with these social groups. The more usual form is connected with the belief that the clan is descended from a mythical ancestor, usually an animal. The clan is under the especial protection of this ancestor and in turn worships it. When these two things are found associated, namely, exogamous clans, in which the descent is maternal, and religious beliefs and practices peculiar to the clan in regard to a mythical ancestor, the name totemism is applied. The best examples of totemism are found 
in Australia, among the Iroquois, and along the Northwest Coast of North America. In many communities every bit as primitive, no such things exist. There are no clans and of course, no clan religion.

In the Southwest, among the Pueblos, we do have clans, well organized and prominent. Although four totally different languages are spoken the names of these clans have the same meanings and are always recognized by the Indians as equivalent or identical. In the smaller pueblos many of the clans appear to have become extinct.

The names of the clans of the Rio Grande pueblos are rather evenly distributed among the natural orders. There is probably some cause for this arrangement but what it is it may be impossible to discover at this late day. In the list given below, which is practically that of Mr. Hodge, only those found in several villages are included. They are: sun, cloud, sky, moon, star, earth, water, fire, turquoise, white bead, coral bead, salt, stone, corn, calabash, oak, cottonwood, tobacco, grass, pine, firewood, arrow, eagle, turkey, parrot, roadrunner, crow, hawk, bear, panther, deer, antelope, buffalo, badger, coyote, gopher, marten, rattlesnake, lizard, frog, and ant. Among the Tewa villages the clans are assignable to one or the other of two major divisions or phratries, the winter and the summer people. The Hopi clans, according to Dr. Fewkes, are grouped in the following phratries: horn-flute, water house, snake, reed, wood, cottontail rabbit, earth, bear, kachina, tansy mustard, tobacco, and badger. The 
names given these phratries are the names of the clans which are dominant in them.

In the Keresan villages of the Rio Grande region the children belong to the clan of the mother. This has been established for Cochiti by a clan and individual census made by Prof. Starr. It seems among some of the Tewa villages the children belong to the clan of the father, however little attention is now believed to be paid to the clans even in the matter of marriage since it is difficult to arrange proper marriages with the clans so much reduced in number and size of membership. The cacique still adheres to what appears to have been the former general custom of addressing each individual by his name followed by the name of his clan.

Among the Hopi the children are of the mother's clan and the clans are exogamous. At Zuñi, while a child is of his mother's clan, he is spoken of as the "child" of the clan of his father and there are certain duties which are performed not by a member of a clan but by a "child" of a clan.

It has been conjectured that in earlier times each clan occupied a definite section of the communal dwelling or even a separate building; that the fields of a clan were in a continuous tract; and that the men of each clan had a separate kiva which served as a common sleeping place and a clubroom. Castañeda, indeed, remarks that the estufas are the property of the men, but the houses the property of the women. Plans have been made of a number of the villages showing the clan relationship of those occupying adjoining 
rooms, but not much more uniformity is found to exist than would be expected to result from the ordinary ties of blood relationship. It is true that certain Hopi kivas are looked upon as clan kivas and certain eagle nests are recognized as clan property.

The women have equal if not superior property rights with the men in the harrested crops and in the flocks of sheep and goats. The horses only are considered the undisputed property of the men to be disposed of without consulting the wives.

It is important to note that the ceremonies of the Hopi are generally associated with certain clans or group of clans who lead in their celebration. In the case of certain clans, the snake clan for example, the name does represent a mythical ancestor from which the clan is believed to be descended. In general, however, the explanation of the clan's name and origin is geographical or incidental. It is believed to have lived in a particular locality, usually where ruins are to be seen, where it bore as a political unit the name which it now has as a clan. When the clans came to Oraibi, in mythical times, each was asked if it had some ceremony that would cause rain to fall, the crops to grow, or in some other way promote the public welfare. It seems then that the social religious system existing in the villages of the Southwest may properly be called totemism, provided that term be used in a broad sense.

The Indian explanation of the origin of the clans, that they have resulted from the migration of former politically independent bodies who have thus been 
united in a common village, camot be aceepted. If those of one village only had to be explained this theory might hold, but clans with similar names exist in the Rio Grande Pueblos, at Zuñi, and in the several Hopi villages. The fact that four distinct languages are spoken in these various villages adds to the difficulty of accepting such an explanation. When it is remembered that such grouping into exogamous clans occurs elsewhere in the world, a social rather than a geographical or ethnic origin will be sought.

\section{Social Customs.}

The Hopi baby is first washed and dressed by its paternal grandmother or by one of her sisters. On the day of its birth, she makes four marks with corn meal on the four walls of the room. She erases one of these on the fifth, tenth, fifteenth, and twentieth day of the child's life. On each of these days the baby and its mother have their heads washed with yucca suds. On the twentieth day, which marks the end of the lying-in period, the grandmother comes early, bathes the baby and puts some corn meal to its lips. She utters a prayer in which she requests that the child shall reach old age and in this prayer gives it a name. A few of the women members of the father's clan come in one at a time, bathe the baby, and give it additional names. After the names have been given, the paternal grandmother goes with the mother and the child to the 
eastern edge of the mesa, starting so as to arrive there about sunrise. Two ears of white corn which have been lying near the child during the twenty days are carried with them. The grandmother touches these ears of corn to the baby's breast and waves them toward the east. She also strews corn meal toward the sun, placing a little on the child's mouth. As she does this, she prays, uttering in the course of her prayer the various names which have been given to the child. The mother goes through a similar ceremony and utters a similar prayer.

The names given relate in some way to the clan of the one who bestows them. Of the various names given the child, one, because it strikes the fancy of the family, generally sticks and becomes the child's name which is retained until the individual is initiated into some ceremony. This usually takes place between the ages of fifteen and eighteen. At that time, a new name which is usually retained throughout the individual's life is given by the man or woman who is sponsor for the novice.

At the present time at least, the Hopi young people arrange their own marriages. When their minds are thoroughly made up, and the young man has acquired some property, the parents are informed of the matter. Marriages usually take place in the fall or winter. The first step is for the mother of the girl to accompany her to the young man's house with a tray of white corn meal. She gives this to the young man's mother, and returns to her home. The girl remains and grinds 
corn for three days. In the morning of the fourth day, the relatives of the couple assemble at the bridegroom's house. The two future mothers-in-law prepare two large bowls of yucea suds. With one of these the mother of the girl washes the boy's head and the boy's mother does the same for the girl. The other female relatives present assist in rinsing the suds from the hair.

When the washing is finished, the bridal pair take a pinch of corn meal and walk silently to the eastern side of the mesa. They breathe upon the corn meal, throw it toward the rising sun, and utter a short prayer. When they have returned to the young man's house, the marriage itself is considered complete although the ceremony is not. The girl assists her mother-in-law in preparing a breakfast which is eaten by the members of both families. After breakfast, the father of the young man runs out of the house and distributes bolls of cotton to the friends and relatives who are expected to separate the seeds from the cotton.

A few days later, the crier announces that the spinning of the cotton is to take place. The men relatives and friends gather in their kivas and spend the day in carding and spinning cotton. This they bring in the erening to the bridegroom's house where they partake of a feast. From the cotton yarn prepared in this way, the father of the bridegroom, assisted by the other men of the family, weaves two large white robes and a white fringed girdle. I pair of moccasins provided with long buckskin strips is also made. The blanket and the moccasins are coated with white earth. When 
the outfit has been completed, which usually takes six or seven weeks, the bride is dressed by her mother-inlaw in the moccasins and one of the robes. The other robe, wrapped in a reed mat, she takes in her hands and goes to her mother's house, where her husband also appears during the day. They live with the girl's people for some months or until a new home is made ready.

The preparation of clothing for the bride by the bridegroom or men of his family is evidently an old custom for Castañeda mentions it as being the practice in his day on the Rio Grande. Villagran, who wrote a long poem on the conquest of New Mexico, describes a wedding during which the robes of the pair were tied together.

When an adult dies, the nearest relatives by blood wash the head, tie a feather offering to the hair so that it will hang over the forehead, wrap the body in a good robe, and carry it to one of the graveyards which are in the valleys near the mesas. The body is buried in a sitting position so that it faces the east. This is done within a few hours after death has occurred. The third night, a bowl containing some food, a prayerstick offering, and a feather and string offering are carried to the grave. The string is placed so that it points from the grave toward the west. The next morning, the fourth, the soul is supposed to rise from the grave, and proceed in the direction indicated by the string where it enters the "skeleton house." This is believed to be situated somewhere near the Canyon of the Colorado. 
The bodies of children who have not yet been initiated into some society are not buried in the ground but are placed in a crevice of the rock somewhere in the side of the mesas and covered with stones. The string offering in this case is not placed pointing toward the west, but toward the house where the family lives. The spirit of the child is believed to return to the house and to be reborn in the body of the next child, or to linger about the house until the mother dies, when it accompanies her to the world of the departed.

\section{Political Organization.}

The political government of each Rio Grande pueblo is in the hands of a governor, council, and a war chief. The governor, chosen annually by a formal election, is in reality named by the cacique, a permanent officer whose duties are chiefly religious. There is usually also a lieutenant governor chosen in the same way. The war chief too is appointed annually and confirmed by the council.

This council, which is the legislative body, is permanent in some pueblos but elected annually in others. It is believed by some to be a survival of an earlier council in which each of the clans was represented by its head.

The governor is the representative of the village in its dealings with other villages and with the general public and is its nominal head. The war chief directs 
all communal work such as that on the irrigation ditches and the communal hunt. In earlier times he led the war expeditions and had charge of the defense of the pueblo. He is the executive officer of the council and carries out its decrees. These frequently have involved the death of persons suspected of witcheraft.

The Hopi pueblos each have a village chief, a crier chief, and a war chief who hold their positions for life. One of the members of each clan is usually recognized as its head and controls the kiva and the house room which is looked upon as the clan home.

The older methods of defensive warfare are well illustrated in the accounts of conflicts between the Spanish and certain pueblos in the sixteenth century. At Zuñi the men withdrew to the housetops and pulled up the ladders. When the Spanish advanced within reach, arrows were discharged and stones were thrown down. The women, children, and old men had been sent to other villages or to Thunder Mountain. Similar methods were resorted to at Tiguex where a besieged pueblo held out for many months because occasional falls of snow furnished a fresh supply of water. Pecos, which had a wall and a spring inside, was said by Castañeda to have resisted successfully the attacks of Plains Indians.

The weapons used were bows and arrows, a stoneheaded club, and a stick half a yard long, set with flints which Espejo says would split a man asunder. For the protection of the warriors, shields of rawhide, leather jackets, and head pieces of leather are mentioned. 
Formerly among the Hopi it was the duty of the Snake, Coyote, and Burrowing Owl clans to avenge the death of a Hopi killed by any one outside of the tribe, to police the village, and in battles to fight in the foremost ranks with war clubs while others were privileged to use bows and arrows.

\section{Religious Practices.}

The religious activities of the sedentary people of the Southwest are so many and so intricate that it is difficult to describe or discuss them, especially in a limited space. There are some common elements, however, which are worthy of notice. The ceremonies often take the form of dramas in which the movements and activities of supernatural beings and animals are imitated. The actors wear masks, paint their bodies, and conduct themselves according to the supposed appearance and character of the divinity or animal represented. The divinities are also represented by large stone images rudely shaped and by smaller ones which are better executed in soft stone or wood.

There are permanent shrines usually near the villages, often walled in on three sides and sometimes sheltering an image or a peculiarly shaped stone. Temporary altars are made during the ceremonies by setting up a line of wooden slabs carved or painted with religious symbols before which dry paintings are made. These dry paintings are made by sprinkling sand of various colors so as to form symbols, and pictures of the gods. 
Small sticks, singly or in pairs, are painted and often have faces indicated on them. Feathers, and a corn husk containing corn meal and honey are usually attached to them. They are placed at the shrines and springs for the deities. Corn meal and pollen are strewed and thrown toward the sun. Corn meal is frequently used to mark ceremonial trails and to define the limits of sacred places. Races generally occur during the ceremonies, but the significance of them is not clear. Bathing the head and the use of emetics are resorted to as methods of purification.

In general it may be said that Southwestern ceremonials chiefly employ dramatic, graphic, and pictorial art to accomplish their purposes which appear to be the influencing of invisible supernatural powers and through them the natural forces. The greater number of the ceremonies are intended to bring rain and to aid in fertilizing the crops.

It is only from Bandelier's short account of his observations among the Pueblos of the Rio Grande published many years ago, and the work of Mrs. Stevenson among the Sia that we are able to get a view at all comprehensive of the religious organization of the Rio Grande region.

At the head of the political and religious systems is the cacique, as he is ordinarily called. The office which is held for life requires years of training and study as a preparation, and its duties are arduous. He is expected to devote himself to a life of fasting and prayer. His fasts vary from slight temporary self 
denials to absolute abstinence of four days duration according to the seriousness of the people's need. He is the mouthpiece of the divinities whom he is called upon by the tribe or by individuals to consult. Because he is believed to speak by divine authority his influence is very great. He names his successor and nominates the ciril officers of the village. He is not supposed, however, to enter into petty quarrels nor to take part in minor discussions in the council. That he may be

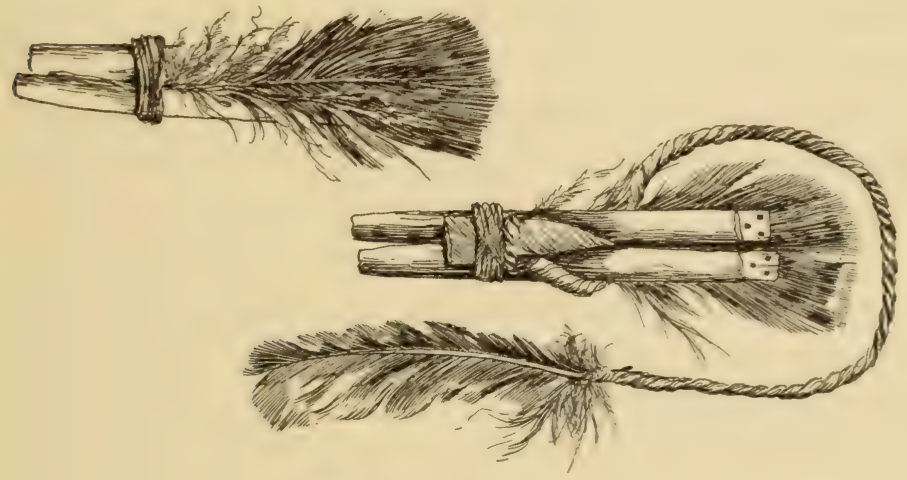

Hopi Prayer Offerings.

free to devote himself to such a life his wants are provided for by his people who supply him with wood and cultivate a field for his benefit. He has one or two assistants from whom his successor is chosen.

There are many societies more or less secret, which have the knowledge of certain prayers, songs, and rites, which they are expected to use for the public benefit. The most important was a group of societies which 
were especially devoted to ceremonies leading to success in war. Among the Sia these societies were those of the Panther, Bear, and Knife. Their leader ranked next to the cacique in religious importance. The hunters in earlier days were also important since they had the fetishes and the ceremonies by which game could be taken. The panther was their patron since he was looked upon as the most successful hunter. The head priest of the hunters was also a most important person. Finally, the many societies (among the Sia, the Snake, Spider, Ant, etc.) who have the power of healing diseases and producing rain had one head shaman, according to Bandelier, whose office gave him great power, particularly in the discovery and punishment of witches.

Then there are two societies or classes of priests, the Cuirana, or winter priests, and the Koshare, the summer priests, to use the Keresan term. The former by their activities cause the seeds to germinate, while the latter bring the crops and all animal and human life as well to maturity. It is the Koshare who act as clowns on all public religious occasions. Each of these societies has a leader who with the cacique and the head-priest of the warriors, hunters, and healers, constitute a most important sacerdotal group.

All adults are expected at some time to participate in the kachina dances. Masks and headdresses are worn to represent a special class of supernatural beings, in the opinion of some, ancestors. Boys and girls go through an initiation which consists of a beating and 
then one of the dancers unmasks that the child may see that the gods are not present in person as he has formerly supposed.

Sia Rain Ceremony. Mrs. Stevenson, who witnessed several of the ceremonies of the Sia, has given a full description of the rain ceremony of the snake order. Prayer-sticks notched and colored were prepared for offering. An altar with a dry painting representing clouds by terraced semicircles was made. On it were placed several fetishes and a clan or society emblem called yaya which is a perfectly kerneled ear of corn entirely covered with feathers.

The ceremony proper begins with a strewing of a line of corn meal from the altar to the door over which as a road the spirits of the gods are supposed to travel and temporarily enter the fetishes. There is much singing, dancing, and praying, mostly by individuals rather than in concert. In a bowl of water to which ground yucca roots have been added a suds is made which represents clouds. Pollen is sprinkled into this bowl and the foam is scattered over the altar.

By means of songs and prayers the gods who dwell in six sacred springs are invoked that they may incite the cloud people to action. By each of these springs there is supposed to be a hollow tree through which the cloud people carry the water up to the clouds. These clouds are but huge masks behind which the cloud people climb and from which they sprinkle the earth. The thunders are also invoked. They are thought to be beings with tails and wings of obsidian 
which clash and make the noise inciting the cloud beings to greater activity.

When the ceremony is finished the sand painting is obliterated and the prayer-sticks carried to a nearby shrine where they are left for the deities. The notches upon these sticks and the painted designs are supposed

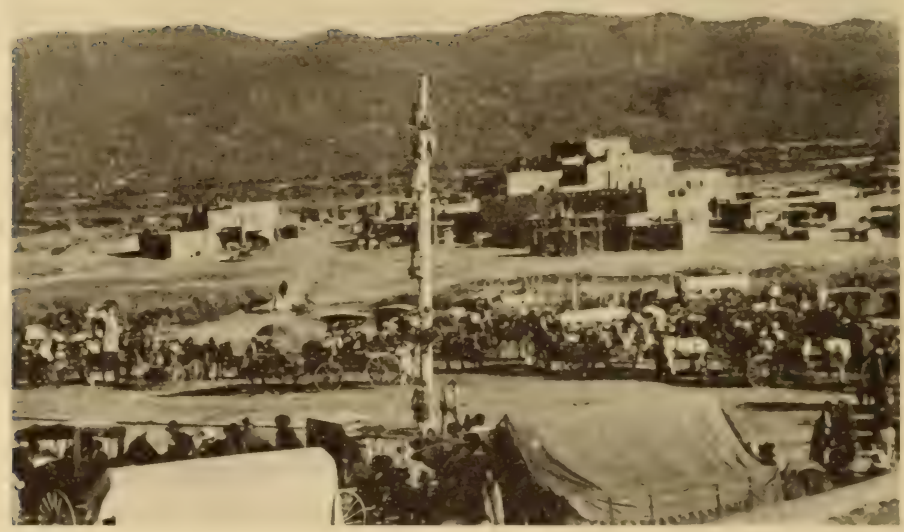

Clowns climbing Pole. Taos.

to convey the message, the attached feathers being given in payment for the favor besought.

Festivals. The public ceremonies of the Rio Grande pueblos have taken on the names and some elements of Catholic festivals. They occur on fixed dates which 
are also the days sacred to their patron saints. There are probably always preliminary activities held secretly. in the kivas which are in part rehearsals, during which, however, prayers are said and acts of worship performed. The last day is devoted to a public spectacle largely attended by risiting Indians, Mexicans, and others.

The ceremony at Taos occurs on September 30th. The image of the saint is brought from the church and placed in an elevated booth overlooking the plaza in which the ceremonies take place. A tall pole erected for the purpose has a great variety of vegetable products, cooked and in their natural state, fastened to the top of it where also is suspended the carcass of a sheep which in recent years has taken the place of that of a deer. The forenoon is devoted to races in which young men from the two large houses compete in relays. The victory is a community one and not individual. The winners are pelted with food by the losers. In the afternoon the clowns appear, men grotesquely dressed and painted who act as offensively as possible. They take the lunch baskets from women and empty them, tear the clothing from a man, or throw him fully clad into the stream, and enter any house they choose. Finally, they approach the pole as if tracking an animal, attempt to shoot toy arrows to the top, tug at its base as if trying to uproot a tree, and at last make attempts to climb it which succeed for one of their number who secures the food for his fellows. As a whole the ceremony is evidently intended as a consecration of the harvest and an expression of thanksgiving for it. 
At the pueblo of Nambe, which is now much reduced in numbers, a dance representing the deer was given as a spectacle on their feast day in 1909. The dancers followed by the drum and the directors of the ceremony made a circuit of the plaza several times, stopping now and then to dance.

Among the Hopi two types of ceremonies are held at separate seasons of the year. The kachina cere-

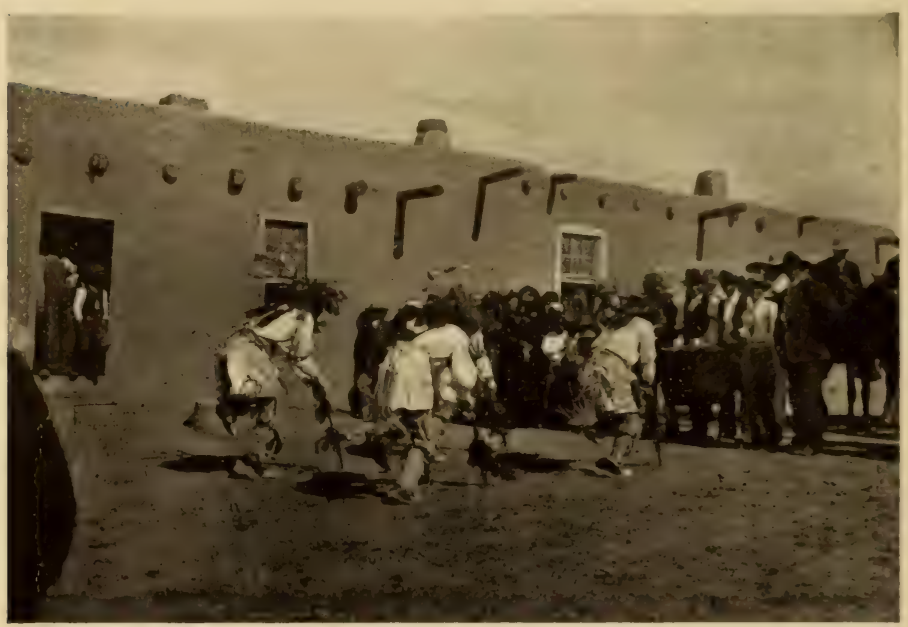

Deer Dance. Nambe.

monies begin with the winter solstice and terminate in midsummer when a farewell ceremony called the Niman kachina is held. Shortly after, the second series is opened with either the snake dance or the flute ceremony and others follow until November when the new fire ceremony completes them. Kachinas are super- 
natural beings, who during the period when their dances are held, are believed to visit the Hopi. When this season is over, they withdraw to their homes in San Francisco peaks and elsewhere. They are represented in the dances by men who are masked and painted to correspond to the traditional conception of the appearance of each kachina. Small wooden images, carved,

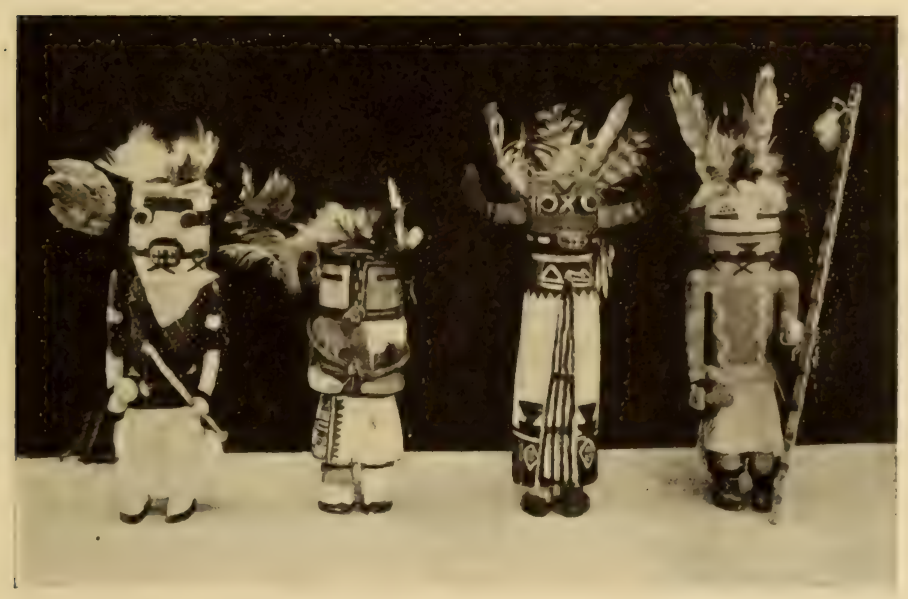

Hopi Kachina Dolls.

painted, and decorated with feathers, are also used to represent them. These dolls after the Niman kachina is held are given to the children to play with.

Ceremonies in which the kachinas appear are of two kinds. The full ceremonies, which are the first held, have in addition to the public performances, several days devoted to secret rites in the kivas, where altars 
are made. The abbreviated kachinas, which come late in the spring, have only the dances in the plazas. In these dances, the men who represent the kachinas wear, in addition to the masks, embroidered kilts and sashes. They carry gourd rattles in their hands and have tortoise-shell rattles tied to their knees. They move forward slowly in a procession with mincing steps timed by the rattles. The priests in charge of the ceremonies and others sprinkle corn meal on them and pray to them as if they were the real kachina beings. These occasions are enlivened by the pranks of clowns who are similar to those of the Rio Grande villages.

The ceremonies of the second series are distinguished from the kachina ceremonies by the absence of masked men and clowns. They are generally spoken of as nine day ceremonies although the Hopi themselves consider that they last from the day of the formal announcement until their completion sixteen days after. All have certain features in common. Altars are made, prayer-sticks are prepared and offered at various shrines, and there is much praying and singing in the kivas. During the kiva ceremonies, the participants smoke in turn, addressing each other with terms of relationship as the pipe or cigarette is passed. On the last two days of the ceremony there are usually foot races and public performances. These ceremonies are given by societies or orders of priests under the direction of the head of the order. Anyone may become a member who is willing to be initiated; but usually some one clan predominates in the membership of each society. 
The Snake Dance. The most widely known of these ceremonies is the snake dance, which is held every second year in all the Hopi pueblos except Hano and Sichumovi. The dances of Walpi and Oraibi are those which attract the largest number of visitors. The ceremony is given jointly by the antelope and snake fraternities. The former are concerned chiefly with the rites in the kiva, while the latter, originally a warrior society, gather and handle the snakes.

To secure the snakes the snake priests go out in pairs provided with digging-sticks, with snake whips of feathers and with bags of buckskin or canvas. The first day they go to the north, the second to the west, the third to the south, and the fourth to the east, for this is the ceremonial circuit of the Hopi. If a sufficiently large number is not secured during the four days, snakes are sought in any place and at any time until enough are found. Those used are chiefly rattlesnakes but bull snakes and others are also employed. The snakes are usually found by following their trails in the dust. If a snake is uncoiled a little corn meal is thrown toward it; it is seized by the neck, stroked gently, and placed in a bag. Should the snake coil, a prayer is said and tobacco smoke is blown toward it until it uncoils. If the trail of the snake leads to a hole it is dug out with a digging-stick. The snakes gathered are confined in pottery vessels in the kiva until they are wanted for the ceremony.

Both the snake and the antelope priests make altars in their kivas. The snake altar is made at Oraibi 
on the evening of the first day. The head-priest brings into the kiva two wooden images of great apparent antiquity. The larger represents Pookong, the elder of the war god twins; the smaller may be intended for his brother, or for some other divinity. Near these are placed small images of the panther, the fetish of the warriors and hunters. At Walpi, and at Oraibi if a candidate is to be initiated, a sand painting is also made. This has a picture of a panther in the center, a snake on each of the four sides, and a frame of four colored bands. Although each band extends entirely around the painting the outer one which is yellow represents the north; the second, the green one, the west; the third, red, the south; and the inner one, which is white, the east. These are the colors which are always associated with the world quarters by the Hopi.

The antelope altar is made in another kiva on the fifth day of the ceremony. The painting consists of a number of semicircular cloud terraces, with a similar border of colored bands. On two sides are rows of sticks, some of them curved, which represent the deceased members of the order. At the back of the altar are the fetishes and the tiponi, the society symbol, kept by the head of the order as a badge of his office. Around this altar a most important rite is held. One of the priests and a woman relative of some member are especially dressed and impersonate antelope man and antelope maiden. The snake priests enter bringing a snake which the antelope man holds during the 
ceremony. The priests smoke, blowing the smoke toward the altar; clouds of tobacco smoke are also blown from a cloud blower; and a priest appointed for the purpose sprinkles a specially prepared liquid upward and over the altar. Many prayers are uttered and eight songs are sung. This ceremony is repeated each morning after the fifth, throughout the ceremony. A messenger is sent out each afternoon with prayer offerings to be placed on the various shrines. The first day he risits the most distant ones making a circuit of many miles; on the three remaining days the distances are decreased. On the afternoon of the seventh day water is brought by a messenger from a distant spring. Before the water is taken a prayerstick is set up and the following prayer is uttered:-

"Now, then, this here (prayer offerings) I have brought for you. With this I have come to fetch you. Hence, being arrayed in this, thus rain on our crops! Then will these corn-stalks be growing up by that rain; when they mature, we shall be glad over them. Then these our animals when they eat will also be happy over it. Then all living things will be in good condition. Therefore do we thus go to the trouble of assembling. Hence it must be thus. Therefore have pity on us. Now let us go! We shall all go. There let no one keep any one back. You all follow me." (Voth, 320.)

In the early morning of the two last days of the ceremony, two snake priests dressed as warriors pass four times around each of the kivas and enter them. They have in their hands bullroarers and lightning frames. The first are sticks fastened to a string which when rapidly whirled make a noise like falling rain. The lightning frames consist of a series of crossed sticks 
so joined that they may be quickly projected to a considerable distance and then rapidly returned. These warriors and the messenger who has brought the water the day before, go down on the plain a mile or two from the village. The messenger first makes cloud symbols, deposits a prayer-stick and utters a prayer at four places some distance apart. When
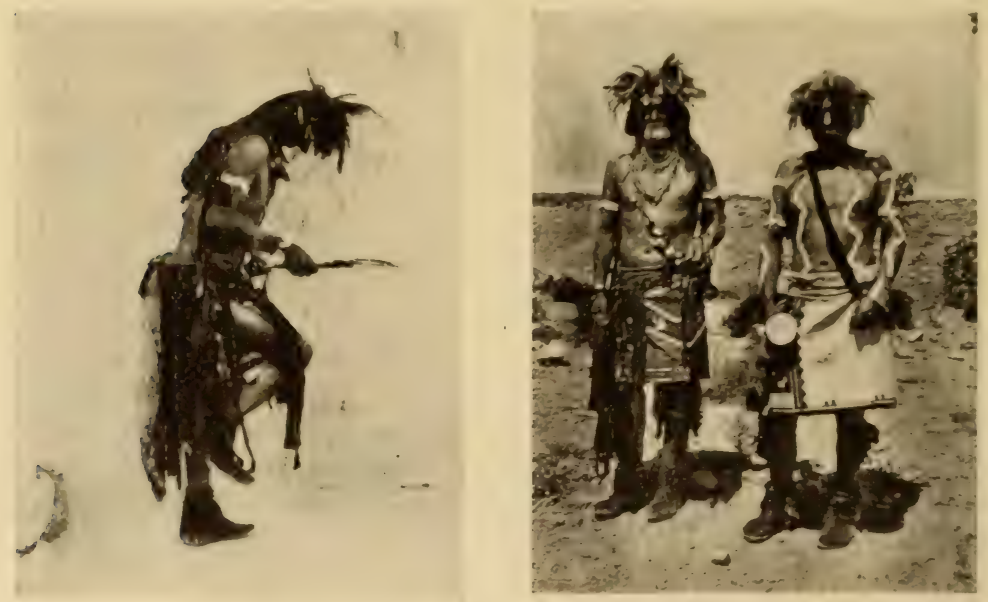

Snake and Antelope Priests.

(Photo. by Howard McCormick.)

he reaches the fourth place the two warriors advance toward him, swinging their bullroarers and shooting out the lightning frames. When they reach the fourth place of offering, the runners start toward the village. The first one passing the messenger is given the netted gourd containing the water brought from the distant 
spring. This he must surrender to any one passing him so that the wimner arrives with it at the village. As the rumners approach the mesa, they are joined on the eighth morning by antelope priests and on the ninth morning by snake priests. Boys follow them up the mesa trails with freshly cut corn stalks. When the rumners have passed, the girls of the village snatch these corn stalks from the boys and carry them to the houses to be used as decorations.

About noon of the ninth day an interesting feature of the ceremony takes place in the snake kiva. A liquid is prepared in a vessel kept for the purpose and the snakes are dipped into it. At Oraibi they are placed on some sand to dry in the sun where at that hour it shines through the hatchway. At Walpi, however, they are thrown with considerable violence upon the sand painting of the altar.

Public performances in the plaza take place in the afternoon of the eighth and ninth days. The antelope priests first come from their kiva, and go in procession four times around the plaza. As they pass in front of a booth which has been provided for the snakes, each man stamps on a plank which has been placed there to represent the place of exit from the lower world. When the fourfold circuit has been completed, they form in a line at either side of the booth. The snake priests then come out and make a similar circuit four times around the plaza and form in a line facing the booth and the antelope priests. Each line is led by its head-priest. The antelope priest is also accompanied by a sprinkler who carries a vessel filled with liquid. 
On the eighth day, the lines dance for some time facing each other and then the sprinkler goes to the snake booth, takes a small bundle of vines and corn stalks in his mouth and dances with it as if it were a snake. He is guarded by a snake priest. But on the ninth day after the two lines of priests have made the

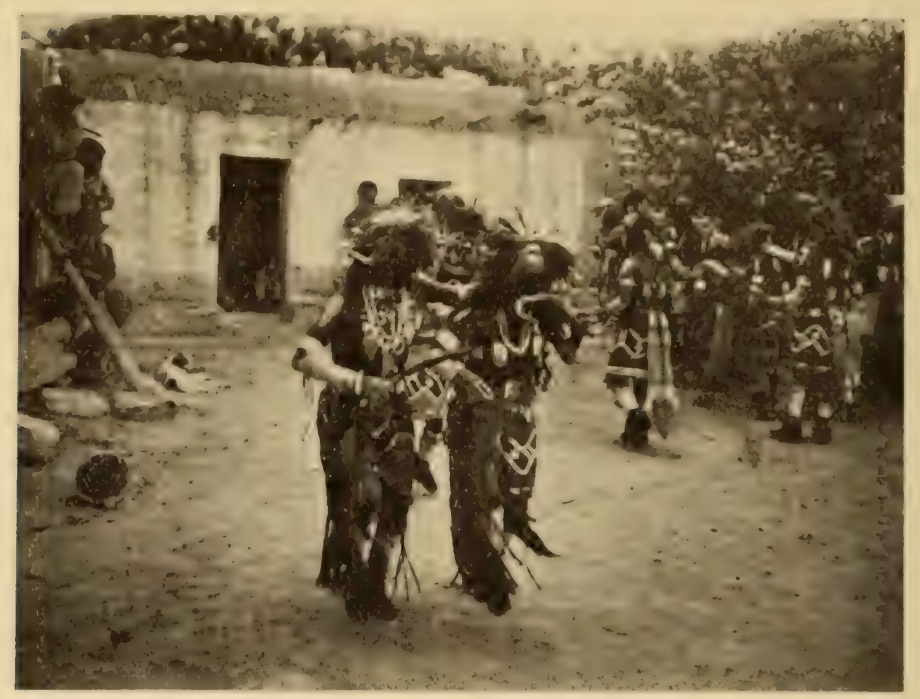

Snake Priests dancing with Snake.

(Photo. by Howard McCormick.)

circuit of the plaza the snake priests go in pairs to the booth. One of each pair is given a snake which he holds in his mouth. His companion follows by his side with a snake whip with which he is prepared to soothe the snake and attract its attention should there be need. They move in this way down the plaza for 
some yards when the snake is dropped. Each pair of dancers is followed by a third snake priest who picks up the snakes as they fall and keeps them in his hands. When his hands are full, he passes some of them to the antelope priests who are still in line. The dancers return for additional snakes until the entire number, fifty or more, have been carried in the dance. The head snake priest then makes a large circle of corn meal and draws six radii which represent the world quarters. Into this circle the snakes are thrown in a heap and the women sprinkle them plentifully with corn meal. At a given signal the snake priests approach, grab as many snakes as they can hold in each hand, run down the trails to the plain, and release the snakes.

In alternate years the flute ceremony is held in the place of the snake dance. This ceremony is given by two orders, the blue and drab flute priests. The final public ceremony takes place at certain springs where songs and prayers are rendered. The rite is characterized by playing on long flutes. An interesting feature of the ceremony is the placing of prayer offerings at the bottom of a deep spring for which purpose a priest enters it.

Following the snake and flute ceremonies are other nine day ceremonies given by societies of women. During the public performance of one of them, the Marau, the women carry in their hands large wooden slabs on which kachinas, cloud symbols, and ears of corn are painted. Following this is the Ooqol ceremony. Alternating with these two ceremonies, the 
Lalakonti dance is given. During the public dance of both the Oogol and the Lalakonti ceremonies, darts are thrown at netted wheels and basket trays are waved in the hands of the dancers. These trays are later given to the spectators.

The last of this series of ceremonies is held in October or November. All the male fraternities join in its celebration. The chief feature is the making of a new fire by means of a firedrill. While this is taking place, the trails to the village are closed by drawing a line of corn meal across them.

The greater number of the Pueblo ceremonies are for the purpose of bringing rain, maintaining the water in the springs and increasing the yield of the fields.

\section{Religious Beliefs.}

From the bewildering number of supernatural beings believed in by the sedentary people, a few stand out with considerable clearness. Of these, the sun is undoubtedly the most important as appears from the offerings made and the prayers directed to it, especially when it is rising.

I goddess of all hard substances is believed to live in a floating house in the western ocean. She and her counterpart in the eastern ocean originated animals and men from cuticle rubbed from their bodies. The small image of the desired being made from this cuticle 
or from clay was placed under a cloth and sung over until it was animated.

spider woman is the originator of the arts and the wise counsellor of those in perplexity. With her live twin grandsons, diminutive war gods, who in the beginning rid the world of man-eating monsters, and became the patrons of the warrior societies. The weapons and arts of warfare were given them by the thunder who is believed to be bird-like with tail and wing feathers of obsidian which makes the noise of thunder attributed to it.

The clouds, usually personified, are addressed when rain is desired. The horned snake, frequently figured on pottery, is a water being feared as well as worshiped since it produces floods rather than helpful showers. The world quarters are frequently personified.

The kachinas are a supernatural race superior to men but inferior to the great nature gods. They live as men do either in the neighborhood of the villages or inside the sacred mountains. These, together with the Koshare and the Cuirana of the Rio Grande peoples benefit mankind by influencing the natural forces in their favor, probably through the instrumentality of ceremonies similar to those of mankind.

For each ceremony there are divine pairs, like the antelope man and maiden, who are looked upon as the originators of the rites.

One must remember, however, that these beings are seldom definite and well formulated. On the contrary there is much contradiction and confusion concerning 
them. They are, of course, reflections of nature and images projected by the human mind as it reacts toward the world and human society. Some of them are doubtless outgrowths of the ceremonies constructed to give old established religious practices a more definite meaning. 


\section{Chapter III.}

\section{THE NOMADIC PEOPLES.}

The term nomadic has been used to distinguish those in the Southwest who do not live in pueblos from those who do live in them. The name is a useful one although it does not give a correct impression concerning the permanency of the homes of some of the tribes treated in this chapter. The nomadic tribes of the Southwest occupied and claimed the territory of that region with little regard to the presence of the Pueblo people. They were chiefly hunters, and game was not plentiful near the settled towns. They planted to a considerable extent but found ample room for their fields without encroaching on the farms of the village people.

\section{Distribution.}

These nomadic people belong to four linguistic stocks, the Athapascan, the Piman, the Yuman, and the Shoshonean.

Athapascan. In the eastern portion of the territory, are the Athapascan tribes who speak languages related to the Déné of the north in the Mackenzie and Yukon 
valleys and to the various scattered bands in western Oregon and northwestern California. They are known as the Apache, the Lipan, and the Navajo. The former name was widely applied by both the spanish and the Americans who succeeded them and was used for several distinct tribes. In the northeast, are the Jicarilla Apache who are again divided into two bands, one of which, the Llanero, lived on the headwaters of the ('anadian River and in the mountains between that stream and the Rio Grande. The Ollero lived west of the Rio Grande especially along the Chama River.

In the mountains between the Rio Pecos and the Rio Grande south of White Mountain were the Mescalero Apache. They consisted of many bands, each of which claimed a rather definite locality as its home. The territory occupied by them extended southward to the mouth of the Pecos but the bands in the lower part of this region were less closely allied to the Mescalero proper in political feeling and there was a slight difference in dialect. West of the Rio Grande in the Valley of the Mimbres was an Apache tribe now nearly extinct. They formerly were called the Mimbreños but are better known from their great war leader. Victorio. When he was defeated a part of his band joined the Mescalero and others united with the tribes west of them. The Apache living on the headwaters of the Gila River are known as the Chiricahua. This tribe really consisted of four almost independent bands. each with a chief. These are the Indians who have 
made the name of Apache so widely known. They had robbed the Mexican settlements for many years before the American occupation. When later they were deprived of their native lands and placed on a reservation, they fled to Mexico where they lived by plundering on either side of the international boundary line. Their most noted chiefs were Magnas Coloradas, Whoa, Cochise, and Geronimo. The last named with a larger part of his band surrendered to General Miles in 1886. They were taken with their families as prisoners of war to Florida. After less than a year they were removed to Alabama and finally were given a place on a reservation at Fort Sill, Oklahoma. Arrangements are now being made for the return of their descendants to their western homes.

The name San Carlos has been applied to the Apache bands gathered on a reservation of that name. They formerly lived on the San Carlos River, on the Gila River near the mouth of the San Carlos, on Arivaipa Creek which flows into the San Pedro, a southern tributary of the Gila, and about certain springs west of the town of Globe, Arizona.

On the White River, which is one of the main tributaries of the Salt River, were a number of bands of Apache quite similar in all respects to those last mentioned. These have often been called the Coyotero because they were looked upon as wild, but are now generally spoken of as the White Mountain Apache.

The Salt River receives a considerable tributary from the north called Tonto Creek. Near the head of this 
stream there is a large valley known as Tonto Basin. A tribe occupied this valley so well isolated from other Apache that a dialectic difference in language was developed. They were closely associated with the Yavapai who are Yuman in their speech. These two peoples were placed on the San Carlos Reservation where they remained until recently.

The Navajo, called by the Spanish Apaches de Navajo, occupy nearly all the region between the San Juan and the Little Colorado Rivers and roam far beyond that territory in all directions. In language they are not very different from the Western Apache, but in culture they are fairly distinct. Just prior to the American occupation, they were almost constantly raiding the Mexican settlements of New Mexico. They killed their first Indian agent and resisted American control. A large number of the tribe were taken prisoners and removed to Fort Sumner on the Pecos River where they were confined for some years.

Piman. Below the Apache on the Gila and Salt Rivers lived the Pima who speak a language, of the Piman stock, so named from them. They claimed the Gila River from the San Pedro westward to its junction with the Salt River near which place their principal villages were located. They were the enemies of the Apache and considerable territory between the two peoples was not actually settled for that reason. South of the Gila, far into Old Mexico, live the Papago whcse language is closely related to that of the Pima. Since they live rather on the wild products of the 
desert than upon agriculture they are less settled in their habits.

Yuman. With the Pima live the Maricopa who came to them from the mouth of the Gila River in historic times. They are now nearly identical in culture with the Pima but their language is Yuman. There is another tribe speaking a Yuman language, the Yavapai, who seem to have lived for centuries along the Rio Verde. They have often been locally called Apache, or, to distinguish them from the Athapascan tribes with whom they are friendly, Mohave Apache.

Of the same linguistic stock are the Havasupai who. have their villages in the canyon of Cataract Creek, a. few miles southwest of the Grand Canyon of the Colorado. They are close friends of the Hopi and seem to resemble them in some respects although they do. not build terraced houses.

The Walapai, also of the same linguistic stock, live in the territory included in the great bend of the Colorado where it swings from the west toward the south.

Along the Colorado itself are the Mohave who formerly lived from the Nevada line southward halfway to the mouth of that river. The Yuma live near the mouth of the Colorado where it receives the waters of the Gila. The last two tribes, while they are cut off from the California tribes by the Mohave desert, in some ways resemble them and are not particularly like the other peoples of the Southwest. They have adapted themselves to the peculiar conditions imposed by their river valley home. 
Shoshomean. North of the San Juan and at its headwaters are the Southern Ute whose language is Shoshonean, connected with the Hopi. They are within the territory which has been included in this handbook because in it are some of the most important ruins and other evidences of its having once been a part of this culture area.

Between Bill William Creek and the Needles a band of Shoshonean speaking people, the Chemehuevi, formerly lived, occupying both sides of the Colorado. They were friends of their Yuman speaking neighbors and probably settled among them a century or more ago as the Maricopa are known to have done among the Pima.

\section{Shelter.}

These nomadic tribes do not show a great degree of uniformity either in their material culture or in their religion. We shall find their houses, their methods of securing food, and their social habits changing as we pass from tribe to tribe.

Both of the eastern bands of the Apache, the Jicarilla and the Mescalero, and also the Ute, lived in skincovered tipis which differ in no important respect from those used by the Plains Indians. The Mescalero sometimes make brush shelters as well, and perhaps always made a practice of using them when they were in the mountains. When on the treeless plains nothing was so desirable as an easily portable dwelling of skins or canvas. 
All of the Apache west of the Rio Grande made houses which had frames of poles, covered with a thatch of weeds or grass. The prevailing type among the San Carlos Apache is dome-shaped. When the house is small, the frame is made by setting poles a few inches in the ground in a circle, bending their tops over, and lashing them together. These poles are held in the

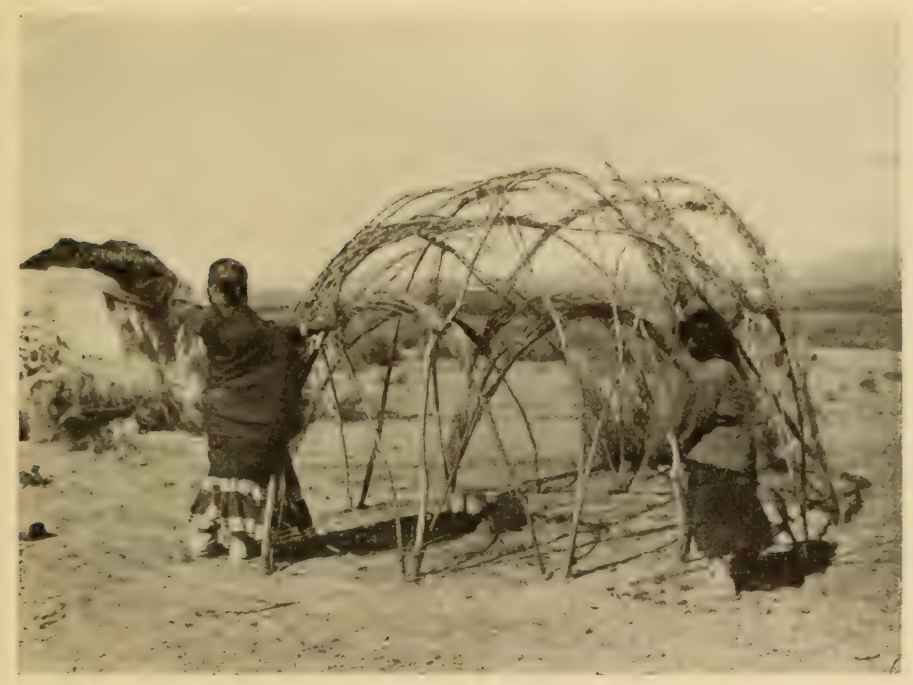

San Carlos Apache Women building a House.

proper curves by horizontal ones lashed to them. When a larger house is needed, poles are first placed forming a series of arches which overlap each other and together complete a circle except for the doorway. These arches support the main ribs running from the ground to the apex. The thatch, which is usually 
bear grass, is applied in regular, overlapping coursess and is bound in place with strips of yucea leaves. The White Mountain Apache houses frequently have two long sloping sides meeting in a line above, like an ordinary gable roof. In recent years, corn stalks and the limbs of trees are frequently used for thatching with the additional protection of a strip of canvas.

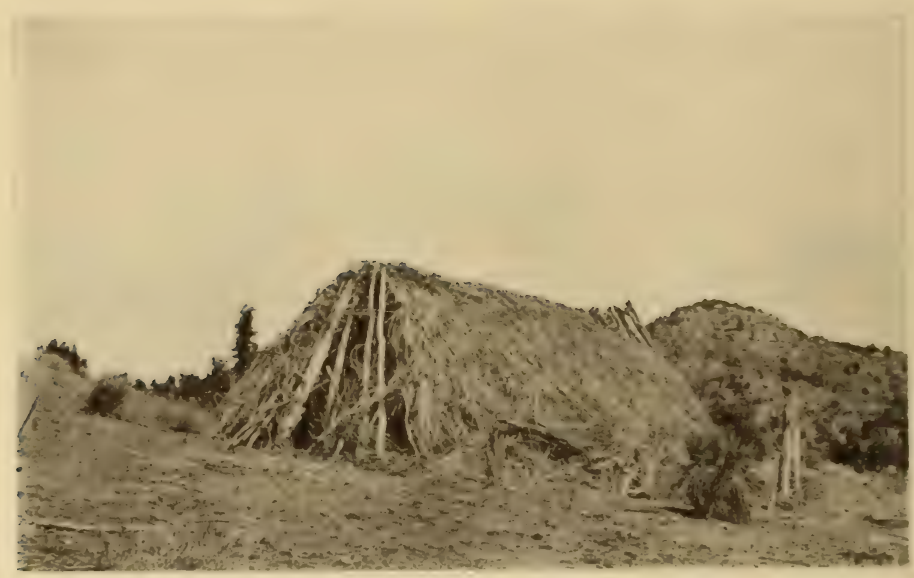

White Mountain Apache House.

The houses of the Pima have a frame in the center consisting of four posts set in the ground at the corners of a square ten to twelve feet apart. The posts are forked at the top and support two logs on which many smaller poles rest. Around this framework a domeshaped light frame is constructed similar to that employed by the Apache. The house is thatched with arrowbush brush and the roof is generally covered with 
earth to a depth of eight or ten inches. The sides are also sometimes banked with earth. No opening is left for the smoke to escape but because of the climate fires are seldom needed in the houses. The Papago houses are similar to those of the Pima.

The Mohave houses have an inner frame similar to that employed in the Pima houses but the outer portion is rectangular with low vertical walls. The sides and

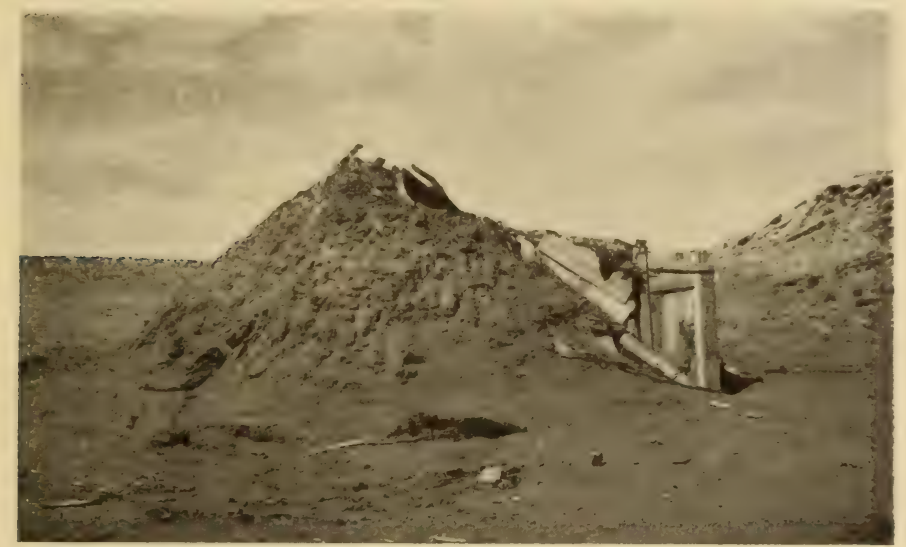

Navajo House.

roofs are thatched and the roof also has a layer of sand.

The Navajo live in winter in earth-covered lodges. The house has for its chief support three large logs with forked tops. These are locked together by placing the fork of one in the fork of a second, and thrusting the fork of the third between them. Other logs and small poles are laid on these until a conical house is enclosed. Brush is placed in the larger cracks and 
earth is piled on to a depth of several inches. Such a house leaks only after a long hard rain. A doorway is made on the east side and between the doorway and the apex a large hole is left to admit light and air and through which the smoke may escape. Six-sided houses are also built of logs placed horizontally. By drawing them in gradually after the walls have been carried to a proper height, the roof is formed. A smoke hole is left at the apex. During the summer the Navajo generally camp with only a shelter of brush or a stone wall to protect them from the prevailing winds.

\section{FoOd SuPPLY.}

The nomadic tribes had a large territory at their disposal. There were fertile and fairly well watered river valleys where corn and beans could be raised and rast tracts of upland covered, if sparsely, with a varied vegetation. Judging from the number of cattle and sheep which that region now supports, before their introduction there must have been sufficient food for many deer, antelope, and elk. A few days' travel east from the Rio Grande were the buffalo plains with a supply of meat limited only by the means of transporting it.

Corn was planted by all the tribes; but the Eastern Apache, the Jicarilla and Mescalero, depended but little upon agriculture. That the Navajo formerly had large fields was stated by Benavides who gave that 
fact as the explanation of their name. The methods employed seem not to have differed particularly from those of the village Indians. The corn was planted in irregularly spaced bunches, rather than in rows. The Mohave and Yuma planted in soil freshly deposited each year by the overflow of the Colorado, and

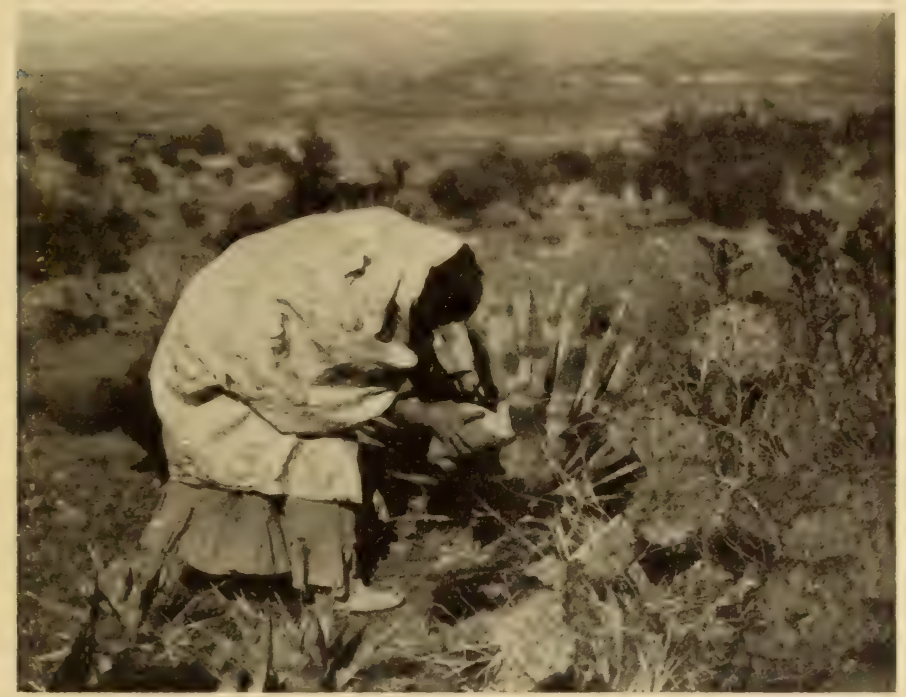

Jicarilla Woman gathering Mescal.

did not make use of irrigation, as did nearly if not all other tribes.

The nomadic people made extensive use of the wild vegetable products. The piñon produces large crops of nuts which the woodrats gather. It is only necessary to rob their nests to secure an abundant supply. The mesquite grows in most localities and furnishes edible 
pods when they are green and later bean-like seeds which are pounded into flour. The amole, Yucca buccata, has a banana-shaped fruit which is cooked in the ashes, and may then be dried for later use. The agave, a century plant, furnishes a large bulk of nutritious food. The plants are watched until signs of the flowering stalk appear when they are seven or eight years old. The entire plant is severed near the base by means of a chisel-shaped stick which is hammered with a stone. The plant is then turned top down and

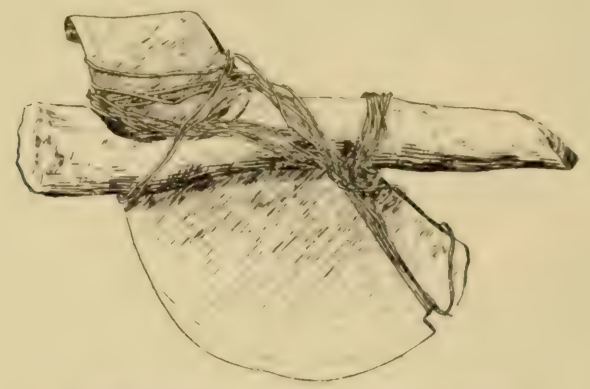

Mescal Knife. San Carlos Apache.

trimmed with a broad knife of native manufacture. A leaf or two is left for a handle by which the stumps are carried to a long deep pit used year after year. This pit is thoroughly heated and filled with stumps, A covering of earth is thrown over them and a fire maintained on top for a day or more. The cooked material is dried in the sun and packed in bales for transportation to the camp. This food, while coarse, is not unpalatable.

There are many species of cacti, most of which have 
edible fruit. The giant cactus, which grows on the lower elevations, because of its great size yededs abundantly. The fruit is pressed in large balls which keep indefinitely. These contain many black seeds which are separated by soaking and ground for flour. There are many berries, seeds of grasses and sunflowers, nuts, and bulbs, which add considerably to the required food supply.

The Eastern Apache made regular trips to the buffalo plains, at the times of the year when the buffalo were driven south by the cold. They killed a large number, dried the meat, and packed it in bags, or parfleches, made of the hides of the animals killed. These were tied on the backs of horses for transportation.

Men went out singly to hunt deer and antelope wearing a headdress with the horns of the animals that they might approach them more readily. There were communal hunts for elk particularly. The leader of the hunt placed the men at the points that commanded the passageways and trails and the animals were driven toward them. Corrals were also used into which the antelope were driven.

The Athapascan tribes, except the Lipan, never eat fish or waterfowl. The taboo is explained by the Indians as due to a fear of water which is connected with the thunder. The Mohave appear to be the only tribe making much use of fish for food.

For some years before and after the American occupation of the region the Western Apache and the 
Navajo lived to a large extent on the cattle, sheep, horses, mules, and burros they were able to drive off in the settlements. The Navajo alone of the nomadic tribes, raised sheep for food and wool.

\section{Clothing.}

The Jicarilla Apache wore buckskin clothing similar to that of the Plains. The Mescalero and the Western Apache women had dresses in two parts, the upper garment had an opening for the head and two large square portions which fell in front and behind to the hips. A skirt reached from the waist to the knees and was generously provided with fringes of buckskin. Less is known of the men's clothing. It seems to have been scanty, except on festive occasions, and in winter. A shirt and leggings were probably worn, with a robe of skins for winter.

The Pima man wore and still wears only a scant breech cloth in the summer. In winter he used to add a deerskin shirt and a robe usually of rabbitskins. The women wear a cotton blanket which they fold round the waist or raise around the neck in cold weather. The Pima are the orily people of the Southwest who still wear sandals. In prehistoric times, sandals of rawhide or of yucca fiber, as described and figured in previous pages, were worn orer the entire area. The Pima make them only of rawhide and wear them about their homes. When away from home, moccasins of buckskin are sometimes used. 
The Mohave women wear skirts made of the inner bark of the willow. The Navajo men sometimes wore shirts and trousers with full length legs of buckskin.

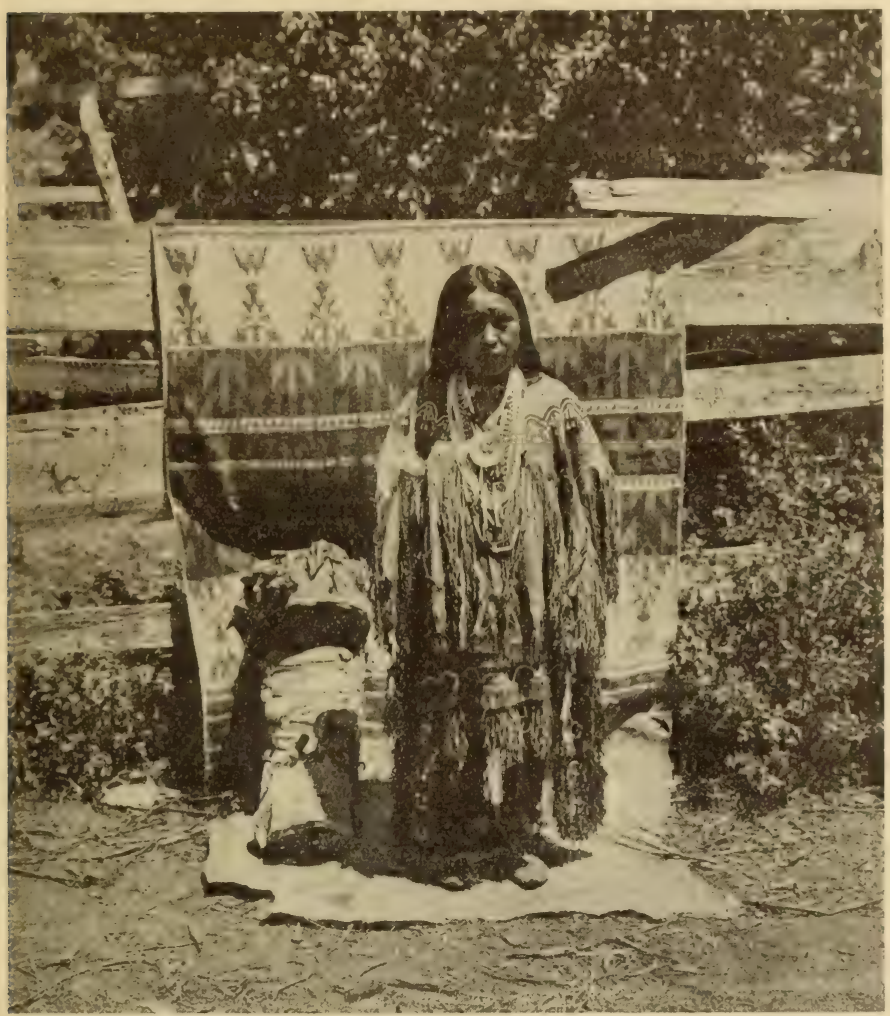

Mescalero Girl in Native Costume.

These were variously colored by dyeing, usually green or red. When cloth became more easily procurable, white cotton trousers with the lower part of the legs 


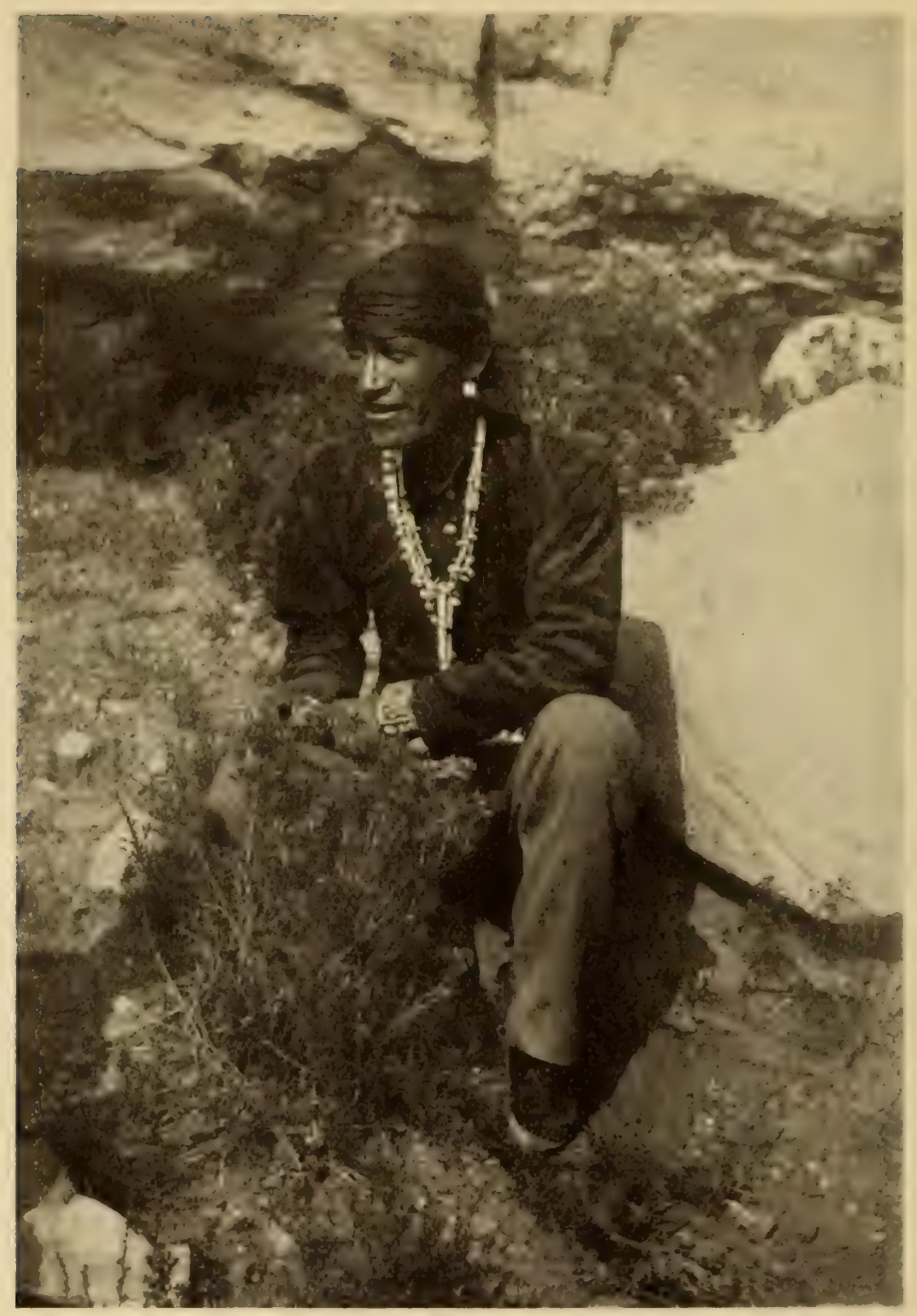

Navajo Man.

(Photo. by Howard McCormick.) 
slit on the outer side were adopted. The upper garment was preferably of velveteen and answered the purpose of both shirt and blouse. I handkerchief or colored strip of cloth is worn about the head to confine the hair. The moccasins which are colored brown come up around the ankle where they are fastened by a silver button. The robe, until recently, was the woolen blanket manufactured by the Navajo women of the type now generally called a "chief."

The women wore a dress consisting of two rectangular pieces of woolen goods sewed up the sides and part way across one end, openings being left for the neck and arms. The decorations of these dresses were of a peculiar sort, restricted to the two ends and symmetrically arranged. Leggings of black wool are worn and buckskin moccasins over these.

Both men and women wear much silver jewelry of native manufacture. Necklaces and belts are the most elaborate but the bracelets and the finger rings set with turquoise are attractively made.

INDUSTRIAL ARTs.

Pottery. All the nomadic peoples appear originally to have made crude pottery. The Jicarilla Apache, the Navajo, and the Pima and Papago, still make what is required for household purposes. The Jicarilla in former days were rather noted for the excellent cooking pots which they made. Their ware was never painted 
and was without decoration other than ridges or series

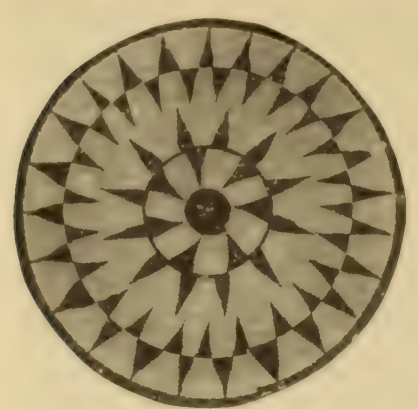

San Carlos Apache Tray. of points modeled in low relief usually near the top. The vessels are made in a similar manner to that employed by the Pueblo peoples but they are fired with pine bark which gives them a lustreless black surface. As the pots cool they are coated with piñon gum which is said to prevent their breaking.

The Narajo make ressels similar in appearance. They are usually cylindrical in shape and with buckskin stretched over them are used in ceremonies for drums.

The Pima and Papago, having built up their vessels by the usual method mold them with a paddle applied to the outside while a curved stone is held inside to preserve the shape. They are polished with smooth stones and then given a slip of shale which contains red ochre. 1 The burning is done in a small pit, mesquite brush jor decayed willow sticks being used for fuel. The designs are painted on after the first burning with gum obtained from the mes-

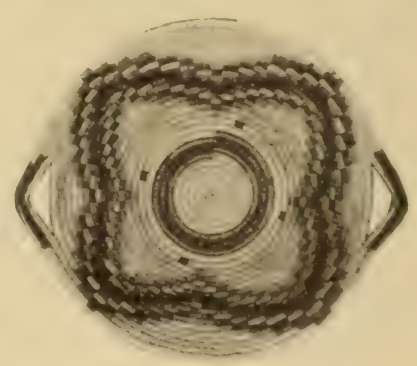

Jicarilla Tray. quite for paint. This is pale when applied but after a 
few minutes of refiring becomes derep black. Vesseds are sometimes given a coating of white clay on which designs in black are painted. The vessels most in demand are large pots which are supported on threebranched sticks and placed in the shade for the storage of drinking water. The ware is sufficiently porous to allow rapid evaporation which keeps the water delightfully cool.

The pottery of the nomadic peoples as compared with that of the village peoples is very inferior in appearance and variety but is well adapted to the limited household uses to which it is put.

Basketry. It is in basketry that the mechanical and artistic skill of the nomadic peoples is best displayed. The baskets of both the Jicarilla and the Mescalero are quite different from those made by the Western Apache, the Yavapai, and the Pima. The Jicarilla baskets are of the coiled or sewed sort, the foundation is of a single twig of sumach or willow. The sewing material is made from similar twigs by splitting them into three parts and separating the sap wood from the heart. The sap portion, which is that used, is trimmed to the proper size and that required for designs is dyed. The old dyes were made from the root bark of the mountain mahogany which gives a red and the root of the barberry which gives yellow. At the present time aniline dyes are used and the colors are gaudy and varied.

The patterns are geometrical: triangles, rectangles, and bands. The names of these designs indicate that they represent certain natural objects such as moun- 
tains, houses, plets of ground, trails, and gates. It is seldom, however, that they are combined in such a way as to make a connected composition. The Jicarilla at the present time make almost no use of baskets except

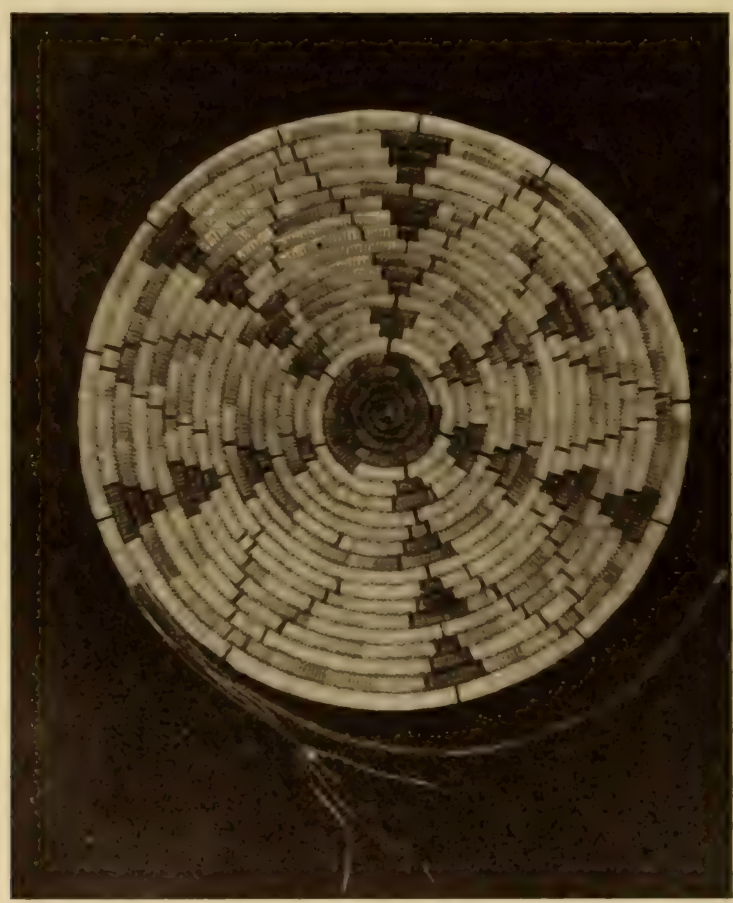

Mescalero Lnfinished Basket.

water jars. These are made of close coiling in the shape of a jug. The inside is coated with piñon pitch which has had its consistency reduced by boiling. This renders the ressel water-tight and provides an 
easily cleaned surface. The outside is kept white by frequent applications of white earth. Two loops of leather or hair are made on one side through which the carrying strap passes.

The Mescalero also make coiled baskets but since they use two rods side by side in each coil of the foundation their baskets have quite a different appearance. The material used for sewing is obtained chiefly by

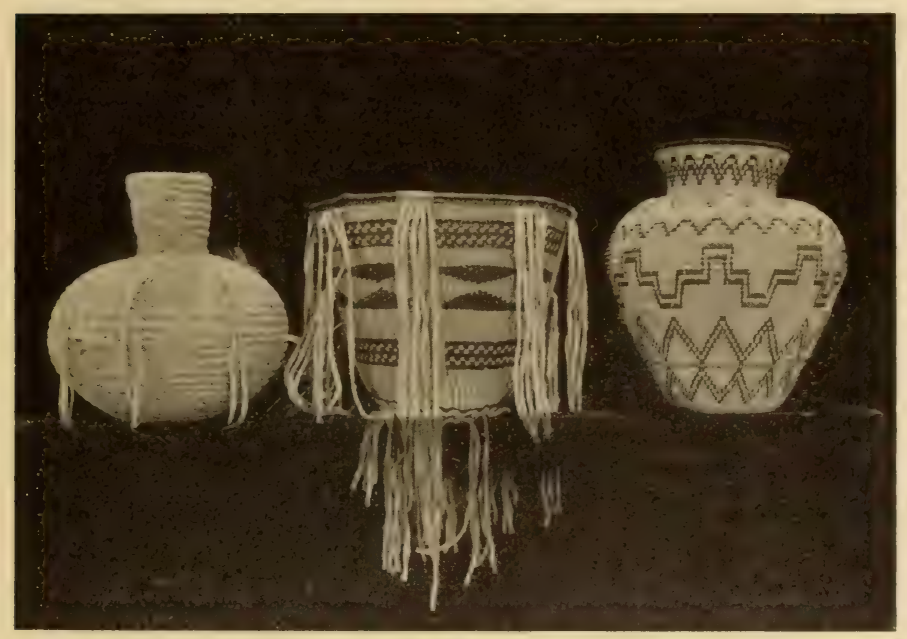

Jicarilla and San Carlos Apache Baskets.

splitting the leaves of the narrow-leaved yucca. These are used green, partly bleached to a yellow or entirely bleached to white. A red material is obtained from the root of the yucca. These decorated baskets are made principally for sale although they are used to some extent for storage. The water jars are similar in 
shape to those made by the Jicarilla but they are frequently pitched on the outside as well as inside. Burden or earrying baskets are still in common use. They are made by varied processes of twining which produee decorative effects. The material most de-
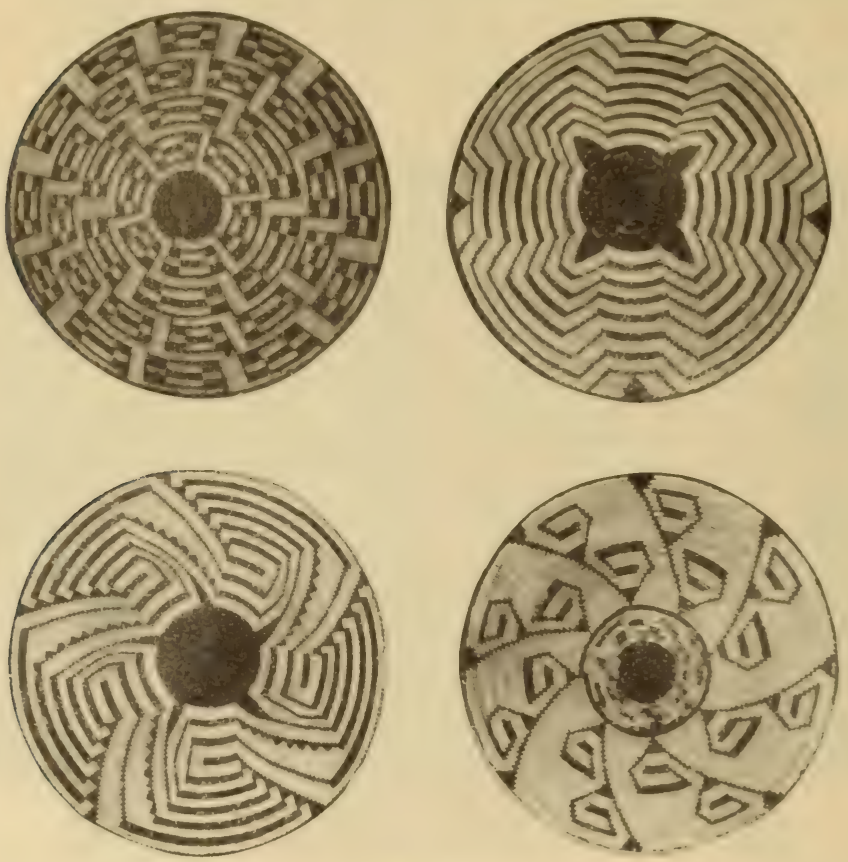

Pima Trays.

sired is mulberry the twigs of which are exceedingly durable. In most cases the women do not assign such names to the designs as would lead one to think the patterns are intended to be symbolic. One old woman, however, pointed out on a very crude basket the milky 
way, morningstar, and a rainbow. These particular things are considered very saced; and in spite of the denials of many of the women it is probable that Mescalero baskets do often have symbols on them which are expected to benefit the users of the basket.

The basket makers of Arizona, the Apache, Yavapai, Pima and Papago, make baskets in black and white exclusively. The Apache and Yavapai baskets are made on a single rod, coiled foundation, either of aromatic sumach or willow. The warp or sewing material, is of sumach, willow, or cottonwood, and is prepared as has been described above. No dyes are employed, but for black, the outer portion of the dried pods of the martynia, sometimes called devil's claw, is used. The patterns are continuous, radiating from the center in zigzags or in bands encircling the basket. They are usually geometrical and apparently are not symbolic. The Yarapai, who of those named, perhaps produce the most beautiful baskets, frequently depict men and animals, conventionalized to meet the requirements of basket work. Carrying baskets of the Western Apache are twined and are made of the same materials employed by the Mescalero. In twining, two rods of the foundation are enclosed each time between the twists of the twining strands. Strips and fringes of buckskin are usually used on these baskets. They generally make their water jars by twining. They give them a coat of red ochre and finely pounded juniper leaves before the piñon pitch is applied.

The baskets of the Pima and Papago which closely 
resemble those of the Apache in appearance are made with a bundle of finely divided leaves of bear grass or cattail reeds for the coiled foundation. The sewing materials are similar to those used by the Apache

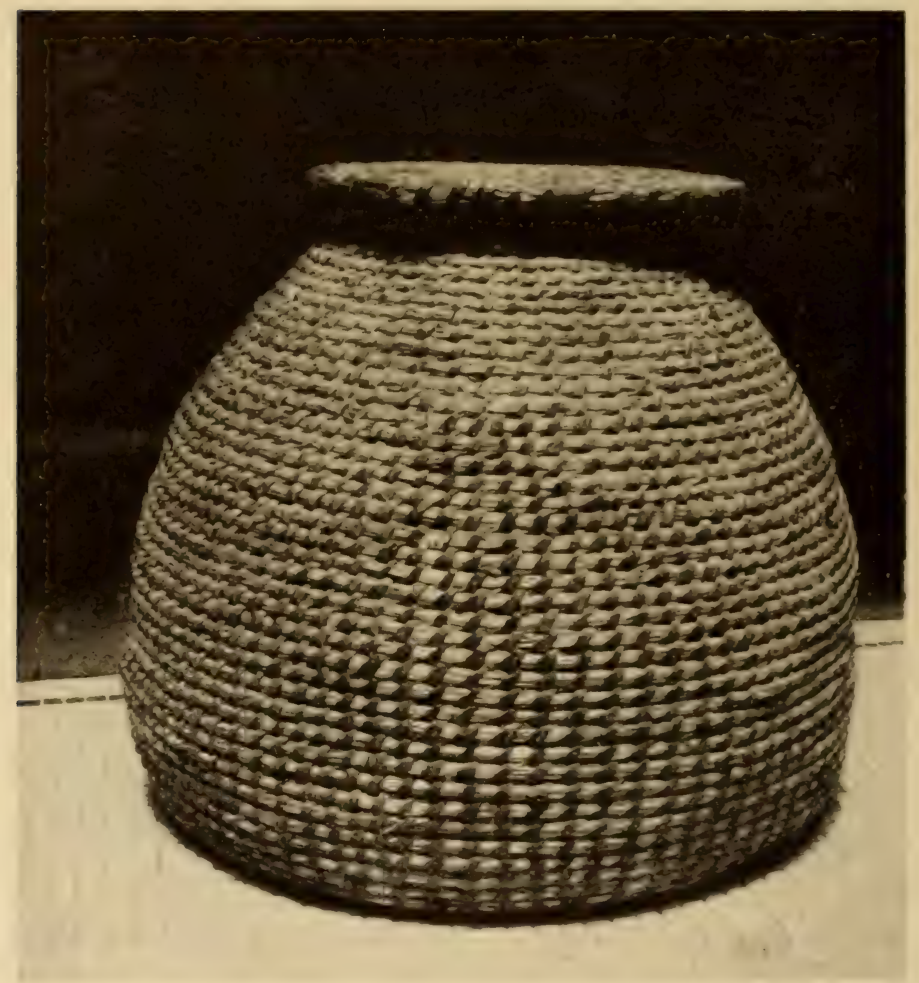

Pima Storage Basket.

except that the Papago often use yucca leaves in baskets intended for sale. The designs resemble those found on Apache baskets except that the bands are usually narrower. 
The Pima and Papago also made large storage baskets, six feet or more in diameter. The foundation is a large bundle of wheat straw coiled spirally, the coils being bound together by frequent wrappings of tough bark strands. These two tribes also make plaited baskets

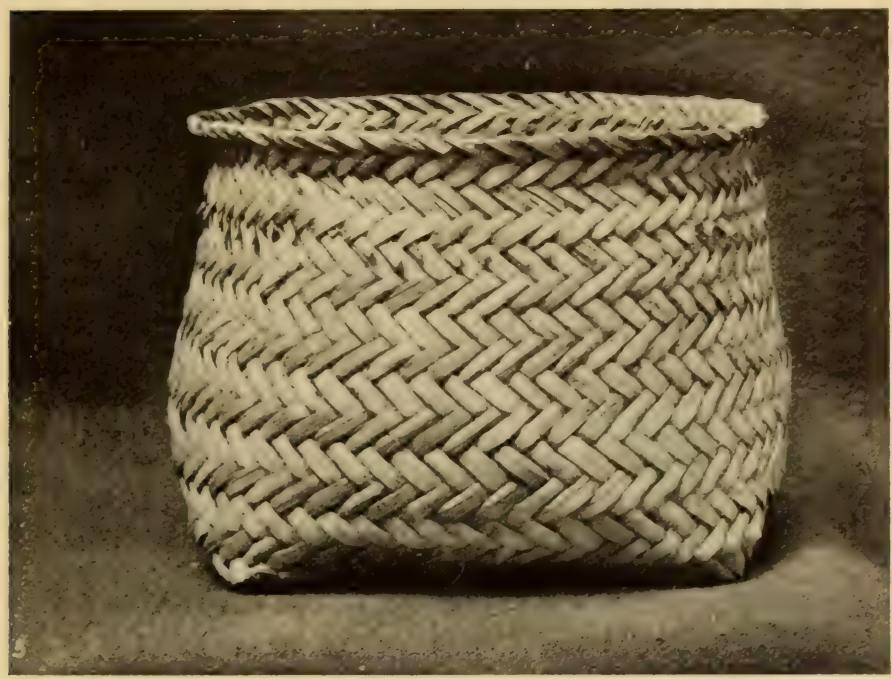

Papago Plaited Basket.

and mats, using for the purpose the leaves of the sotol, a yucca-like plant. In place of the carrying basket they used a net made of agave fiber twine. This is stretched on a frame of sticks which keeps it in proper form for carrying on the back.

- Few basket-makers excel the Chemehuevi in the technical perfection and pleasing decoration which their baskets display. They resemble in a general way the baskets of their neighbors. 
Weaving. It is not known that any of the nomadic peoples with the exception of the Pima and Papago raised cotton or manufactured cloth by weaving before the coming of the Spanish. The Pima have

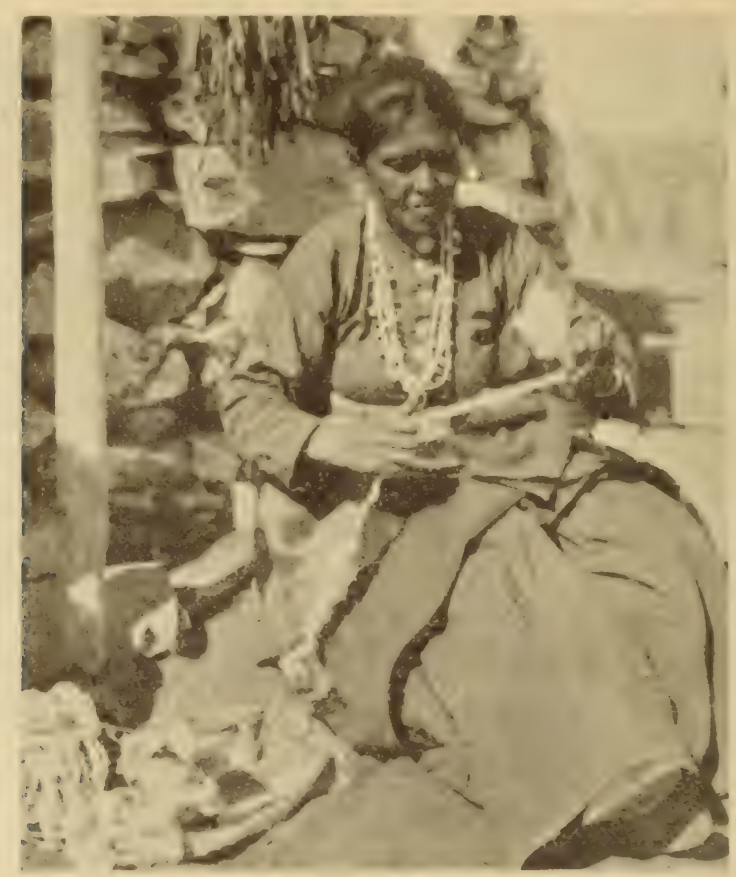

Navajo Woman Spinning.

discontinued the manufacture of cotton cloth in recent years, but still weave belts.

That sheep were introduced in the southwest in the seventeenth century we know, for certain of the Rio Grande villages are credited with flocks of sheep at 
the time of the rebellion in 1680 . The Navajo were the only nomadic people to turn to a pastoral life.

When blankets are to be made from the wool, it is sorted, spread out on a sloping stone, and then washed

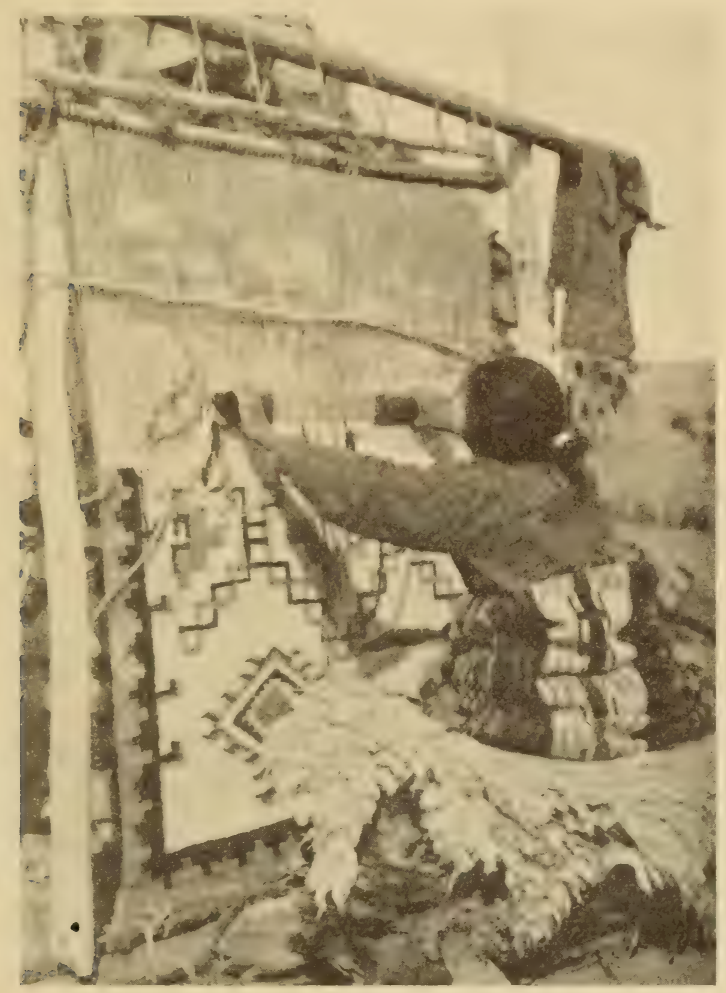

Navajo Woman beating down the Woof with a Batten Stick.

by pouring hot water containing an extract of the yucca root over it. The carding is done with a pair of ordinary European hand cards and there is no evidence of 
a more primitive means ever having been employed. The spindle, however, is the same as that found in cliff ruins. It consists of a small stick at the base of which is a wooden disc to give momentum and facilitate the winding of the yarn.

The loom is a simple frame in which the warp is placed vertically. The weaving is done beginning at the bottom, the blanket being lowered as the work progresses. No shuttle is used; the yarn is inserted with the fingers or by the aid of a small stick. The woof is forced down by pressure with a fork or by the blow of a batten stick. The weaving is peculiar in that the woof strands of a particular color are not carried entirely across the blanket, but only as far as that color is required for the design. It is then dropped and another color taken up.

In plain weaving the warp is divided into two divisions or sheds by attaching alternate threads by means of loops of yarn to two small sticks. The sheds or sets of warp strands are separated by pushing down a small rod and crossed by pulling up on the stick to which the loops are attached.

Diagonal weaving is done by making three instead of two sheds, by this means every third strand of the warp can be lifted and a raised pattern is made with a slope to one side or the other. By reversing the direction of this slope, diamonds are produced. This style of weaving is used particularly in the saddle blankets.

Sashes are woven on a similar loom which since it is small is stretched on a forked stick or by fastening one 


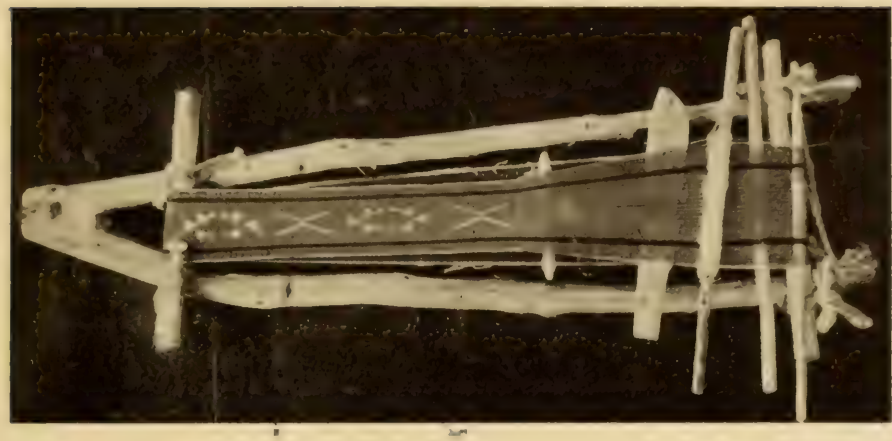

Navajo Belt Loom

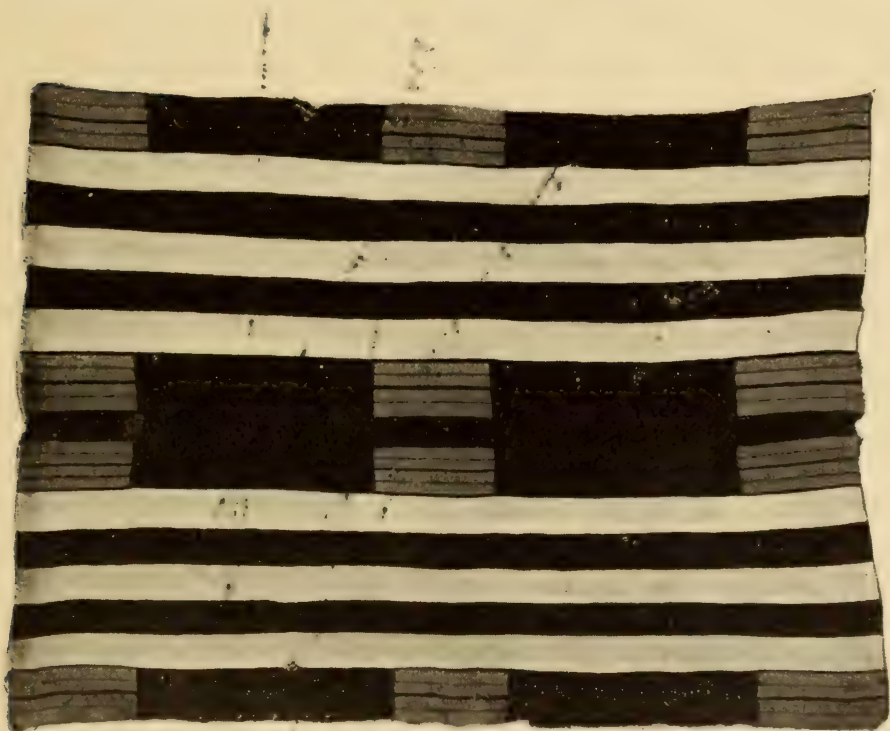

Navajo Chief Blanket. 
end to a tree and the other to the waist of the weaver. The patterns are brought out by causing the warp instead of the woof to appear in the desired places.

The colors employed are the natural white and brown of the well-washed wool, a gray which results from the mingling of these, and various native and eommercial dyes. Black they produce by combining a concoction of sumach (Rhus aromatica), roasted ochre, and piñon gum. Dull red was obtained by placing the yarn in a liquid made by boiling the bark of alder and mountain mahogany in water. Lemon yellow was secured by the use of the yellow flowers of the shrubby Bigelovia grancolens and a native alum. Old gold resulted from rubbing into the wool a paste made of sorrel roots and crude alum ground together. In rather early days indigo blue was obtained from the Mexicans and displaced an earlier native blue. I bright scarlet and a rose color were obtained in the early history of blanketmaking by ravelling woolen cloth obtained from Europeans. Blankets containing such material are called "bayeta" from the spanish name of flannel used in the soldiers' uniforms. There were a few years during which the Navajo frequently bought yarn ready spun and dyed from the traders. These blankets are usually called Germantowns.

The early examples of Navajo weaving often have broad stripes, closely resembling the blankets made by the Hopi. Later many geometrical figures appear, standing alone, or combined with horizontal and rertical stripes or with each other. The general arrangement 
is usually symmetrical, but both the completed pattern and the individual designs lack the exactness of machine work.

The more common designs are squares, parallelograms, diamonds, and triangles. Diamonds are often formed by intersecting diagonal lines which run across the blanket, half diamonds resulting at the sides. The outlines of the figures in many cases are broken with right angles, that is, made to consist of a series of steps. These designs have Narajo names descriptive of them, such as "sling" for the elongated diamond, "three "points" for the triangle. The ordinary diamond is called "star large," by which the morningstar is meant. This and the zigzag line representing lightning and triangular masses called clouds have more or less religious connotation and may be symbolic in their intention. The swastika, which is now often seen on blankets, has recently been introduced in response to the commercial demand for it.

It is proper to suppose that the Navajo who formerly did not weave learned the art from their Pueblo neighbors who are known to have practised it in prehistoric times. They seem to have taken over the loom and the general methods of preparing the yarn and wearing it. The practice of making designs in colors which do not cross the entire width of the blanket seems to have originated with the Navajo. The Hopi robes have stripes running entirely across them; but the skirts of the women and the shirts of the men have the designs added by embroidery after the blanket is woren. The 
method employed by the Navajo of making the design while the weaving is in progress is similar to that with which they were familiar in basket making. It is then

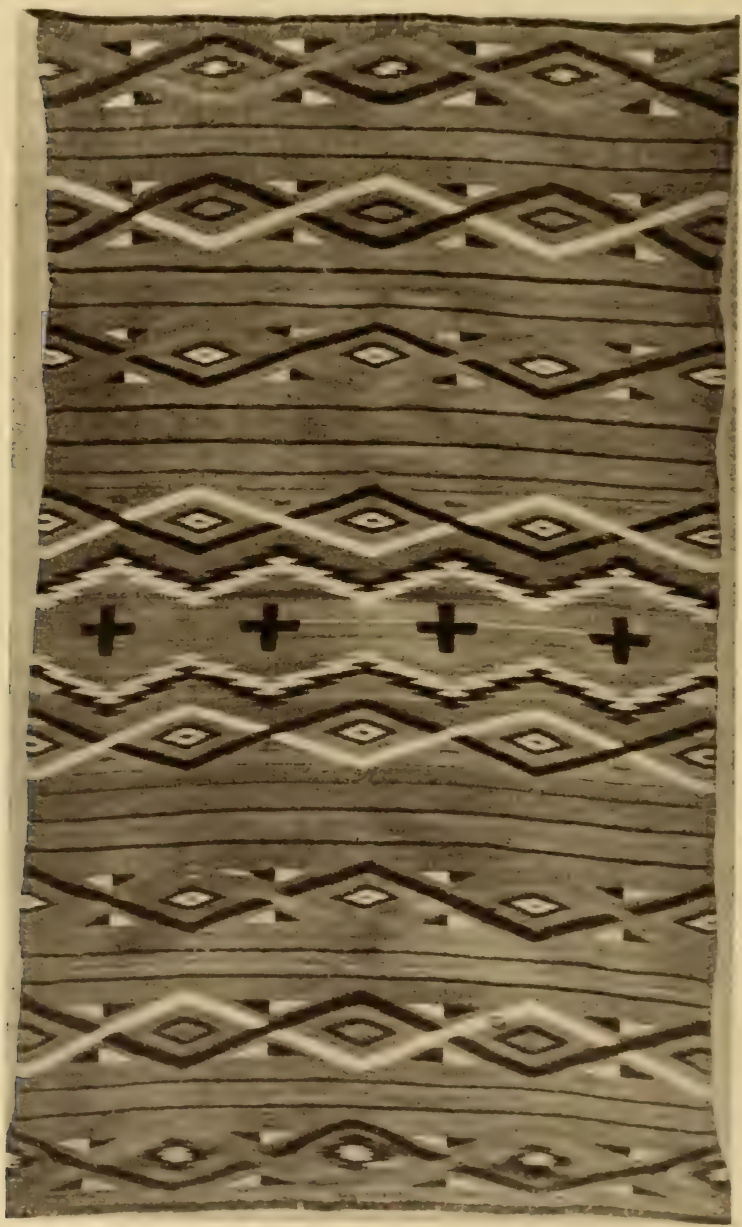

Navajo Blanket. Sage Collection. 
possible that the designs now found on Navajo blankets were in large measure adapted from basketry designs. Unfortunately, the Navajo at the present time make very few baskets, so that a comparison between the designs on blankets and baskets is impossible.

Silverwork. The art of metal working is certainly an introduced one in the Southwest. It is practised by many tribes in North America usually with the softer metals like German silver. The Navajo, however, use Mexican silver coins and have become very expert. Most of the work is done by pounding the material on a small anvil with an ordinary steel hammer. A small forge with bellows is used to soften the metal and to melt it when it is necessary to make casts in molds. The hammered pieces are decorated by stamping designs on them with steel dies which are prepared by the Navajo themselves.

The products are bracelets, finger rings set with turquoise matrix, large oval discs for leather belts, and neck ornaments. These neck ornaments are usually a string of hollow spherical beads and a pendant consisting of two joined crescents. Between the beads are often placed conventionalized squash blossoms.

Beadwork. The Apache do much work with glass beads. These are either sewed to articles of leather and buckskin, such as purses, tobacco bags, awl cases, belts, and moccasins; or they are woven in a belt loom having a warp and woof of cotton thread. The beads are strung on the woof by means of two needles which pass a double thread through the beads and on either 
side of the warp strands. The designs are mostly geometrical. similar to those found in basket work. but realistic ones are found in which circular saws. bows and arrows, and butterflies are represented.

Social Organizatios.

The Eastern Apache, as far as can be discovered, have no clans, or other divisions regulating marriage. The Western Apache and the Navajo have clans which are exogamous and seem to serve no other purpose than that of regulating marriage. The explanation of the names, which are geographical ones, is that in mythical times a band camped for a time at a place where a cottonwood tree stood by a stream or where some accident befell them and from this tree or circumstance, a name was given the clan. Were one to trust to these myths he would conclude that the clans represent former geographical or political groups. This is probably not the case for the rarious clans are now completely scattered orer the country occupied by these two peoples. An exogamous group can hardly remain a local or political one since the husband in each family must belong to a clan different from that of the wife.

Dr. Washington Matthews by using several informants found fifty-one clans among the Navajo. Most individuals are well acquainted with the prominent ones. In sereral cases Matthews found a grouping of 
clans into small units, the tie being such that marriage could not take place within the group; but no well defined phratries appear.

It was only after persistent inquiry that anything concerning clans could be learned among the Irizona Apache, although Bourke published a list of such clans many years ago. The difficulty seem to be the result of real decadence in the feeling for clans and clan restrictions. The myth recounting the origin of the clans which was finally secured is similar to that told by the Navajo and many of the names of the clans are the same. Among the Navajo and Apache descent is in the female line, the children belonging to the mothers' clan.

Among the Pima, Russell reports the existence of five groups in which descent was traced in the male line. These he says have no relation to marriage or ceremonies and have no internal organization. It seems probable that such divisions in order to exist must some time have had a greater significance than they appear to have now.

\section{Social Customs.}

The young men among the Apache in former days secured their brides by displaying their ability as hunters. The man came to the lodge of his chosen maiden with a deer which he placed outside. If her family were willing to have him as a son-in-law, the 
deer was taken and eaten. The young man lived with his father-in-law for some time and hunted for the support of the family. A strict mother-in-law taboo exists among the Athapascan tribes of the Southwest. The young man must never meet his mother-inlaw or any of her sisters or her mother. They are never permitted to be in the same room together or directly to address one another. When it is absolutely necessary for communication to take place between them, one shouts from a distance to the other using the third person. "Tell him to come and eat, his dinner is ready," his mother-in-law may call, and leave her lodge while the young man comes to eat. The penalty for the infringement of this taboo is believed to be blindness inflicted by some supernatural power. The Indians assign no other reason for the existence of this restriction and probably no other is felt than that such meetings and intercourse are improper.

The adult dead are buried at a distance from the camping places and the graves are covered with stones and brush. The personal property is placed by the grave and a horse or two is generally killed near by. The Jicarilla used to cut off the heads of the horses so sacrificed as is the custom among some of the Plains tribes. Dead infants are usually suspended in trees wrapped in their cradles. The reason for this different treatment of children is not known but the custom has been noted in the preceding pages as a prehistoric one in this region. Great fear is shown of dead bodies and all objects associated with them. The Apache burn 
the houses and the Navajo desert them after a death has occurred. Widows and widowers are unwelcome guests for several months among the Jicarilla and are forced to camp apart.

\section{Political Organization.}

The government of the nomadic tribes is much less formal than that of the sedentary peoples. The Jicarilla now have a chief elected from each of the two bands. One of these is recognized by the agency officials and by the Indians themselves as tribal chief. In earlier times the two divisions appear to have been politically independent, each having chiefs of coördinate rank. Both war and hunting parties were under the control of a head man who directed them. While it is probable that the same individual frequently acted in this capacity it is not certain that the office of war chief was definitely bestowed.

The other Apache and the Navajo were divided into many small bands each with its chief who held office for life and was frequently succeeded by his son if he proved himself efficient. The office seems to have been bestowed by common consent. The Navajo and the Apache bands united in common action against other tribes and against the Mexicans and Americans under the leadership of such men as had proved themselves capable leaders. As examples may be mentioned Geronimo who led several bands of the Apache for a 
number of years, and Manuelito among the Navajo who led them in their fight against the Americans.

Each Pima village had a chief, a public crier, and a council. The tribe as a whole had a head chief who held his office for life or at the pleasure of the village chiefs who chose him, and who often designated his son to be his successor.

\section{Games.}

The Apache and Navajo have several games which are played partly for amusement but largely in the hope of gain. As elsewhere in North America, these games have a semi-religious character. There is a myth which explains their origin and songs and prayers

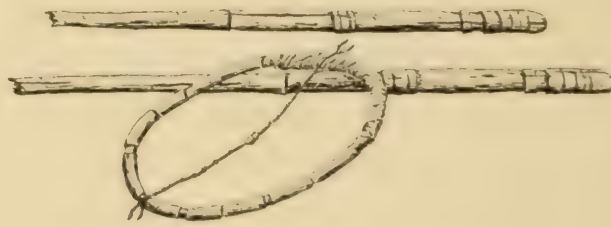

Hoop and Pole Game. Apache.

to bring about success in playing. The game to which most dignity is attached is the hoop and pole game. The implements employed are a hoop with incised bands and a string stretched along the diameter in which many knots are tied, and two long poles, the 
larger ends of which have a number of incised rings. To play it two men stand side by side at one end of a level streteh of ground. One rolls the hoop down this stretch and both throw the poles after it. If the hoop falls on the butt of one of the poles a count is made according to the knots of the string or the incised rings which happen to be in contact with the rings cut into the pole. The incised rings are named for the lightning and the hoop represents a snake. Women are never allowed to witness the playing of this game.

A guessing game is played by a number of players divided into two parties. A man representing one of these parties hides a ball in one of several piles of sand or in a moccasin. The other party must guess its location.

The women play a game with three split staves which are dropped vertically on a stone. There are several counts according to the position in which they fall. If the split side of all three sticks is up, the count is five, but if the rounded sides of all three are up, the count is ten. The score of the game is kept by moving a stick for each player around a circle marked by forty small stones. There are openings at four points, called rivers. If the stick of a player falls into a river she must return it to the beginning place again. 
RELigion.

Ceremonies. The religious practices of the nomadic peoples have much in common with those of the Pueblos. They make sand or dry paintings, those of the Navajo being very numerous and very elaborate. Masked or otherwise distinguished individuals represent divine persons in the ceremonies. Pollen is strewed and is the regular accompaniment of prayers. The Navajo make use of prayer offerings and also have fetishes which are used both in hunting and in the care of their flocks and herds. The Apache make much use of sacred beads and feathers which are worn about the person on the wrists or as a bandolier across the breast.

A ceremony held for girls when they attain womanhood is considered of prime importance among the Apache tribes and has been maintained while other ceremonies have fallen into neglect. The essential features of these ceremonies are numerous songs and prayers uttered by the priest hired for the occasion, dancing by the girl or girls for whom it is held, a footrace by the girl, and the painting of the girl and of the spectators, who expect good fortune as a result.

The Jicarilla ceremony is peculiar in that a boy is associated with a girl in the ceremony. He is called Yinaiyesgani and the girl Esdzanadlehi. These names are those of the culture hero and his grandmother, but they are undoubtedly associated also with the sun and the moon. 
The Mescalero ceremony lasts four nights. A special lodge is built with many ceremonial observances. Behind the fire in this lodge the girl sits and near it the priest. Early in the evening he begins singing the songs of the ceremony keeping count of them by placing small sticks in a circle about the fire beginning at the east. The songs are mostly sung in groups of four, the priest stopping between each set to smoke, pray, and sing a special tobacco song. About twenty-five songs are sung during each of the first three nights ending about midnight. The girl stands and dances during some of the songs, the movements changing in accordance with the character of the songs.

While this is taking place inside, another ceremony occurs by a fire in front of the lodge. Masked and painted men representing the Ganhi appear and dance about the fire. The Ganhi are believed to live in the interior of certain mountains and rocks where they have a world which is more beautiful and better provided with food than this. They apparently correspond to the kachinas of the Pueblo Indians. The Indians generally, both men and women, join in the dances, during the ceremony. The women choose their partners and receive a present from them at the end of the evening's dancing. The entire community is feasted during the days of the ceremony.

On the last night the priest sings all night long repeating the songs of the previous nights. By including or excluding certain songs he makes the prescribed ones describing the dawn come just as dawn appears. The priest paints a red disc to represent the 
sun on the palm of his hand with four beans streaming toward his fingers and four more toward his wrist. This painting he applies four times to the crown of the girl's head. He then paints four lines outward from the corners of her mouth and puts yellow pollen on her forehead. The priest paints the women and children present with red on the right side of their faces, the soles of their feet, and their breasts, and dusts pollen on their left cheeks.

With appropriate songs the priest then conducts the girl out of the lodge toward the east where a buffalo robe is spread. On this he paints four footprints in pollen and four in red ochre. The girl having stepped on these, runs first around a basket filled with feathers which are presented to her by attendant girls and then to an indicated bush or tree in the distance.

While this ceremony is primarily for the benefit of the girl, securing for her a happy, useful, and honorable life, it is intended to bring good fortune to the entire community. The songs sung show how greatly the feeling for number and balance accentuated by references to certain colors and contrasted qualities has pervaded Southwestern ceremonials. The following song is sung when the poles forming the frame of the lodge are tied together.

Nayenezganin's male lodge-poles of blue are tied with a sunbeam. IsdjanaLijn's female lodge-poles of white are tied with a rainbow,

The second time they are placed together.

Nayenezganin's male lodge-poles of yellow are tied with a sunbeam, The third time they are placed together.

IsdjanaLijn's female lodge-poles of black are tied with a rainbow, The fourth time they are placed together. 
The Jicarilla have an annual festival which resembles very elosely that held at Taos. The entire tribe camps near a large lake in the southwestern corner of their reservation. The two bands, the Ilanero and the Ollero, pitch their tipis on opposite sides. On the day preceding the public festival, the young men of each band accompanied by the older men go some distance from the camp and hold a preliminary race by which those

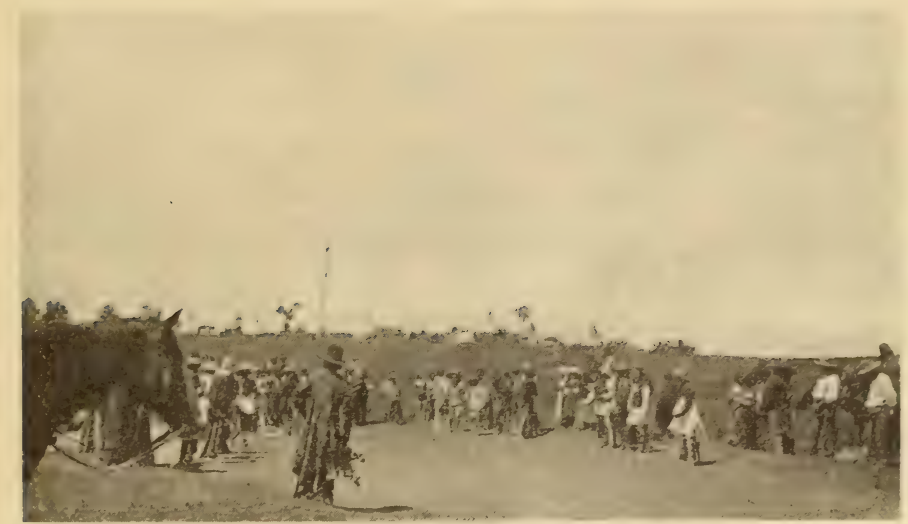

Jicarilla Relay Race.

who are to run in the final race are chosen. Two booths are constructed, one at each end of the race course. From these the two bands issue in irregular groups surrounding a drum. The dancers have cottonwood branches in their hands and are led by a man carrying a standard from which flies a cotton cloth and on the top of which are two ears of corn. The two bands of dancers approach each other and pass, 
each going to the goal of the other. During the night and the early morning, ceremonies are held in the booths, a sand painting is made, the racers are painted, and prayers are said for them by priests. About noon the relay race takes place, practically under the same conditions and in the same manner as has already been described for Taos.

The Jicarilla have a healing ceremony held at the request of someone who is ill. A large place is enclosed by a brush fence. At one end of this a tipi is fixed or a booth is made. Within this a sand painting is drawn representing many animals. A buffalo skin is stretched over a pit and beaten like a drum, the moccasins of the patient being used for drumsticks. The shoulder blade of a deer or antelope is rubbed over a notched stick producing considerable noise. Rattles are also used as an accompaniment to loud singing. This singing and noise is intended to scare away the evil influence which has resulted from the patient's having crossed the tracks of a bear or rattlesnake. Within the brush enclosure a dance is held at night. Men painted in two styles and decorated with fir boughs come in and perform many seeming miracles such as making corn increase in a pot, and taking rabbits from a seemingly empty ressel. These two sets of dancers probably correspond to the Cuirana and the Koshare of the Rio Grande pueblos. The Ute hold a ceremony similar to this each spring known as the bear dance.

The Navajo have dereloped many elaborate cere- 
monies each of which is under the eontrol of a school of priests, the numbers of which are maintained by those who apply for initiation and training. These ceremonies for the most part, are held at the request and expense of some individual who is ill or indisposed.

A special conical lodge of logs covered with earth is built in which the ceremony is carried on. All the ceremonies seem to be alike in certain particulars such as the use of a sweat bath, the making of many sand paintings, and the singing of a great number of songs. At some point in the ceremony, masked men representing the more important gods of the Navajo enter in a procession. Prayer offerings are made of sections of reeds filled with tobacco. They are painted with the colors and are deposited in the particular situations prescribed for the deity for which they are prepared.

On the last night a public performance is held which is largely attended. Besides the masked dancers representing the gods, clowns appear who play tricks on one another and often act in a very obscene manner.

The songs and prayers are beautiful in their imagery and have many references to natural elements to which sex is attributed. Varying positions and movements are indicated in an established order. The number four prevails in the prayers and songs themselves, and they are generally repeated four times with minor variations. The following prayer recorded by Dr. Matthews belongs to the Night Chant.

Tsegihi.

House made of the dawn. 
House made of evening light.

House made of the dark cloud.

House made of male rain.

House made of dark mist.

House made of female rain.

House made of pollen.

House made of grasshoppers.

Dark cloud is at the door.

The trail of it is dark cloud.

The zigzag lightning stands high up on it.

Male deity!

Your offering I make.

I have prepared a smoke for you.

Restore my feet for me.

Restore my legs for me.

Restore my body for me.

Restore my mind for me.

Restore my voice for me.

Happily may I walk.

Happily with abundant dark clouds, may I walk.

Happily with abundant showers, may I walk.

Happily with abundant plants, may I walk.

Happily may I walk.

Being as it used to be long ago, may I walk.

May it be happy (or beautiful) before me.

May it be beautiful behind me.

May it be beautiful below me.

May it be beautiful above me.

May it he beautiful all around me.

In beauty it is finished.

In beauty it is finished.

Betiefs. While the ceremonies of the Athapascan tribes of the Southwest present considerable specialization and variety, the deities reverenced and the myths related about them are in the main identical. The sun is probably credited with the greatest amount of power and is most frequently referred to in song and addressed in prayer. Among the Jicarilla, at least, the earth is 
also an object of worship. The Mescalero songs give the moon a place seeond only to that of the sun. The winds are with them objects of worship as they are also with the Western Apache and the Navajo. The thunder is everywhere feared and looked upon as a mighty power seldom to be mentioned. Clouds and rain, however, have a place of much less importance than with the village people. There are sacred mountains and rivers but these are of necessity different for the different tribes.

One of the more personal gods, Esdzanadlehi, was the sole survivor of a flood or according to some, the ravages of monsters. She is probably to be identified with the Hopi goddess of hard substances. Yinaiyesgani, the culture hero, her grandson destroyed the monsters and made the world safe for human habitation. By some he is said to have a brother who is, however, quite secondary in importance. The Navajo have a series of gods who intervene in human affairs from time to time. They are believed to dwell in the ruins of Canyon de Chelly and in remote places. They are represented in the dances by masked and painted men and receive offerings and are frequently invoked. There are also gods of the water courses and springs. The Jicarilla and the Western Apache know similar gods, in several cases even using the same personal names for them. The Mescalero and the San Carlos believe also in the Ganhi who live in the interior of the mountains.

The dead are supposed to go to the lower world 
through the opening by means of which the people originally came forth.

The Indians of the southwest have many myths and tales which they relate particularly during the winter. Very many of these myths explain the origin of the world. While these vary in details, according to the tribe and the individual who tells them, they agree as to the general facts. The San Carlos tell of a time before the world existed when Spider, Mirage, Whirlwind and Black Obsidian lived suspended in space. Obsidian rubbed his side and from the removed cuticle produced the earth. They then lifted up the sky and supported it at each of the four corners with an obsidian pillar inside the core of a whirlwind. People and animals came to exist within the world in an unexplained manner. They were threatened with a flood and escaped by means of reeds or a ladder through an opening in the sky of the lower world, the crust of this. They were all destroyed by monsters except a girl, Esdzanadlehi. The water pitying her lonely condition became the father of a daughter who in turn by the rays of the rising sun became the mother of Yinaiyesgani. This boy risited the sun, his father, withstood serere tests as to his sonship, and secured weapons and promised aid. With these weapons he killed a giant, a monster elk or antelope, a great eagle, and many other evil things. When this work was completed and the world was repeopled by the creation of men and women from ears of corn, Esdzanadlehi went to the western ocean where she is now living in a floating 
palace of shell. Aceording to the Navajo, Yinaiyesgani lives with his brother near the mouth of the San Juan River.

Later, a man who was considered worthless because he gambled away all his property, went down a river in a hollow log, conducted by the gods. He landed at a favorable place and prepared a farm for which his pet turkey furnished the seed. He found his way to the home of a man who had all game animals domesticated. He married this man's daughter who received these animals as her marriage portion. Thus, was food supplied for mankind.

According to the myths, the various ceremonies of the Navajo were taught to some Indian who by accident or at the direction of the gods went to a ruin or other dwelling place of the supernatural beings and learned there the songs, prayers, and rites.

A long myth explains the origin of the Navajo people and their clans. The nucleus was created by Esdzanadlehi in her western home. As they journeyed eastward they met various parties who joined them and who were given names according to the attendant circumstances of their meeting. Other myths explain the origin of fire, and of night and day. There are many animal tales, a large number of them being associated with coyote who is now represented as being exceedingly keen of wit and again as very stupid. These myths and stories told to considerable companies during the evenings of winter are sources of both amusement and instruction. 


\section{('hapter IV.}

\section{CONCLUSION.}

Ix the preceding pages an attempt has been made to describe briefly the modern and prehistoric cultures of the Southwest. In doing this some pains have been taken to point out the influences of environment and the results of Spanish and American contact. It may be well in conclusion, to ask, if not answer, some questions regarding the relationship of these peoples of the Southwest to each other and to their neighbors. When the relationship of tribes is considered it is well to be certain what sort of relationship is in mind.

Many are interested in the physical appearance of men and endeavor to trace the distribution of mankind by this means. Now such physical characteristics as the color of the skin, the character of the hair, the shape of the head, the contour of the body, are inherited, and two peoples who closely resemble each other in these respects may be presumed to have descended from the same ancestors. When two peoples so resembling each other are found separated, one or the other must have migrated or those who once lived between the two peoples have disappeared from some cause.

If then we ask whether physically the prehistoric people, the modern sedentary, and the nomadic people are of common descent, the question must be answered 
from observances of the bodily appearance of these people and the remains of the prehistoric people which have been so splendidly preserved. There is no marked difference in the color of the skin, they are all of the chocolate brown found generally in North America. Nor is their hair in any way different, it is coarse and round in cross section, and therefore straight. In stature according to Dr. Hrdlicka there is considerable variation:

$\begin{array}{lcll} & \text { Inches } & & \text { Inches } \\ \text { Maricopa } & 68.8 & \text { Walapai } & 66.3 \\ \text { Yuma } & 67.7 & \text { Isleta } & 66.2 \\ \text { Pima } & 67.3 & \text { Mescalero Apache } & 65.9 \\ \text { Mohave } & 67.5 & \text { Southern Ute } & 65.6 \\ \text { Jicarilla Apache } & 67.4 & \text { San Juan } & 65.3 \\ \text { Navajo } & 67.4 & \text { Acoma } & 64.9 \\ \text { White River Apache } 67.3 & \text { Taos } & 64.6 \\ \text { Papago } & 67.2 & \text { Hopi } & 64.4 \\ \text { Havasupai } & 67.1 & \text { Zuñi } & 64.3 \\ \text { Yavapai } & 67.08 & \text { Jemez } & 64.05 \\ \text { San Carlos Apache } & 66.7 & \text { Sia } & 63.9\end{array}$

The proportion of the length to the breadth of the head has been much used in describing and classifying races. The skulls recovered from the ruins of southern Utah are extremely long and narrow. Of the modern peoples of the Southwest only the Pima and Papago and some of the people of Taos have heads of this shape. The heads of the remainder of the prehistoric people, those of the Maricopa, Yuma, Mohave; and most of the sedentary people, the Hopi, the Zuñi, and the Rio 
Grande Pueblos generally have moderately broad heads. Only the Apache, the Harasupai, and the Walapai have heads which are exceedingly broad as compared with their lengths.

When various physical characteristics are compared, it appears that the Narajo and Hopi closely resemble each other in bodily form, and that the Apache. Walapai, and Havasupai are similar. Too little is known of surrounding tribes to warrant any conclusion as to relationship outside of the area.

The languages of the Indians of North Imerica have proved a most convenient and definite means of classification. There have been found to exist related languages spoken over large areas. The Algonkin is. or was, spoken in much of the eastern portion of North America and by several large tribes living at the eastern base of the Rocky Mountains. On the Pacific Coast. on the other hand, there are many languages unrelated to each other, or to any other known languages. Two languages are considered related when they have more words or word elements in common than can be explained as the results of borrowing or accident.

In the matter of language nothing can be said concerning the prehistoric peoples. They did not have a phonetic method of recording language but were only able to represent an object by carving its shape on the face of a cliff. We are therefore unable to determine their relationship to existing linguistic groups. Imong the Pueblos, we have four linguistic stocks. The Hopi alone speak a language which is represented elsewhere. 
Their speech, Shoshonean, is related to the Ute, Paiute, and Comanche, and probably less closely to the Pima and ancient Mexican. The language of Zuñi has no traceable connection with any other known language. Acoma, and certain of the villages in the Rio Grande valley compose the Keresan linguistic stock. The other villages, which comprise the Tanoan stock originally had three dialects, one of which, the Piro,

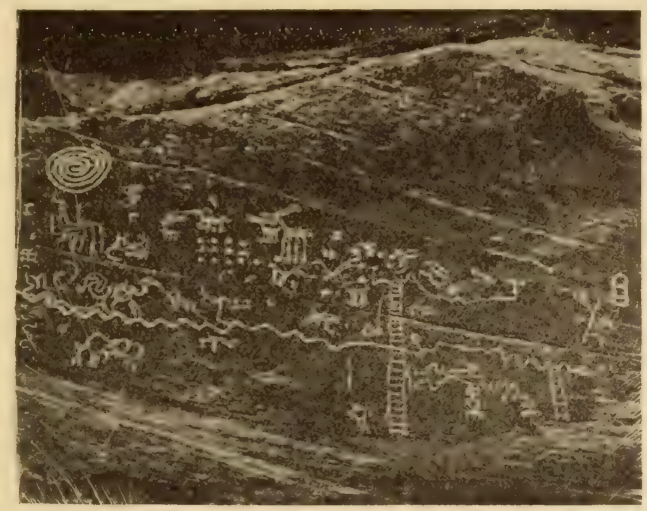

Petroglyphs, San Juan Valley.

(Courtesy of Dr. Prudden.)

is now nearly extinct. The other two are known as the Tewa and the Tiwa. The nomadic peoples, as has been"stated above, belong to four linguistic stocks, the Athapascan, the Piman, the Yuman, and the Shoshonean. The Athapascan tribes are so far removed from the other tribes speaking related languages on the Pacific Coast northward from northern California and in northern Canada, that a migration 
southward has generally been assumed. There are indications that the stock heretofore called the shoshonean is in reality remotely related to the Piman and Nahuan of Mexico. If this should be established, related languages would be found extending from Yucatan northward through the mountain regions nearly to (anada. The Yuman languages seem originally to have been confined to the valley of the (olorado from which they spread eastward to the Rio Verde and westward to the California coast.

Interest mainly centers, however, in the habits and the products of whatever people happens to be under discussion. The culture of neighboring peoples should be examined to determine, if possible, whether the particular culture is related to that of other tribes. These resemblances in culture must extend to details in order to point convincingly to a common origin. It is not enough that two peoples make baskets, but the same methods of making, and the same style of ornamentation should be found.

In the matter of culture we have seen that the sedentary people raised corn, beans, squashes, and cotton employing irrigation when necessary. The men rather than the women devoted themselves to this work. Corn was ground by means of an inclined stone slab over which a rough stone was pushed up and down. The art of spinning with a simple spindle and of wearing on a rude loom was known and practised in prehistoric times. They knew how to prepare stones and lay them in suitable walls for the construction of large 
communal houses, they also understood several methods of building with clay. They made pottery by a definite method of coiling and decorated it with various colors.

Now these particular arts and methods were known and practised southward to and beyond Peru. The people of the Southwest seemed to have shared with the Mexicans and Peruvians a common culture as far as these particular elements are concerned, and it seems probable that this much of the culture at least originated somewhere within this territory. That the origin of the main and common elements of this culture was somewhere nearer the center of the area, south of the Pueblo region it is reasonable to suppose. Culture is dispersed in two important ways, first, by migrations which do take place, but are rarer than is generally supposed, in which a moving people carry their implements and their arts to a new region; and second by uninterrupted social contact of such a sort that the members of one political and linguistic body meet for trade and intermarry, thereby transferring objects and arts from one tribe to another. It is not then necessary to believe that the Aztecs migrated from the Southwest or the Pueblos from Mexico. That this culture which includes the raising of maize is an old one we must believe. With all the force of nearly four hundred years of European contact, little change has been wrought in the life of these sedentary people. For the development of that culture and its peculiar adaptation to the Southwest, more than a few centuries surely must have been necessary. 
The nomadic peoples, particularly the Athapascan speaking tribes, only in part partake of this southern culture. They raise corn but not cotton. They learned the use of the spindle and the loom after the introduction of sheep by the spanish. They never learned or practised masonry and never lived in community houses. In some respects they were similar in their habits of life to the Indians of the Plains. They appear then to belong to the culture of the north rather than of the south. Again, it is not necessary to assume a migration of a large body of people into this area from the north, although connections of language make such a migration probable. Instead of a stream of migration, the culture may have been transferred by waves passing from people to people through ordinary social contact.

The fact that two cultures exist in this same region has usually been interpreted to mean that the nomadic people have not yet had time to adopt the culture of the sedentary people. But when two peoples are adjusted to the physical environment, each in their own way, and to each other, there is no reason why a balance so established should not exist indefinitely. Analogous relations have long endured between the roving Bedouin of Syria and Egypt and the agricultural Fellahin living in the villages of the same region. Indeed, analogous relations exist wherever there is found in the same region a rural and urban population.

While it is true that in certain main features the Indians of the Southwest share in the cultures of the 
north and the south, in many respects their culture is unique. The location of the prehistoric houses under cliffs, the terracing of the upper stories of the community houses, the details of dress, the designs found in pottery, baskets, and blankets, the relationship of clans to priesthoods, and perhaps the greater part of their ceremonial life appear to be the main elements of a special culture confined to the Southwest and probably developed there. 



\section{BIBLIOGRAPHY.}

Bandelier, A. F. Ethnology and Archaeology. Papers of the Archaenlogical Institute of America, American Series, $1,3,4$, and 5 .

Bourke, John G. The Snake-Dance of the Moquis of Arizona. New York, 1884.

Cushing, Frank Hamilton. Zuñi. Second and Thirteenth Annual Reports, Bureau of American Ethnology.

Dorsey, G. A., and Voth, H. R. Hopi. Publications of the Field Columbian Museum, Anthropological Series, Vol. 3.

Fewkes, J. Walter. Archaeology and Hopi Ceremonies. Fifteenth, Seventeenth, and Twenty-second Annual Reports, Bureau of American Ethnology; Bulletins, Forty-one and Fifty-one, Bureau of American Ethnology; Journal of American Ethnology and Archaeology, Vols. 2 and 4.

Hewett, Edgar L. Jemez Plateau. Bulletin 32, Bureau of American Ethnology.

Hodge, F. W. Ethnology and Archaeology. American Anthropologist, Vol. 6, No. 3, and Vol. 9, No. 8.

Holmes, William H. Archaeology. Tenth Annual Report of the United States Geological and Geographical Survey.

Jackson, William H. Archaeology. Tenth Annual Report of the United States Geologieal and Geographical Survey.

Kroeber, A. L. Mohave. American Anthropologist, N. S., Vol. 4, No. 2.

Matthews, Washington. Navajo. Memoirs, American Museum of Natural History, Vol. 6.

Mindeleff, Cosmos. Navajo and Archaeology. Thirteenth, Sixteenth, and Seventeenth Annual Reports, Bureau of American Ethnology. 
Mindeleff, Victor. Tusayan and Cibola. Eighth Annual Report. Bureau of American Ethnology.

Nordenskiöld, G. Thr Cliff Dwellers of Mesa Verde, Southwestern Colorado; their pottery and implements. Translated by D. Lloyd Morgan. Stockholm, 1893.

Prudden, T. Mitchell. Archaeology. American Anthropologist, N. S., Vol. 5, No. 2.

Russell, Frank. Pima. Twenty-sixth Annual Report, Bureau of American Ethnology.

Stevenson, Matilda C. Sia and Zuñi. Eleventh and Twenty-third Annual Report, Bureau of American Ethnology.

Voth, H. R. Hopi. Publications of the Field Columbian Museum, Anthropological Series, Vol. 3; American Anthropologist, N. S., Vol. 2, No. 2.

Winship, George Parker. History. Fourteenth Annual Report, Bureau of American Ethnology. 


\section{INDEX,}

Abo, 65.

Acoma, 60, 64, 68, 73; dress from, 87 ; kivas, 76 ; population of, 65 ; types of houses, 71 .

Adobe, building material, 72,73 . Agave, used as food, 138.

Agriculture, 18, 39-40, 79, 80-83, 85, 136-137; implements used in, 82.

Aguas Calientes, 66.

Algonkin languages, 178.

Altars, 57, 107, 111; antelope, 118; snake, 117.

Alvarado, Hernando de, 60.

Animals, creation of, 124.

Antelope, hunting of, 84 .

Apache, 65, 178.

Aprons, 49.

Arrows, 54 .

Art, 108; decorative, 96; symbolic, 96-97.

Athapascan, languages, 179; tribes, 127-130.

Awatobi, 64.

Awls, use of, 52 .

Axes, 53.

Balcony House, 34 .

Bandelier, A. F., 108, 110.

Baskets, 45; ceremonial, 94; material used, 145, 149, 150; methods of making, 45-46, 145, 146, 147, 149, 150; Navajo, 158-159.

Batten stick, 52 .

Bells, copper, 56 .

Bayeta blankets, 156 .
Beadwork, 160.

Bear dance, 170.

Belts, 87, 154-156.

Benavides, 136.

Bernalillo, 65 .

Blankets, cotton, 48; feather, 49; Hopi, 156, 157; Navajo, 87, 142, 154.

Blanket-weaving, origin of, 157158.

Breech cloth, 86 .

Buckskin, used for clothing, 85, 140.

Buffalo, hunted, 8, 11, 12, 58, 61, 79, 84, 136, 139.

Bullroarers, 119.

Burial, 24, 57, 104, 105, 162; baskets found with, 45,46 ; in caves, 56.

Cacique, 99, 105, 108-109, 110.

Cactus, used for food, 139.

Canyon de Chelly, 21.

Casa Grande, 22, 27.

Casas Grandes, 22.

Castañeda, Pedro de, 64, 66, 67, 72 , 78, 79, 99, 104, 106.

Cavate lodges, 38-39.

Caves, natural, 39.

Ceilings, 28, 34, 73.

Ceremonies, clan, 100; originators of, 125 .

Chaco Canyon, 21, 24.

Chamuscado, Francisco Sanchez, 61

Chemehuevi, 132.

Chief, band, 163; village, 106, 164; war, 84, 105, 163. 
Chiricahua, 128

Cibola, 60, 64; seven cities of, 70 .

Clans, 19, 97-98, 160-161; kivas, $99,100$.

Clay, as building material, 72 .

Cliff Palace, 21, 31.

Clowns, in ceremonies, 171.

Cochiti, 65, 67, 68 .

Comanche, 11, 68 .

Cooking, in the ground, 84 .

Copper, use of, 56.

Corn, cooking, 83; cultivation of, $33,80,81,136$; storing, 82 .

Corn meal, ceremonial use of, 102 , 103, 108, 111.

Coronado, Francisco, Vasquez, 59, 66.

Cotton, cloth, 51, 87; cultivation of, $90,136,152,180$; used in weaving, 48 .

Cottonwood Creek, 45, 56 .

Coyotero Apache, 129.

Cradles, 94.

Cremation, 56.

Cuirana, 110, 125, 170.

Culture, distribution of, 181; relation of, 182.

Cushing, Frank H., 84.

Dancing, in puberty ceremony, 167; in snake dance, 122 .

Dead, beliefs concerning, 173-174

Decoration, of baskets, 46; of kivas, 76; Navajo dresses, 142; pottery, 91,93 ; of walls, 26,92 .

Designs, on bags, 49 ; on baskets, $47,145-146,148-149,150$; in beadwork, 160 ; on Navajo blankets, 157,159 ; on pottery, 41 , $42,44,45,93$.

Defense, means of, 24 .

Deer dance, 114.
Digging-sticks, 117.

Dress, 85-99, 103-104, 140, 141, 142.

Doors, 29.

Doorways, 32, 74 .

Drill points, 54 .

Dulce Ruin, 34-35.

Dyes, 156.

Earrings, 90.

Earth, worship of, 172.

Eastern Apache, 139.

Espejo, Antonio de, 62, 85, 106.

Estevan, 58, 59.

Estufas, 78, 79.

Fauna, 14.

Fetishes, 84, 118, 166.

Fewkes, Dr. J. W., 98.

Firedrill, 124.

Fire-making, 54.

Fireplaces, 33, 73.

Fish, taboos, 84, 139.

Flageolets, 54 .

Floors, 73.

Flora, 14.

Flute ceremony, 114, 123.

Food, methods of securing, 79-83, 81-85; preparation of, 15, 33, 83-84, 136-140.

Footraces, 121.

Forestry, 17.

Franciscan missionaries, 19, 61 .

Galisteo Basin, pottery from, 57 .

Games, 164-165.

Germantown blankets, 156 .

Geronimo, 129, 163.

Grand Gulch, 54, 56; baskets from, 45 .

Gran Quivira, 22, 65.

Guessing game, 165.

Guzman, Nuño de, 58. 
Hair, method of dressing, 88; used in weaving, 88 .

Hales, Henry, 42.

Hano, pueblo of, 64,68 .

Havasupai, 131, 178 .

Head form, 177-178.

Healing ceremony, 170 .

Hodge, F. W., 41, 98.

Hoop and pole game, 164 .

Hopi, 60, 64, 67, 68, 71, 73, 74, 76, $79,81,83,84,93,94,98,99,131$, 156-157, 158, 178.

Houses, 18, 70-74, 133, 134, 135136.

Hrdlička, Dr. A., 177.

Hunting, 41, 80, 84-85, 106, 139.

Hupa, 79.

Images, stone, 107.

Irrigation, $40-41,80-81,106,137$, 180.

Isleta del Sur, 65 .

Jemez, 66, 68, 71, 76.

Jicarilla Apache, 128, 132, 140, 142, $145,146,169,172$.

Kachinas, 125, 167; ceremonies, 114, 116; dances, 110; dolls, 115.

Keresan, clans, 99; kivas, 76; language, 68, 179.

Kilts, 86 .

Kiowa, 11.

Kivas, 24, 30, 33, 36, 106, 113, 115, 117.

Koshare, 110, 125, 170.

Laguna, 68.

Language, 68, 70, 178.

Leggings, 89, 142.

Lightning frames, 119.

Little Colorado River. 42.

Llanero, 128, 169.
Looms, 51, 77, 154, 155-156.

Los Muertos, 40.

Marau ceremony, 123.

Maricopa, 131.

Marriage, 102-103, 161.

Masks, 78 .

Masonry, 72.

Matsaki, 64 .

Matthews, Dr. Washington, 160, 171.

Mendoza, Antonio de, 58.

Mesa Verde region, 56.

Mescalero Apache, 128, 132, 145, 173.

Mesquite, as food, 138.

Metates, 33, 53, 73-74, 83.

Mimbrenos Apache, 128.

Mindeleff, Victor, 73.

Mishongnovi, 68, 71-72.

Moccasins, 89, 140, 142.

Moenkapi, 68.

Mogollon Mountains, 14.

Mohave Apache, 131.

Mohave, 131, 137.

Mother-in-law taboo, 162.

Myths, 174.

Nambe, 68, 114.

Names, 101-102.

Narvaez, 58.

Navajo, 87, 94, 130, 140, 160, 171, $173,175,178$.

Nelson, N. C., 57, 66.

New Galicia, 58, 60.

Niza, Marcos de, 59.

Night Chant, 171.

Niman kachina, 114, 115.

Nordenskiöld, G., 34.

Nomadic peoples, distribution of, 127-132.

Nutria, 70, 81. 
Ojo Caliente, 64, 70, 81 .

Ollero, 128, 169 .

Omaha, 61.

Oñate, Juan de, 62, 72.

Ooqol ceremony, 123.

Oraibi, 72, 94, 121.

Ornaments, of turquoise, 159

Paintings, dry, 107, 111; ceremonial, 169,170 ; on walls, 32 .

Pajarito Plateau, 22, 24, 25, 56.

Papago, 130.

Pawnee, 61.

Pecos, pueblo of, 22, 106.

Pescado, 81.

Pestles, 53.

Phratries, 98-99.

Physical characteristics, 176,177 , 178.

Picuris, 66, 68, 88.

Pima, 130, 145, 161, 164.

Piñon, for food, 83, 137.

Piro, 65, 119.

Plains Indians, relations with, 11 , 12.

Pojoaque, pueblo, 68.

Political organization, 105-107, 163164.

Pollen, ceremonial use of, 111.

Pottery, 41, 43, 45, 90-92, 142, 144. 145.

Prayer offerings, 108, 112, 166; sticks, 112, 116, 119, 120

Prayers, in snake dance, 119.

Property rights, 99, 100 .

Puberty ceremony, 166, 167.

Pueblo Bonito, 21, 24, 36-38, 43 $44,54$.

Puyé, 24

Quara, 22, 65.

Quirix, 65
Quivira, 61

Rabbitskins, used for clothing, 140 .

Race, 170.

Rain, ceremony for, 108, 111.

Painfall, 11, 14, 17.

Rattles, 54, 116, 170.

Rebellion, cause of, 62 .

Religious beliefs, 124-126; practices. 107-124.

Rio Chama, ruins, 22.

Rio Grande pueblos, 68, 72; ceremonies of, 112; clans of, 98 .

Rio Verde, 22.

Ruins: prehistoric, 21, 22, 30-34, $35,36,39$.

Salinas, 65.

Salt River. 26.

San Carlos Apache, 129.

San Cristobal, 66.

Sandals: $46-48,140$.

Sandia, mountains, 66 ; puehlo. 68.

Sand paintings, 170 .

San Felipe, 65, 68, 71.

San Francisco, peaks, 115; river, 42.

San Ildefonso, 63, 67, 68, 71, 92.

San Juan, 21, 42, 68, 71, 76, 93.

San Marcial, 65.

Santa Ana, 6568.

Santa Clara, 68, 71, 76, 92

Santo Domingo, 65, 68, 71.

Sevilleta, 65 .

Sheep, introduction of, 90, 140, 152 .

Shelters, 74, 132 .

Shields, 106.

Shipaulovi, 68, 71

Shoshonean language, 179

Shrines, 107,108 .

Shumopovi, 68,72

Sia, $65,68,108,111-112$.

Sichumovi, 68 . 
Silverwork, 142, 158.

Snake, dance, 114, 117-124; horned, 125.

Social, customs, 18, 101-105, 161163 ; organization, $97-100,160$ 161.

Societies, 109-110.

Socorro, 65.

Songs, ceremonial, 167, 168, 171.

Spaniards, arrival of, 19 .

Spider Woman, 125.

Spindles, 52, 154.

Springs, sacred, 111.

Spruce Tree House, 21, 34.

Stature, 177.

Stevenson, Mrs. M. C., 108, 111.

Sun, worship, 173.

Tabira, see Gran Quivira.

Taboos, 84, 139, 162.

Tales, 175.

Tanoan language, 68, 179.

Tanos, 66.

Taos, 66, 68, 71, 78, 84, 88, 113.

Tesuque, 68 .

Tewa, 179; clans, 98, 99.

Throwing sticks, 84 .

Thunder Mountain, 64, 67, 106.

Tiguex, 65, 67, 106.

Tipis, 132.

Tiwa, 179.

Totemism, 97, 100.

Tovar, don Pedro de, 60.

Trade, 12, 56, 85.

Tufa, building material, 25 .

Tularosa pottery, 43,45 .
Turquoise, 54, 90

Tusayan, 60, 64.

Tutahaco, 65.

Ute, 12, 68, 132, 170 .

Vaca, Cabeza de, 58.

Vargas, Diego de, 63.

Vegetable food, $80,83,137$

Villages, farming, 70,81 .

Walapai, 131, 178.

Walls, construction of, 27-28, 31; ornamentation, $72,73$.

Walpi, 64, 68, 72 .

Walfare, 18, 106.

War gods, 125.

Watch towers, 24, 34 .

Water jars, 146, 149.

Weapons, 106.

Weaving, 45, 46-48, 51, 87, 94-95, 152-158, 180.

Western Apache, 139, 173.

White Mountain Apache, 129.

Winds, worship of, 173.

Ximena, 66.

Yavapai, 130, 131, 145.

Yucca, for food, 138.

Yucca fiber, 49, 87, 140.

Yuma, 131, 137; languages, 180.

Yuqueyunque, 66.

Yurok, 79.

Zuñi, $60,64,67,70,71,73,78,81-$ $82,84,88,94,99$. 





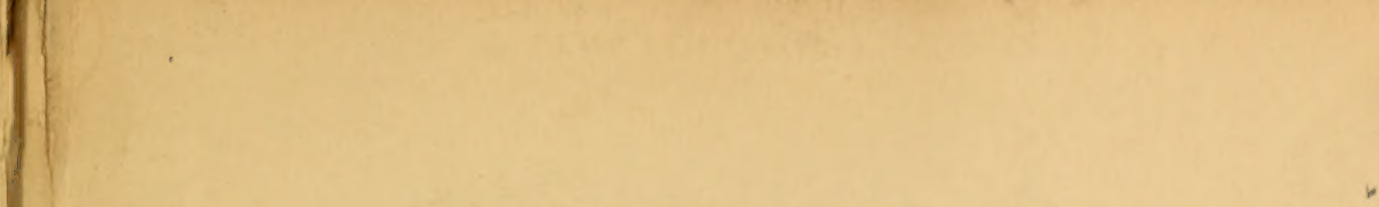




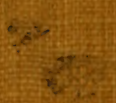

